Review

\title{
Water Soluble Polymers as Proton Exchange Membranes for Fuel Cells
}

\section{Yun-Sheng Ye, John Rick and Bing-Joe Hwang *}

Department of Chemical Engineering, National Taiwan University of Science and Technology, Taipei 106, Taiwan; E-Mails: yunsheng.ac95g@nctu.edu.tw (Y.-S.Y.); Schriftsteller@ myopera.com (J.R.)

* Author to whom correspondence should be addressed; E-Mail: bjh@ mail.ntust.edu.tw;

Tel.: +886-2-273-13-141-6234; Fax: +886-2-273-76-644.

Received: 14 February 2012; in revised form: 1 March 2012 / Accepted: 14 March 2012 /

Published: 26 March 2012

\begin{abstract}
The relentless increase in the demand for useable power from energy-hungry economies continues to drive energy-material related research. Fuel cells, as a future potential power source that provide clean-at-the-point-of-use power offer many advantages such as high efficiency, high energy density, quiet operation, and environmental friendliness. Critical to the operation of the fuel cell is the proton exchange membrane (polymer electrolyte membrane) responsible for internal proton transport from the anode to the cathode. PEMs have the following requirements: high protonic conductivity, low electronic conductivity, impermeability to fuel gas or liquid, good mechanical toughness in both the dry and hydrated states, and high oxidative and hydrolytic stability in the actual fuel cell environment. Water soluble polymers represent an immensely diverse class of polymers. In this comprehensive review the initial focus is on those members of this group that have attracted publication interest, principally: chitosan, poly (ethylene glycol), poly (vinyl alcohol), poly (vinylpyrrolidone), poly (2-acrylamido-2-methyl-1-propanesulfonic acid) and poly (styrene sulfonic acid). The paper then considers in detail the relationship of structure to functionality in the context of polymer blends and polymer based networks together with the effects of membrane crosslinking on IPN and semi IPN architectures. This is followed by a review of pore-filling and other impregnation approaches. Throughout the paper detailed numerical results are given for comparison to today's state-of-the-art Nafion ${ }^{\circledR}$ based materials.
\end{abstract}

Keywords: water soluble polymer (WSP); proton exchange membrane (PEM); fuel cell 


\section{Introduction}

There has been an enormous increase in the global demand for energy in recent years as a result of industrial development and population growth. The production of efficient and clean energy is a desired goal for modern industrial societies. The environmental demands associated with energy production have focused our attention towards the development of the fuel cell; however, its development still presents scientific researchers with many challenges. Fuel cells differ from batteries in that they require a constant supply of fuel, but while this fuel input is supplied they can produce electricity continually. Fuel cells may be classified according to the fuel source used, the operating conditions and the fuel cell's structure, some examples being: (1) solid oxide fuel cells (SOFC) that have a ceramic ion/solid oxide conducting electrolyte; (2) molten carbonate fuel cells (MCFC) with a molten carbonate salt electrolyte; (3) alkaline fuel cells (AFC) with an alkaline solution electrolyte (such as potassium hydroxide $\mathrm{KOH}$ ); (4) phosphoric acid fuel cells (PAFC) with an acidic solution electrolyte; (5) solid proton exchange membrane fuel cells (PEMFC); and (6) direct methanol fuel cells (DMFC).

Figure 1. Comparison of the six main types of fuel cells.

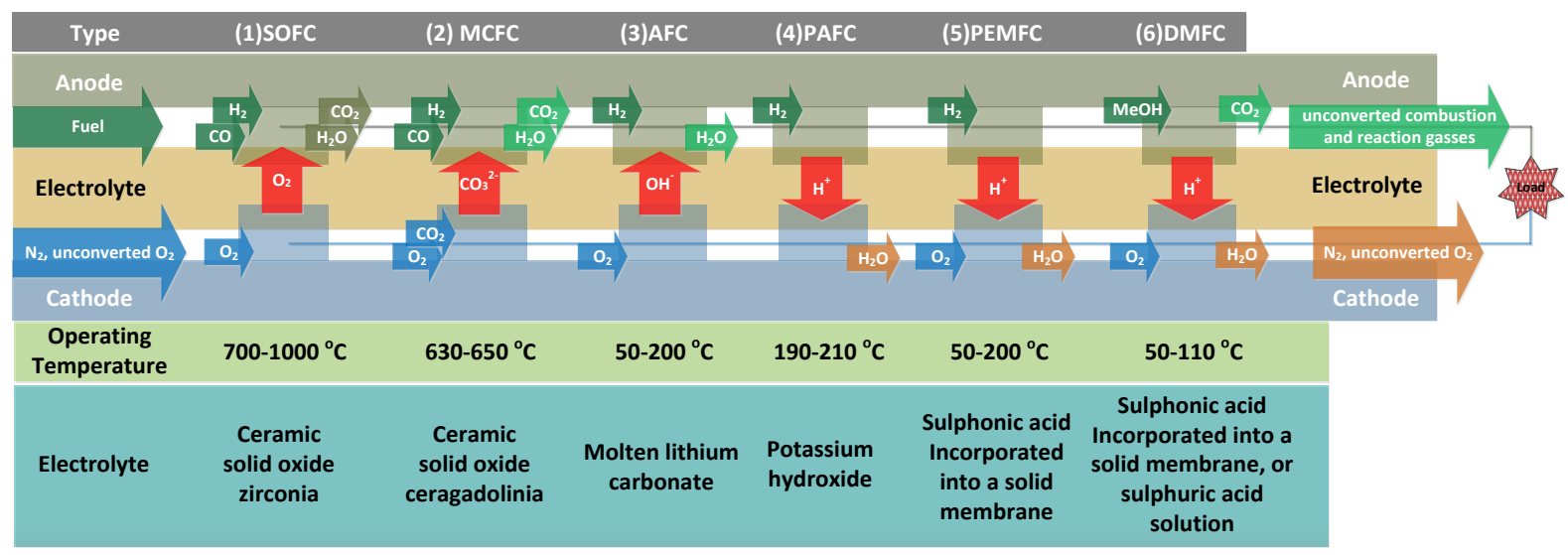

Figure 2. Schematic representation of a proton exchange membrane fuel cell (PEMFC) and a direct methanol fuel cell (DMFC).

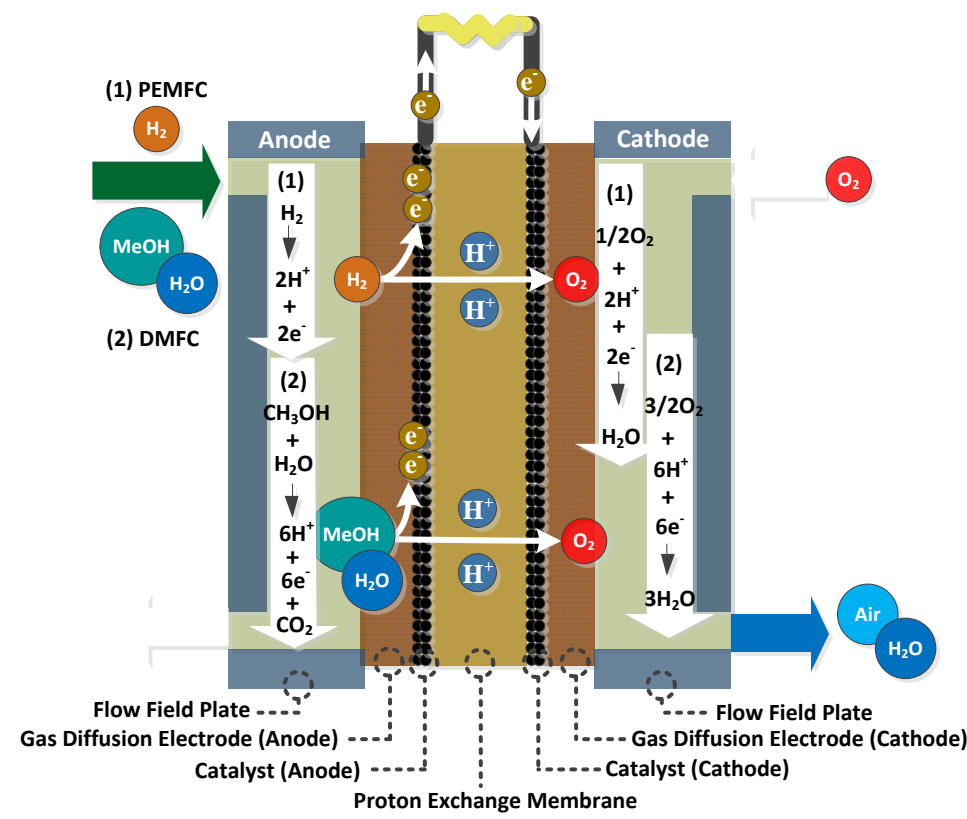


Figure 1 compares and illustrates the prominent features six types of fuel cells [1]. Among them, PEMFC and DMFC offer many advantages such as high efficiency, high energy density, quiet operation, and environmental friendliness. Basically, in a PEMFC system, chemical energy is generated by the electrochemical reaction of the fuel (e.g., $\mathrm{H}_{2}$, methanol, or ethanol) with the oxidant producing water, electricity and heat. The primary reactions of the PEMFC and DMFC are shown in Figure 2.

The most important part of PEMFCs and DMFCs is the proton exchange membrane (also termed the polymer electrolyte membrane (PEM)) that is responsible for proton transport from the anode to the cathode and thus the entire fuel cell's performance. PEMs have the following requirements: high protonic conductivity, low electronic conductivity, impermeability to fuel gas or liquid, good mechanical toughness in both the dry and hydrated states, and high oxidative and hydrolytic stability in the actual fuel cell environment. Currently, most commercially available membranes for PEMFCs are based on perfluorosulfonic acid (PFSA) polymer membranes (e.g., Nafion ${ }^{\circledR}$, Flemion ${ }^{\circledR}$ and Acipex ${ }^{\circledR}$ ). These PEMs have many advantages, such as their good physical and chemical stabilities, and their high proton conductivities, at moderate operating temperatures, in a wide range of relative humidities. There are, however, several drawbacks which have limited Nafion ${ }^{\circledR}$, s application including its high cost and high methanol permeability, together with its environmental incompatibility with other materials. To overcome these obstacles, extensive efforts have been made to develop alternative low-cost membranes as potential PEMs.

Most current development strategies use modified PFSA polymers (partially fluorinated), acid-functionalized aromatic hydrocarbon-based polymers or a number of sulfonated aromatic polymers such as poly (arylene ether)s (PAE) [2,3], poly (acrylene ether sulfone)s (PAES), [4-6], poly (phenylene)s (PP) [7,8], poly (ether ether ketone)s (PEEK) [9,10], poly (phenylene sulfide) (PES) [11] and polyimide (PI) [12,13] as potential PEMs. Sulfonated or phosphonated polybenzimidazoles (PBI) [14-16], polybenzoxazoles (PBO) [17,18] and polybenzothiazoles (PBT) [19,20] have also been investigated for possible use as PEMs. Nevertheless, there are still unresolved application issues with these membranes due variously to low proton conductivity under low humidity conditions, and poor stability during long-term operation.

Acid-based blends are considered as another class of fuel membrane design, which use basic polymers, such as poly (ethylene oxide) (PEO) [21,22], poly (vinylalcohol) (PVA), poly (acrylamide) (PAAM), poly (vinylpyridine), or poly (vinylpyrrolidone) (PNVP) complexed with strong acids, such as sulfuric acid or phosphoric acid. These blends possess low proton conductivities $\left(\sim 10^{-3} \mathrm{~S} \cdot \mathrm{cm}^{-1}\right)$ in both their dehydrated and hydrated states. However, in order to show sufficient conductivity it is usually necessary to load the membrane with a high acid content; however, this can result in poor mechanical stability especially at temperatures above $100{ }^{\circ} \mathrm{C}$. Another concern is tertiary $\mathrm{C}-\mathrm{H}$ bond stability in the oxidative environment of fuel cells. Approaches to improving the polymer's mechanical strength have included: (1) cross-linking; (2) using high $\mathrm{T}_{\mathrm{g}}$ polymers such as PBI and poly (oxadiazole); and (3) adding an inorganic filler or/and a plasticizer. Among the materials noted above, acid-doped PBI membranes have received the most attention. These membranes have very good properties that allow them to be used in PEMFCs at temperatures as high as $200{ }^{\circ} \mathrm{C}$ without humidification $[23,24]$. 
Reflecting the already mentioned requirement of the acid-based membranes for a high degree of acid doping, the sulfonated aromatic polymer membranes require a high degree of sulfonation; however, high sulfonation or high acid-doping levels leads to a mechanical strength decrease making the membranes impractical for use in fuel cell applications. Different methods are being explored to improve the proton conductivity without sacrificing mechanical strength or vice versa. Copolymerization, grafting, polymer blending or crosslinking may be efficient approaches towards conferring on membranes the properties needed for PEM application. Regardless of the fabrication method, the selection of the polymers for PEMs for DMFCs is a very important consideration because proton conductivity and methanol permeability are properties that are largely dependent on the polymers. Water soluble polymers (WSPs) have recently become increasingly interesting to both industry and academia, as they can be used in soft material applications such as biomaterials [25], drug delivery [26], dispersants [27], and flocculants [28]. WSPs with hydrophilic properties are used in membrane materials where they confer additional water retention ability (particularly at high temperatures and low RHs) [29]. In a network or blended system, a critical consideration is the choice of the hydrophilic WSP to be combined with a polymer electrolyte this combination should have the aim of preventing coarse or unstable morphologies that result in poor mechanical properties.

The present review aims to review the classification of membranes containing WSPs. We also consider the selection of WSPs, membrane architectures and synthetic pathways. Several WSPs, such as chitosan (CS), poly (ethylene glycol) (PEG), poly (vinyl alcohol) (PVA), Poly (vinylpyrrolidone) (PNVP), poly (2-acrylamido-2-1-propanesulfonic acid) (PAMPS) and Poly (styrene sulfonic acid), will first be described and their suitability for application in fuel cell PEM will described. After a description of the categorization of WSPs and their associated characteristics, various membrane architectures resulting from polymer blends, simply crosslinked polymers, semi-interpenetating polymer networks (semi-IPN) and interpenetrating polymer networks (IPN) are described. Particular emphasis is given to synthetic pathways, proton conductivities, methanol permeabilities, chemical stabilities, mechanical properties and resulting membrane performances. The difficulty encountered here has been to indentify existing membranes that incorporate WSPs even when they are not described as such by the authors. To the best of our knowledge, this is first review focused on the use of WSP membranes in fuel cell applications.

\section{Water Soluble Polymer as Fuel Cell Membranes}

Water soluble polymers (WSPs) represent an immensely diverse class of polymers biologically important members of this class include polynucleotides, polypeptides, and polysaccharides [30]. The three most abundant naturally occurring polymers cellulose, chitin, and starch are commonly derivatized by the incorporation of hydroxyethyl-, hydroxypropyl-, carboxymethyl-, sulfate, and phosphate groups to enhance their water solubility. The use of nonionic polymers and charged polymers (cationic, anionic and zwitterionic) has been explored for a large number of applications. For nonionic WSPs, sufficient numbers of polar functional groups must be inserted into the polymer's backbone to impart the desired solvation characteristics. Major commercial WSPs such as poly (acrylamide) (PAM), poly (ethylene oxide) (PEO), poly (vinyl alcohol) (PVA), poly (vinylpyrrolidone) (PNVP), and poly (hydroxyethyl acrylate) (PHEA) have been widely used in biomedical, 
pharmaceutical, cosmetic, and personal care products (Table 1). Charged WSPs can be classified into two main groups (polyanions and polycations) according to the types of charges in the molecular backbone. Table 2 lists representative groups of industrially significant monomers used for preparing polyanions and polycations. Polyanions and polycations have been utilized extensively in water treatment, papermaking, mineral processing, petroleum recovery, dispersion, and flocculation.

In the present review, membranes that have been synthesized with WSPs containing membrane blends, simply crosslinked membranes, semi-IPN and IPN membranes are reported. After introducing the materials we then relate the properties of WSPs to their potential applications in fuel cells membranes.

Table 1. Repeating units in representative nonionic homopolymers.

\begin{tabular}{|c|c|}
\hline Name & Structure \\
\hline Poly (acrylamide) (PAM) & $\begin{array}{c}\left.+\mathrm{CH}_{2}-\mathrm{CH}\right)_{n} \\
\mathrm{C}=0 \\
1 \\
\mathrm{NH}_{2}\end{array}$ \\
\hline Poly (ethylene oxide) (PEO) & $+\mathrm{CH}_{2}-\mathrm{CH}_{2}-\mathrm{O}+_{\mathrm{n}}$ \\
\hline Poly (vinyl alcohol) (PVA) & $\underset{\mathrm{OH}}{\left(\mathrm{CH}_{2}-\underset{\mathrm{I}}{\mathrm{C}}\right)_{n}}$ \\
\hline Poly (vinylpyrrolidone) (PNVP) & $+\mathrm{CH}_{2}$ \\
\hline Poly (hydroxyethyl acrylate) (PHEA) & $\begin{array}{l}\mathrm{O} \\
\left.\stackrel{1}{\mathrm{C}} \mathrm{H}_{2}\right)_{2} \\
\stackrel{\mathrm{O}}{\mathrm{O}}\end{array}$ \\
\hline
\end{tabular}

Table 2. Representative anionic and cationic monomers incorporated in polymers.

\begin{tabular}{|c|c|c|c|}
\hline Name & Structure & Name & Structure \\
\hline \multicolumn{2}{|c|}{ Anionic Monomers } & \multicolumn{2}{|c|}{ Cationic Monomers } \\
\hline Acrylic acid (AA) & $\begin{array}{c}\mathrm{CH}_{2}=\mathrm{CH} \\
\mathrm{I} \\
\mathrm{C}=\mathrm{O} \\
\mathrm{O} \\
\mathrm{OH}\end{array}$ & $\begin{array}{l}\text { Diallyldimethylammonium chloride } \\
\text { (DADMAC) }\end{array}$ & $\begin{array}{c}\stackrel{\ominus}{\ominus} \mathrm{CH}_{3} \\
\mathrm{CH}_{3}-\mathrm{I}_{1}^{+}-\mathrm{CH}_{2}-\mathrm{CH}=\mathrm{CH}_{2} \\
\mathrm{H}_{2} \mathrm{C}-\mathrm{CH}_{2}-\mathrm{CH}=\mathrm{CH}_{2}\end{array}$ \\
\hline $\begin{array}{l}\text { Methyl methacrylate } \\
\text { (MAA) }\end{array}$ & $\mathrm{CH}_{3}$ & $\begin{array}{l}\text { Diallyldiethylammonium chloride } \\
\text { (DADEAC) }\end{array}$ & 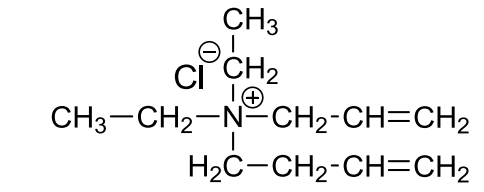 \\
\hline $\begin{array}{c}\text { p-Styrene carboxylic } \\
\text { (SCA) }\end{array}$ & $\mathrm{COOH}_{\mathrm{COH}}$ & $\begin{array}{l}\text { Diethylaminoethyl methacrylate } \\
\text { (DEAEMA) }\end{array}$ & 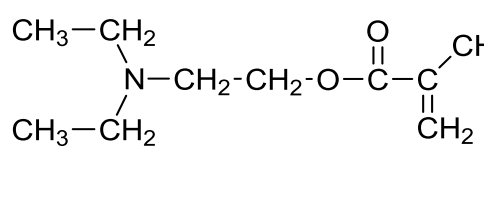 \\
\hline
\end{tabular}


Table 2. Cont.

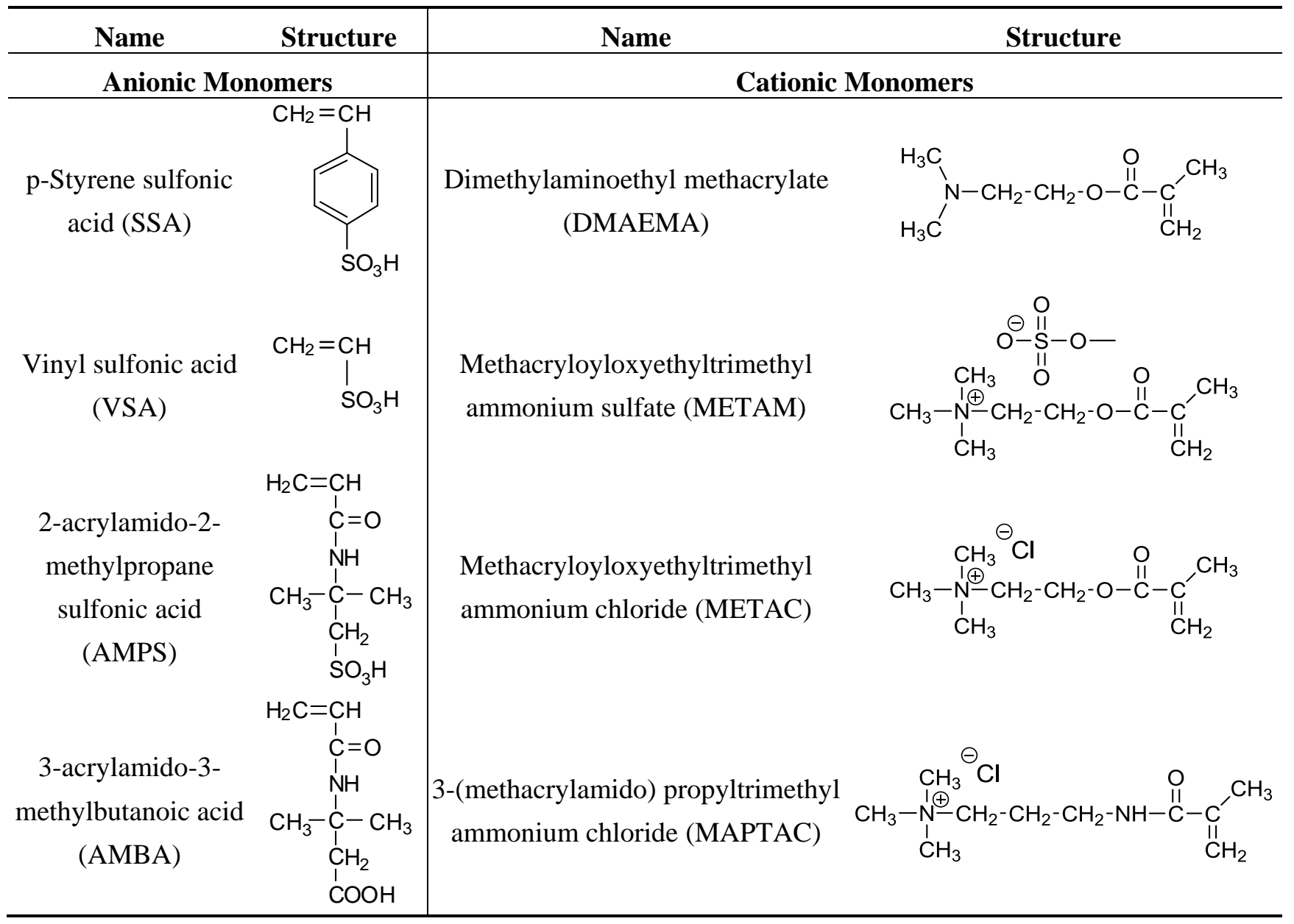

\subsection{Chitosan (CS)}

Chitosan (CS), the structural supporting material of crustaceans, insects, etc, is the N-deacetylated derivative of chitin, a naturally abundant polysaccharide (Figure 3(a)). The parent chitin is insoluble in most organic solvents; $\mathrm{CS}$ is readily soluble in dilute acidic solutions below $\mathrm{pH} 6.0$ due to the quaternisation of the amine groups that have a pKa value of 6.3, making CS a water soluble cationic polyelectrolyte (Figure 3(b)). CS is a natural and low-cost biopolymer which has many excellent properties such as biocompatibility, non-toxicity, chemical and thermal stability; thus it has been considered for use in a wide range of applications [31,32]. Membranes based on natural low-cost CS are easily formed and have high hydrophilicity, good chemical and thermal resistance. In addition, the free amine and hydroxyl groups on the CS's backbone, each possessing a lone pair of electrons available for complexation, are readily accessible reactive sites that allow the CS to be modified and incorporated into sophisticated functional macromolecular systems. 
Figure 3. (a) Chemical structures of Chitin and Chitosan (CS); (b) Schematic illustration of chitosan's versatility.

(a)
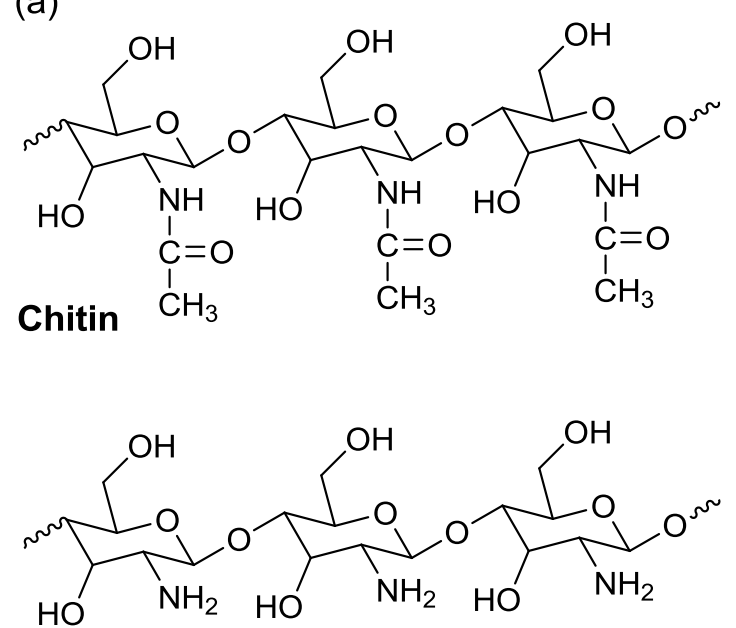

(b)

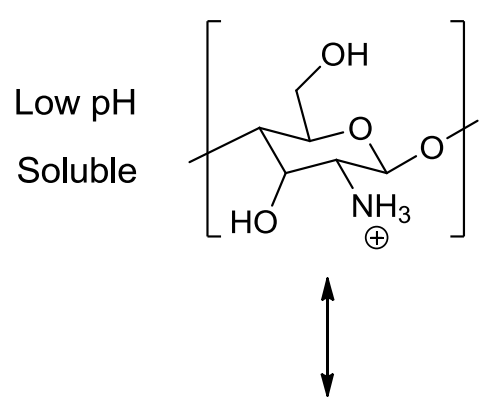

Insoluble

\section{Chitosan}

CS is potentially a useful membrane material due to its non-permeability to alcohol. However, in its native state, CS films exhibit very low conductivities and high degrees of swelling [33]. Although, high swelling levels in the membrane are a prerequisite for reaching high proton conductivities, at the changes associated with swelling impact upon the membrane's performance in terms of methanol permeability, dimensional stability and thermal stability. To solve the low conductivity and high swelling problems, CS was usually either ionically crosslinked with sulfuric acid [33,34] or incorporated into inorganic particles [35-38]. In addition, different Chitosan-based PEMs have been studied and have showed promising properties for application in the field of PEMFCs [39-42].

\subsection{Poly (ethylene glycol) (PEG)}

Poly (ethylene glycol) (PEG), poly (ethylene oxide) (PEO) or poly (oxyethylene) (POE) are oligomers or polymers of ethylene oxide that are chemically synonymous. PEG is a well known and industrially important polymer, commercially supplied in high and low molecular weight grades to the pharmaceutical and textile industries, which can be used e.g., as an encapsulating agent for drug delivery, or as a fiber-forming aid [43]. Moreover, PEG has been widely investigated for use both in lithium batteries [31,44] and dye sensitized solar cells (DSSCs) [45,46] due to its chemical stability and its ability to solvate lithium salts. Fuel cell applications exploit PEG's flexible hydrophilic backbone when it is used in membrane materials to improve water retention. PEG can be transformed through modification of the functional groups at the end of the polymer chains to provide a multitude of variations and specific chemical functionalities, such as alcohols, amines, carboxylic acids, and thiols. Bai et al. introduced diamine terminated PEG $\left(\mathrm{M}_{\mathrm{w}}=1,000\right)$ as copolymer segments to modify the membrane properties of sulfonated polyimide (SPI). The results showed that SPI membranes with PEO segments exhibited enhanced mechanical properties and thermal stabilities, as well as better proton conductivity, with respect to $\mathrm{Nafion}^{\circledR}$ at high relative humidity (RH) levels $(>50 \%)$ at both 70 and $120{ }^{\circ} \mathrm{C}$. Moreover, PEG can be used as crosslinker that can improve both chemical and hydrolytic 
stability without compromising proton conductivity or brittleness [47-50]. Compared to using rigid arylene polymers as crosslinkers, the crosslinked membranes with PEG become more flexible and show a greatly reduced water uptake and swelling ratio with only a slightly sacrifice in proton conductivity [51]. PEG can also be introduced into semi-IPN membranes as a crosslinker to improve the membrane's toughness and strength, while simultaneously enhancing the membranes proton conductivity and water stability at high temperatures $\left(\sim 100{ }^{\circ} \mathrm{C}\right)[52,53]$.

\subsection{Poly (vinyl alcohol) (PVA)}

Poly (vinyl alcohol) (PVA), a polyhydroxy polymer, is the largest volume, synthetic WSP produced in the world. The excellent adhesion capacity of PVA to cellulosic materials makes it useful as an adhesive and coating material that is highly resistant to solvents, oil and grease. Moreover, it is widely used in synthetic fibers, papers, textiles, coatings, and in binders due to its excellent resistance, wide ranging crystallinity, good film formation capacity, complete biodegrability and high crystal modulus [54]. PVA is usually selected as a cross-linker because of its film-forming capacities, hydrophilic properties, and the high density of reactive chemical functionalities available for crosslinking by irradiation, chemical, or thermal treatments [55]. The hydroxyl groups of PVA and dialdehyde containing monomers are crosslinkable by acetal or hemiacetal reactions between the hydroxyl and aldehyde groups under acid conditions [56]. In addition, the hydroxyl groups of PVA and the carboxylic acid groups of polymers or monomers form a network structure via dehydration (esterification) between the carboxylic acid and hydroxyl groups that contributes to strong bonding during thermally activated reactions (Figure 4) [55].

Figure 4. Scheme showing chemically cross-linked poly (vinyl alcohol) (PVA)-based network structures.

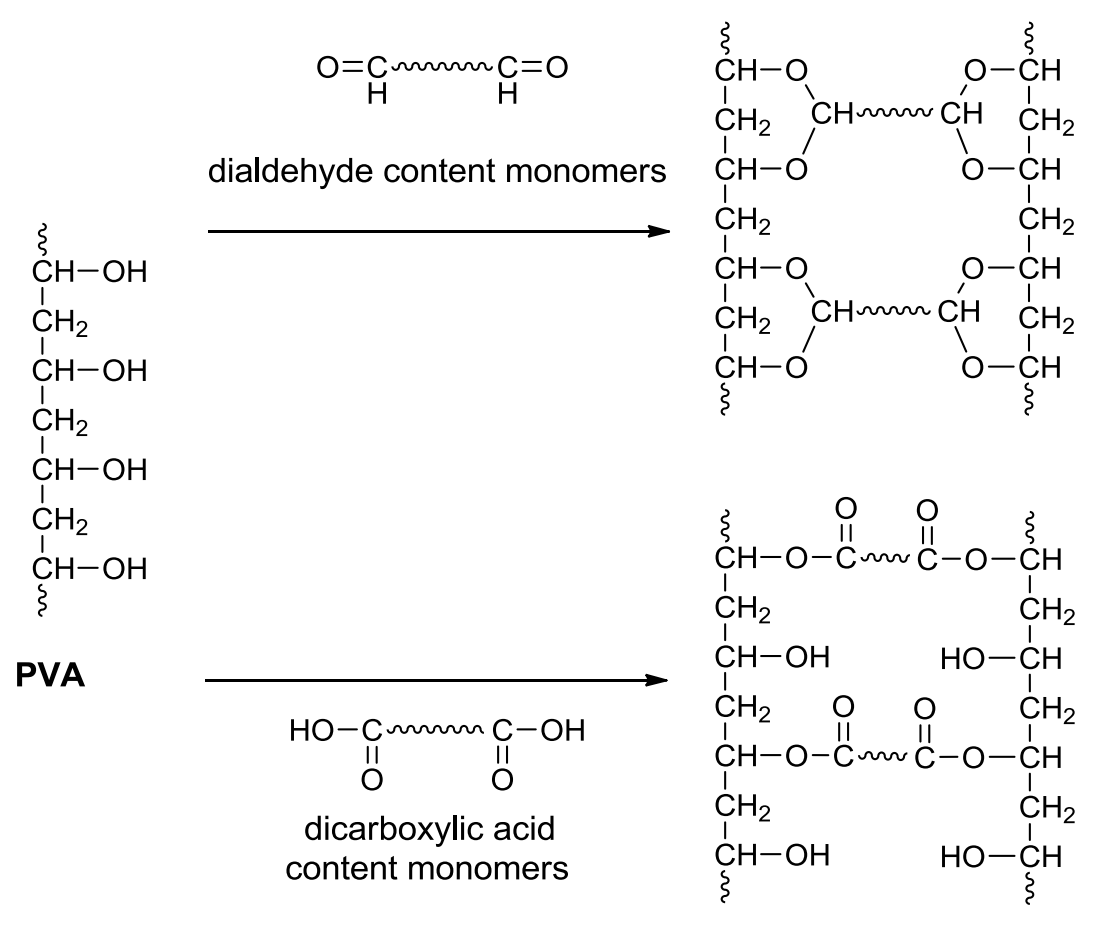

crosslinked PVA 
Owing to the high affinity of water for alcohols, PVA membranes have been used as alcohol dehydration reagents to break the alcohol-water azeotrope [57]. Taking advantage of this high affinity, PVA seems to be a very attractive material for preparing PEM in DMFCs applications. Pivovar et al. [58] explored the potential of PVA as a proton exchange membrane in DMFCs from proton conductivity and methanol permeability experiments. The results indicated that the PVA membranes employed in the pre-evaporation process were much better methanol barriers than Nafion ${ }^{\circledR}$ due to their dense molecular packing structure caused by inter- and intra-molecular hydrogen bonding. In addition, PVA with its excellent mechanical properties and its inherent chemical stability advantages make it well-suited for fuel cell membrane applications.

A drawback of PVA membranes is the absence of negatively charged ions - thus, it is a poor proton conductor when compared to the commercially available Nafion ${ }^{\circledR}$ membrane. For this reason, it is necessary to incorporate proton sources into PVA to enhance both its proton conductivity and its hydrophilicity. To this end Li et al. [59] have produced PVA membranes doped with phosphotungstic acid (PWA). However, the excessive swelling of PVA-PWA composite membranes limits their mechanical strength. For PEM applications, PVA is commonly incorporated into the PEM as a crosslinked partner via aldol condensation [60-70] or esterification [49,71-76] to form a 3D network structure. Moreover, the degree of crosslinking of the PVA-based membranes has been shown to be easy to control via successive chemical treatments (aldol condensation or esterification). The resulting membranes show that swelling, as well as chemical and mechanical properties are able to be effectively controlled by the presence of the dense network structure, this is especially useful with respect to the inhibition of methanol permeability. Therefore, PEMs having optimized properties were prepared via the introduction of PVA as crosslinking structure.

\subsection{Poly (vinylpyrrolidone) (PNVP)}

Poly (vinylpyrrolidone) (PNVP) is widely used in the pharmaceutical, cosmetic, textile, adhesive, coating, and ceramic industries. This is due to the unique physical and chemical properties of PNVP, particularly its good solubility in water and organic solvents, its chemical stability, its strong complexing ability with both hydrophobic and hydrophilic substances, and its non-toxic character. PNVP was selected as a membrane material due to its strong polarity, which gives it good compatibility with other polymers while avoiding unstable morphologies that give rise to poor mechanical properties. Moreover, acid-base interactions between the amino group of PNVP and the sulfonic acid groups of sulfonated polymer, or other host polymers, can form ionically cross-linked ionomer networks able to lower methanol permeation and promote proton transfer [77-79]. Lu et al. [80] reported the exceptional water or methanol sorption selectivity of PVA/PNVP blends that implied PNVP seemed to be a potential material for preparing PEM in DMFCs. Recently, PNVP has been used as a stabilizer to improve the oxidative and mechanical properties of the membranes [63]. Moreover, by incorporating PNVP into semi-IPN membranes we can effective reduce the methanol permeability due to the resulting low methanol uptake and methanol self-diffusion coefficients [81]. These results show that PNVP's hydrophilic groups play an important role in controlling methanol permeability. 


\subsection{Poly (2-acrylamido-2-methyl-1-propanesulfonic acid) (PAMPS)}

Water soluble 2-acrylamido-2-methylpropanesulfonic acid (AMPS) and its sodium salts are widely used as effective flocculants and additives. Its homopolymer, poly (2-acrylamido-2-1-propanesulfonic acid) (PAMPS) was found to have a higher proton conductivity than partially hydrated Nafion ${ }^{\circledR}$ [82]. PAMPS is considered to be hydrated when associated with only ca. six molecules per equivalent group, this being much lower than either partially hydrated Nafion ${ }^{\circledR}$ or polystyrene sulfonic acid (PSSA) where 15 water molecules per sulfonic acid groups are necessary [83]. This implies that the conductivity of PAMPS polymer, when compared to Nafion ${ }^{\circledR}$, may be more tolerant to water content fluctuations, which is an important asset for fuel cell operation at high temperatures. Such advantages allow PDMAS to be a new potential component of proton conducting electrolyte membranes in DMFC applications. However, the PAMPS homopolymer is generally water swollen to the point of being soluble; hence, the PAMPS homopolymer can only be used in the of form gels, or alternatively copolymerized or extensively crosslinked to control swelling.

Copolymerization with a suitable monomer is an effectively method to control the swelling level of membranes, i.e., by tuning the ratio of the hydrophilic monomer content in the polymer's backbone [84]. However, the AMPS monomer is immiscible with most of the monomer oils and thus its use has seldom been reported. Qui et al. synthesized AMPS-co-methyl methacrylate (MMA) copolymer by the free radical polymerization of MMA and AMPS in water [85]. The resulting poly (AMPS-co-MMA) membrane showed high proton conductivity and low methanol permeability, its methanol permeability coefficient being much lower than that of Nafion ${ }^{\circledR}$. However, this kind of solution casting to form membranes still has potential problems, e.g., poor mechanical and chemical properties as compared with crosslinked membranes. Therefore, it is desirable to fix the PAMPS in a stable structure using a crosslinking approach while maintaining high proton conductivity and improving the mechanical and chemical properties of the resulting membranes. A linear PAMPS homopolymer can be combined with a PVA network to form a semi-IPN architecture. However, these semi-IPNs are generally stiff and brittle and thus they are difficult to handle as membranes [61,64]. Therefore, a third media presence is necessary, in the network structure that can effectively modify the mechanical properties of the resulting membranes. It has been reported that the addition of unreactive and neutral polymer components to PAMPS-based semi-IPNs can generate membranes with higher flexibility and robustness without a significant decrease in conductivity or an increase in permeability $[49,61,63,64,86,87]$. PAMPS has also been incorporated into semi-IPNs as a crosslinked partner by in situ synthesis pathways [88-90]. The resulting crosslinked hydrogels showed the highest reported conductivity for materials of this type $\left(0.5 \mathrm{~S} \cdot \mathrm{cm}^{-1}\right)$ [88].

\subsection{Poly (styrene sulfonic acid) (PSSA)}

Poly (styrene sulfonic acid) (PSSA)-based fuel cell membranes were first used in the 1960s in NASA's Gemini space program; however, durability was found to be limited to about 1,000 $\mathrm{h}$ at an operating temperature of $60{ }^{\circ} \mathrm{C}$ [91]: because the PSSA-based membrane was susceptible to chain degradation initiated by radicals $(\mathrm{HO} \bullet, \mathrm{HOO} \bullet)$ present in the fuel cell. Although there are instances of 
poor polystyrene performance, some investigators still advocate the use of sulfonated polystyrene in PEMFCs.

Grafting, polymer blend, and crosslinking strategies have been used to modify PSSA-based membranes to yield membranes with higher chemical stabilities. Holdcroft et al. [92,93] reported the synthesis of polystyrene with grafted poly (sodium styrenesulfonate) (PSSNa) using stable free radical polymerization (SFRP) techniques as shown in Figure 5(a). These grafted copolymers displayed excellent proton conductivities (up to $\sim 0.24 \mathrm{~S} \cdot \mathrm{cm}^{-1}$ ). Different from above method (random systems), the block copolymers of styrene-based membranes were synthesized for PEM application. DAIS-Analytic's PEMs (and related materials) are based on well-known commercial block copolymers of the styreneethylene/butylene-styrene family e.g., Kraton G1650 block copolymer. These sulfonated Kraton ${ }^{\circledR}$-type block copolymers are post-sulfonated by a sulfur trioxide/triethyl phosphate sulfonating complex [94]—a related structure is shown in Figure 5(b). DAIS membranes are reported to be much less expensive to produce than $\mathrm{Nafion}^{\circledR}$; however, the oxidative stability of these aliphatic hydrocarbon copolymers is much poorer than perfluorinated copolymers [93]. For this reason, DAIS membranes are being promoted for the low temperature $\left(<60^{\circ} \mathrm{C}\right)$ portable fuel cell power market.

Figure 5. Chemical structure of (a) PS- $g$-PSSA and (b) sulfonated sulfonated styrene-(ethylene-butylene) styrene (SEBS) block copolymer.

(a)

(b)
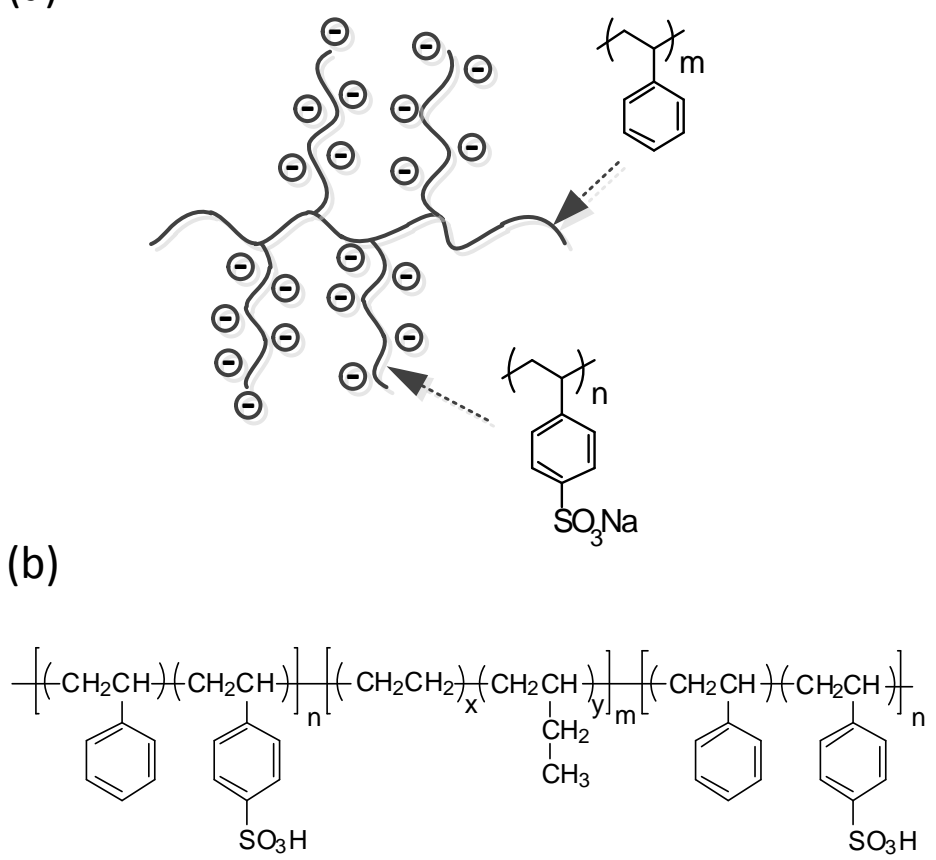

In the grafting strategy, thermally and chemically stable fluorinated polymers (fluorinated ethylene propylene (FEP) [95,96]) or partially fluorinated polymers [ethylene tetrafluoroethylene (ETFE) $[97,98]$ or polyvinylidene fluoride (PVDF) [99]] were chosen as the base polymers and shown to produce materials with some improved performance. It has been reported that the most stable polystyrene analogue is a vinyl perfluorosulfonic system developed by Ballard Power [100]. Using $\alpha, \beta$, $\beta$-trifluorostyrene, Ballard's third generation PEM (trade name BAM) has displayed long-term stability 
(over 100,000 h), and high proton conductivity $\left(\sim 0.08 \mathrm{~S} \cdot \mathrm{cm}^{-1}\right)$. Unfortunately, the high cost of these membranes is comparable to that of other perfluorinated polymers.

Polymer blending is another potentially cost-effective route to achieving partially fluorinated PEMs. However, the poor compatibility between hydrophilic PSSA and hydrophobic fluorinated polymers seriously affects the membranes properties especially its methanol permeability and its mechanical integrity [101]. Introducing a third component in blended membranes was found to be an effective method for enhancing the interface between two poor compatibility phases. Proton conductivities, methanol permeabilities and mechanical properties were all improved by the addition of an appropriate third component such as PNVP [78] or block copolymer [101-104].

Linear or crosslinked PSSA has been used as a polyelectrolyte in semi-IPN architectures. PSSA homopolymer, or as copolymer, has often been combined with a PVA network to form a semi-IPN architecture through an impregnation process [60,62] or by in situ synthesis [66-68]. This strategy is similar to the PAMPS polymer system that involves the use of intra- and inter-molecular hydrogen bonds to form a dense composite network structure, resulting in good film forming properties, good resistance to chemical attack, and also low permeability to alcohols on crosslinked PVA-based composite membranes. When PSSA is crosslinked, it is frequently combined with hydrophobic neutral partners, such as PVDF, poly (tetrafluoroethylene) (PTFE), poly (vinylidene fluoride-hexafluoropropylene) PVDF-HFP-based, or poly (vinyl chloride) (PVC) by an impregnation process. Crosslinked PSSA membranes that use PSSA as linear polymer show proton conductivities equal to or slightly lower than that of Nafion ${ }^{\circledR}$, while their ion exchange capacity (IEC) values are higher. Generally, the methanol permeability of these semi-IPNs is lower than that of Nafion ${ }^{\circledR}$.

\section{Blend Polyelectrolyte Complex Membranes}

Polymer blend technology may represent a more versatile approach for the development of new membrane materials, because the material properties of blends can be varied over a wide range. Relative to a single-component polymeric material, a blend enjoys several degrees of freedom that allow tailoring of the material to meet the membrane's requirements, such as good mechanical properties and good proton transport. Polymer blends in which a sulfonated polymer with high proton conductivity is combined with a non-conductive thermoplastic, chosen to maintain mechanical integrity, has become a popular contemporary approach to designing improved PEM materials.

For polymer blending systems, three types of blends can be distinguished: (1) completely miscible; (2) partially miscible; and (3) immiscible [105]. In most cases, the polymer blends are immiscible because of the high degree of polymerization of their components, especially in hydrophilic/hydrophobic polymer blends. In order to avoid immiscible polymer blends it is necessary to enhance the formation of single phase miscible polymer blends. The most commonly strategies are the introduction specific intermolecular interactions, for two base components of the blend, such as acid-base interactions, hydrogen bonding, ion-dipole, $\pi-\pi$, or charge transfer interactions [106-110]. In addition, the use of block or graft copolymers has also improved the compatibility of immiscible polymers, where one block is identical or at least miscible with one blend component, and the second constituent block is identical to/or miscible with the second blend component [111,112]. 
A variety of different blended polymer pairs chosen to introduce specific interactions have been considered as PEM candidates for fuel cells application [113-117]. Such interactions are reported to improve compatibility in 'two blend' polymers and also reduce methanol cross over in DMFCs. However, these interactions may also weaken the sulfonated ion pair, thus reducing the amount of water needed to promote proton transport. Another approach is to introduce a third media in the blend membrane to improve compatibility while maintaining the proton conductivity and mechanical properties of the blend membranes. Next, we describe the preparation of blend complex membranes based on water soluble polymers (WSPs) developed for fuel cell membrane applications, together with their conductivities, and permeabilities.

Linear PSSA (poly styrene sulfonic acid) or sSEBS [sulfonated styrene-(ethylene-butylene) styrene] polyelectrolytes have often been blended with poly (vinylidene fluoride) (PVDF) to prepare composite membranes (Table 3; 1-6). PVDF was chosen as the structural component because of its good mechanical strength and its chemical stability. To overcome the poor compatibility between hydrophilic PSSA and hydrophobic PVDF, Chen et al. [118] mixed poly (styrene sulfonic acid-methyl methacrylate) random copolymer (PSSA-r-PMMA) with PVDF prior to casting the blend membrane. The presence of PMMA repeating units in the PSSA-r-PMMA copolymer promotes better compatibility between the copolymer and the PVDF. The resulting membranes show that the SSA segments are distributed very uniformly over the PVDF matrix, forming nano-scale domains. The high dispersion of SSA segments in the membrane provides plentiful interconnecting SSA channels and thus favors proton transfer. There appears to be an optimum ratio of PSSA in the copolymer, as with over $40 \mathrm{wt} \%$ PSSA in the blend, the membrane became fragile, and thus no substantial increase in proton conductivity was gained. The optimal membranes show a proton conductivity range that is quite close to what Nafion ${ }^{\circledR}$ 117 offers $\left(\sim 10^{-2} \mathrm{~S} \cdot \mathrm{cm}^{-1}\right)$.

Table 3. Characteristics of various water soluble polymers combined in blended polyelectrolyte complex membranes.

\begin{tabular}{|c|c|c|c|c|c|c|c|c|}
\hline Line & Polymer & $\begin{array}{l}\text { Acid monomer/ } \\
\text { polymer }\end{array}$ & $\begin{array}{c}\text { Third } \\
\text { Component }\end{array}$ & $\begin{array}{c}\text { Ionic partner } \\
\text { (wt } \%)\end{array}$ & $\begin{array}{r}\text { Proton } \\
(\mathrm{S} \cdot \mathrm{c} \boldsymbol{} \\
\text { /measure }\end{array}$ & $\begin{array}{l}\text { conductivity } \\
\left.\mathrm{m}^{-1}\right) \times 10^{3} \\
\text { ment condition }\end{array}$ & $\begin{array}{c}\text { Methanol } \\
\text { permeability } \\
\times 10^{8}\left(\mathrm{~cm}^{2} \cdot \mathrm{s}^{-1}\right)\end{array}$ & References \\
\hline 1 & PVDF & PSSA-r-PMMA & - & $10-40$ & $2-41$ & $25^{\circ} \mathrm{C}$ & - & [118] \\
\hline 2 & PVDF & PSSA & PNVP & $10-50$ & $\sim 63-158$ & $30-80{ }^{\circ} \mathrm{C}$ & - & [78] \\
\hline 3 & PVDF & sSEBS & $\begin{array}{c}- \\
\text { PMMA-BA-PMMA }\end{array}$ & $\begin{array}{l}40-70 \\
38-70\end{array}$ & $\begin{array}{l}0.2-12.5 \\
0.7-19.4\end{array}$ & $\mathrm{RT}, 100 \% \mathrm{RH}$ & - & [102] \\
\hline 4 & PVDF & sSEBS & $\begin{array}{c}- \\
\text { MAM } \\
\text { SBM }\end{array}$ & $\begin{array}{c}50 \\
\sim 50 \\
\sim 50\end{array}$ & $\begin{array}{c}0.21-18.7 \\
5.8-6.8 \\
5.2-32.8\end{array}$ & $\mathrm{RT}, 100 \% \mathrm{RH}$ & - & [103] \\
\hline 5 & PVDF & PSSA & $\begin{array}{c}- \\
\text { PS-b-PMMA }\end{array}$ & 40 & $\begin{array}{l}1.26 \\
3.86\end{array}$ & $25^{\circ} \mathrm{C}, 83 \% \mathrm{RH}$ & $\begin{array}{c}0.98 \\
0\end{array}$ & [101] \\
\hline 6 & PVDF & sSEBS & $\begin{array}{c}- \\
\text { PS-b-PMMA }\end{array}$ & $\begin{array}{c}30-100 \\
50-70\end{array}$ & $\begin{array}{l}0.03-7 \\
2.0-2.2\end{array}$ & $25^{\circ} \mathrm{C}$ & $\begin{array}{c}0-134 \\
0-1.6\end{array}$ & [104] \\
\hline 7 & CS & PAAc & - & $10-75$ & $20-100$ & $25-120^{\circ} \mathrm{C}$ & $4.8-8.7$ & [40] \\
\hline 8 & $\mathrm{CS}$ & $\mathrm{SA}$ & - & 50 & $40-90$ & $30-100{ }^{\circ} \mathrm{C}$ & 4.6 & [42] \\
\hline 9 & PVA & SPEEK & - & $50-100$ & $\begin{array}{c}3-41 \\
\sim 20-72\end{array}$ & $\begin{array}{l}25^{\circ} \mathrm{C} \\
80^{\circ} \mathrm{C}\end{array}$ & $\sim 10-110$ & [119] \\
\hline 10 & PNVP & SPEEK & - & $70-100$ & $\sim 1-25$ & $\mathrm{RT}$ & $39.5-142$ & {$[120]$} \\
\hline
\end{tabular}


With the aim of getting a finely dispersed and homogeneous blend membrane and to insure solid-state adhesion between the blend components, a third component, liner poly (vinylpyrrolidone) (PNVP), has been added to PSSA/PVDF blend membranes [78]. The PNVP polymer with oxygen-containing units is able to form Lewis acid-base pairs with PVDF and PSSA to improve blending compatibility. With respect to the proton conductivity of the resulting membranes, increasing both the content of PNVP and of PSSA produces favorable effects. A PVDF/PNVP/PSSA (1:4:5 by elementary proton) blended membrane showed the best proton conductivity i.e., $\sim 0.15 \mathrm{~S} \cdot \mathrm{cm}^{-1}$ at $70{ }^{\circ} \mathrm{C}$, which is comparable to that of Nafion ${ }^{\circledR} 117\left(\sim 1.65 \mathrm{~S} \cdot \mathrm{cm}^{-1}\right)$.

Block copolymer has also been incorporated into blended membranes as a compatibility media in which each of the blocks is entirely miscible in one of each of the blend components (Table 3; 3-6). Mokrini et al. [102] prepared sulfonated poly (styrene- $b$-(ethylene-r-butylene)- $b$-styrene/polyvinylidene fluoride (sSEBS/PVDF) blend membranes by using an extrusion blending process and further sulfonation by sold state grafting of sulfonic acid moieties. These membranes with a higher S-SEBS content $(70 \mathrm{wt} \%)$, exhibit higher conductivity $\left(1.25 \times 10^{-2} \mathrm{~S} \cdot \mathrm{cm}^{-1}\right)$ but inferior mechanical properties, in contrast to membranes with a lower S-SEBS content. It was found that, by adding $2 \mathrm{wt} \%$ of poly (methyl methacrylate-butylacrylate-methyl methacrylate) triblock copolymer (PMMA-BA-PMMA), as a compatibilizer, the mechanical properties, ion exchange capacity, and proton conductivity of the blend membrane improved. Compatibilized blend membranes also showed higher conductivities, $1.9 \times 10^{-2} \mathrm{~S} \cdot \mathrm{cm}^{-1}$, and improved water management. The same authors have also incorporated other block copolymers, poly (styrene-butadiene-methylmethacrylate) block copolymer (SBM) into sSEBS/PVDF blended membrane as third components to optimize the blends performance [103]. As low an amount as $1 \mathrm{wt} \%$ block copolymer when incorporated was sufficient to dramatically reduce segregation and improve mechanical properties. The resulting compatibilized blend membranes showed conductivities up to $3 \times 10^{-2} \mathrm{~S} \cdot \mathrm{cm}^{-1}$ at $100 \%$ RH.

Other block copolymer i.e., poly (styrene- $b$-methyl methacrylate) block copolymer (PS- $b$-PMMA) has also been successfully incorporated into PSSA/PVDF [104] and sSEBS/PVDF [101] as a third component (Table 3; 5 and 6). It was found that both blend membranes were incompatible, especially those containing high weight ratio of PSSA or sSEBS in the blend membranes. Poor compatibility between the two polymers in the blend membranes were result in poor mechanical properties and high methanol permeability. However, by adding $5 \mathrm{wt} \%$ of the PS- $b$-PMMA block copolymer into PSSA/PVDF or sSEBS/PVDF, the compatibility, proton conductivity, and methanol resistance of the blend membrane increased. The highest proton conductivity was obtained in a S-SEBS/PVDF/PS-bPMMA blend membrane; the value was about 24 times that of a plain S-SEBS/PVDF membrane, which in addition showed a significant reduction in methanol permeability as compared with a plain S-SEBS/PVDF membrane (from $13.4 \times 10^{-7}$ to $0.16 \times 10^{-7} \mathrm{~cm}^{2} \cdot \mathrm{s}^{-1}$ ).

Oppositely charged polyions (polycations or polyanions) that interact electrostatically to form polyelectrolyte complexes (PECs) have been used as PEMs for DMFCs [40,42] (Table 3; 7 and 8). These PECs have an ionic crosslinked structure that not only reduces swelling but also improves specific properties such as structural strength and thermal mechanical stability and thus removes the need for other crosslinking agents. Due to its electrostatic interactions with polyanions, chitosan (CS) is an attractive PEC candidate material. A PEC membrane combining CS and poly (acrylic acid) (PAA) has been synthesized and assessed for applicability in fuel cells [40]. Among the blends synthesized, 
the CS/PAAs50/50 complex (1:1: by weight ratio) exhibited the highest proton conductivity $\left(3.8 \times 10^{-2} \mathrm{~S} \cdot \mathrm{cm}^{-1}\right)$. The methanol permeability of the CS/PAAs 50/50 complex was $\left(3.9 \times 10^{-8} \mathrm{~cm}^{2} \cdot \mathrm{s}^{-1}\right)$ this value being about one-seventh that observed for a Nafion ${ }^{\circledR} 117$ membrane. The tensile strength of the CS/PAAs50/50 blended membrane $(26.1 \mathrm{MPa})$ is higher than the individual homopolymer polymers (18.1 MPa for CS and $8.8 \mathrm{MPa}$ for PAAc), due to its dense ionic crosslinked structure. Similar results have been obtained from the same study [42] for CS blended with alginate (SA) to form an ionic crosslinked PEC membrane. The CS/SA membrane demonstrated promising properties for DMFC applications because of its low methanol permeability $\left(4.6 \times 10^{-8} \mathrm{~cm}^{2} \cdot \mathrm{s}^{-1}\right.$ at $50 \mathrm{vol} \%$ methanol concentration), excellent physico-mechanical properties (tensile strength: $72.3 \mathrm{MPa}$ ) and relatively high proton conductivity $\left(4.2 \times 10^{-2} \mathrm{~S} \cdot \mathrm{cm}^{-1}\right)$.

Finally, blended complex membranes have been prepared by mixing sulfonated poly (ether ether ketone) (SPEEK) with WSP, PVA [119] (Table 3; 9). The SPEEK/PVA blend membranes show that PVA can increase the membrane's water uptake while simultaneously reducing methanol absorption. However, the proton conductivity of the blended membranes decreased (from $4.1 \times 10^{-2}$ to $0.3 \times 10^{-2} \mathrm{~S} \cdot \mathrm{cm}^{-1}$ at $25^{\circ} \mathrm{C}$ ) as the PVA content increased (from 0-50 wt\%) in the membranes, due to the negligible contribution to proton transport from PVA in the blend membranes. PNVP, has also been introduced into SPEEK based membranes to modify their properties [120] (Table 3; 10). Acid-base interactions occur between the sulfonic acid group of SPEEK and the tertiary amide groups of PNVP that interestingly have an insignificant effect on water uptake; however, a great reduction of methanol uptake and methanol crossover is observed. As the amount of PNVP is lowered to less than $20 \mathrm{wt} \%$ in the blends, the acid-based interactions cause a great reduction of methanol permeability (to about one-third that of pure SPEEK) while maintaining adequate proton conductivity $\left(>1.5 \times 10^{-2} \mathrm{~S} \cdot \mathrm{cm}^{-1}\right)$.

In summary, several strategies have effectively optimized the blends performance by introducing specific intermolecular interactions for two base components of the blend or by the introduction of a compatibility media into the blend. The methanol permeability of these blended membranes is generally lower than that of plain membranes due to the formation of acid-base structures or the nature of blend polymer. However, these features also decrease the conductivity, thus the conductivity of these blend membranes is similar to, or lower than, that of plain membranes except PECs. The reported results show that the blend membranes do not generally improve all of the target properties to any significant extent. But the properties of the blended membranes are tunable according to the category, or content, of the blend polymers and can thus be formulated with the desired properties for fuel cell applications.

\section{Polymer Network Architectures as Proton Exchange Membranes}

Crosslinked polymers are defined as polymers comprising one or more networks that are interlaced on a molecular scale and covalently, or non-covalently, bonded with each other. The mobility of the polymer chains leads to great variability that can turn a liquid polymer into a 'solid' or 'gel'. The properties of the polymer, such as its: chemical resistance, swellability, permeability, thermal stability, and mechanical properties, depend strongly on its architecture, and density. Due to the desirability of being able to selectively introduce these features in a controlled manner, crosslinked polymers 
are increasingly being used as engineering materials to provide for a variety of requirements in different applications.

Cross-linking appears to be an efficient and simple approach to enhancing membrane performance; hence, it has been considered as a route for introducing improved PEMs in direct methanol fuel cell (DMFC) applications, in which the membrane properties of crosslinked PEMs. The numerous crosslinked membranes that have been designed with a view to meeting these requirements include common chemical networks (a polymer comprising only one network without a linear polymer entrapped within the network polymer) [121-124], interpenetrating polymer networks (IPNs) [68,125] and semi-IPNs [126-128]: an illustrated common polymer network and the associated IUPAC polymer network definition are shown in Figure 6 [129]. A possible drawback to the use of cross-linked polymers is that the crosslinking might hinder the mobility of ions and hence lower the final conductivity. Thus, the development of more efficient membranes with improved chemical and mechanical stabilities that do not detrimentally affect proton conductivity remains an important challenge.

Figure 6. Schematic examples of different types of common polymer network.

\section{Polymer Network}

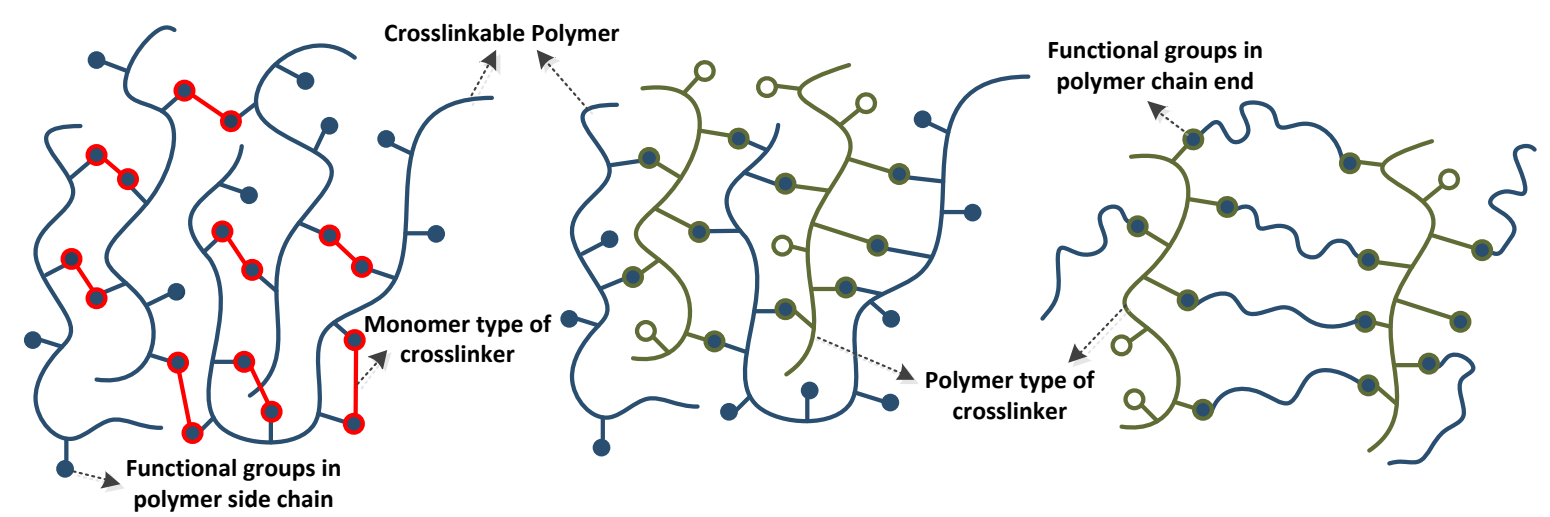

\section{IUPAC definition for polymer network:}

A highly ramified macromolecule in which essentially each constitutional unit is connected to each other constitutional unit and to the macroscopic phase boundary by many permanent paths through the macromolecule, the number of such paths increasing with the average number of intervening bonds; the paths must on the average be co-extensive with the macromolecule.

Water soluble polymers (WSPs) have been introduced into crosslinked membranes due to their high flexibility and hydrophilicity. WSPs are expected to serve as better crosslinkers than either hydrophobic alkylic or aromatic crosslinkers. The essential differences are reflected in the production of a finer network morphology, enhanced toughness and strength, improved water absorption and retention, and better proton conduction. Currently there are a number of reports highlighting the successful introduction of WSP into crosslinked membranes that show promising properties for fuel cell applications. In this section, we describe the preparation of crosslinked membranes based on WSPs using chemical crosslinking, excluding membranes synthesized by using IPNs and semi-IPNs strategies. As these latter two network structures have their own characteristics, crosslinked membranes based on IPNs and semi-IPN architectures will be described a following section. 


\subsection{Crosslinked Poly (vinyl alcohol) Based Membranes}

Poly (vinyl alcohol) (PVA) has often been selected to serve as the polymer matrix in crosslinked membranes due to its high differential selectivity for water over methanol or alcohol, its excellent film forming capacities and its possession of dense reactive chemical functions favorable for crosslinking [57,58]. A major disadvantage of PVA as a membrane is its poor mechanical stability. To overcome this drawback, a crosslinking strategy has been employed to fabricate a DMFC membrane. However, the PVA membranes are poor proton conductors as compared with Nafion ${ }^{\circledR}$; hence it is necessary to combine it with a monomer, oligomer or polymer that contains negatively charged ions (carboxylic and/or sulfonic acid groups), such as sulfosuccinic acid (SSA) [71], poly (styrene sulfonic acid-co-maleic acid) (PSSA-PMA) [72], poly (acrylic acid-co-maleic acid) (PAA-PMA) [76], p-sulfonate phenolic (s-Ph) [130], sulfonated polyhedral oligosilsesquioxane (sPOSS) [131], sulfonated poly (phthalazinone ether sulfone ketone) (SPPESK) [132], sulfonated poly (arylene ether ketone) (SPAKE) [74] or 4-formyl-1,3-benzenedisulfonic acid disodium salt (DSDSBA) [70] (Table 3; 1-9). Figure 7 illustrates the preparation of PVA-based crosslinked membranes.

Figure 7. Scheme illustrating the preparation of PVA-based crosslinked membranes.

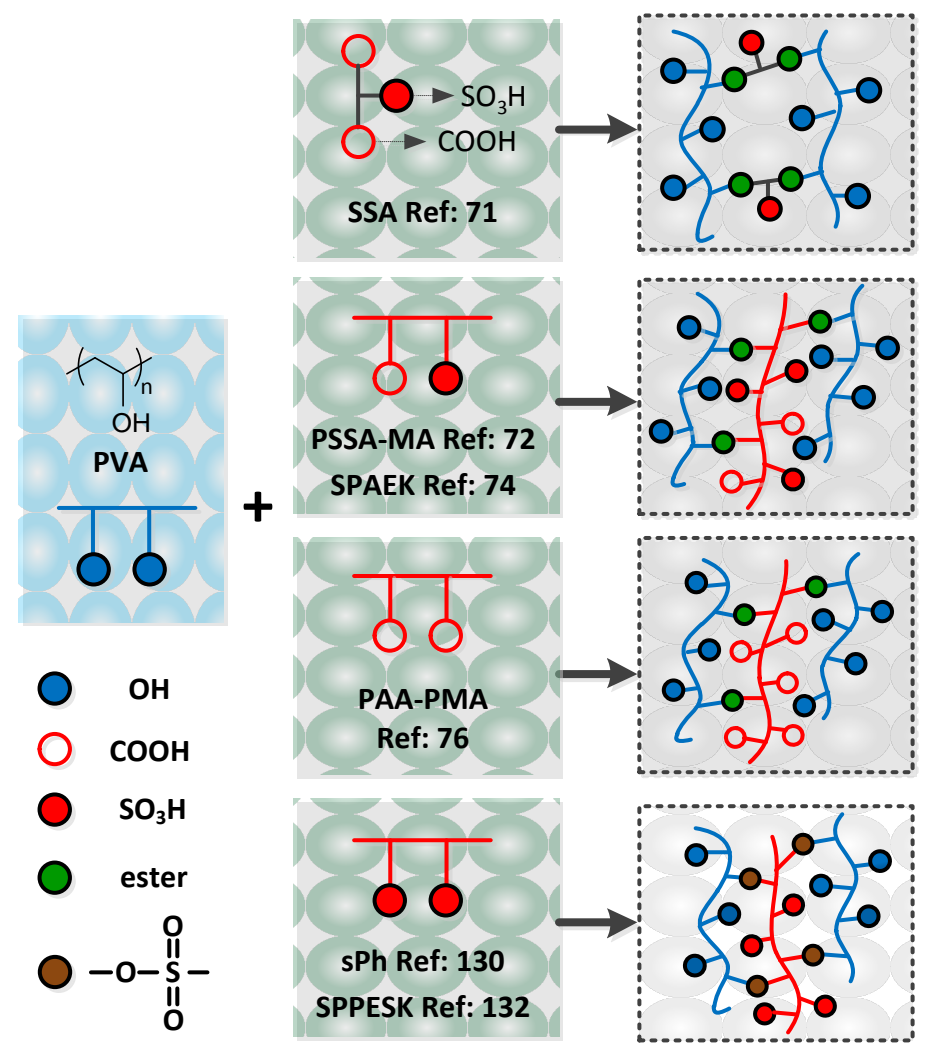

Crosslinked PVA membranes have been prepared using various amounts (5-30 wt $\%$ ) of sulfosuccinic acid (SSA) as the crosslinking agent and also by varying the crosslinking conditions to achieve desirable proton conductive properties for fuel cell applications [71] (Table 4; 1). The results obtained showed that the degree of crosslinking in the PVA/SSA membranes significantly affects their water retention properties, proton conductivities and methanol permeabilities. As the amount of SSA in the PVA/SSA membrane was reduced to less than $17 \mathrm{wt} \%$, the proton conductivity and methanol 
permeability decreased due to the dominant effect of crosslinking on proton and methanol transport. Above this, the concentration-effect of the sulfonic acid groups contained in the SSA dominates any effects due to crosslinking on the proton's conductivity and methanol permeability. Thus, crosslinking agents containing sulfonic acid groups can play a decisive role in proton conduction $\left(-\mathrm{SO}_{3}{ }^{-} \mathrm{H}^{+}\right)$and at the same time act as a barrier to methanol transport. Similar results have also been obtained for PVA-based crosslinked membranes by using poly (styrene sulfonic acid-co-maleic acid) (PSSA-PMA) as both crosslinker and as a donor of the hydrophilic group (carboxylic and/or sulfonic acid groups) [72] (Table $4 ; 2$ ). The results show that proton and methanol transport decreased with an increase in the PSSA-PMA content. The effect of crosslinking may play a more dominant role than does an increase in the number of ionic exchange sites. For the two systems above (PVA/SSA and PSSA-PMA), the proton conductivities and the methanol permeabilities of all the membranes were in the ranges $10^{-3}$ to $10^{-2} \mathrm{~S} \cdot \mathrm{cm}^{-1}$ and $10^{-7}$ to $10^{-6} \mathrm{~cm}^{2} \cdot \mathrm{s}^{-1}$ (in the temperature range $25-90{ }^{\circ} \mathrm{C}$ ), depending on the crosslinking conditions. The same authors have also mixed other kinds of crosslinkers, e.g., poly (acrylic acid-co-maleic acid) (PAA-PMA) with PVA to form crosslinked membranes and investigated the aging effect on swelling time, morphology and proton conductivity [76] (Table 4; 3). It was found that swelling loosened the polymer's structure, resulting in an increase in the free volume capable of containing free water molecules. Swelling of the membrane may provide space for the transport of protons and thereby increase the mobility of protonic charge carriers, leading to slightly increased proton conductivities. Although the proton conductivities of these crosslinked PVA/PMA membranes are known to increase, no report of their methanol permeability has yet appeared.

Other crosslinkers containing proton sources (sulfonated phenolic resin (s-Ph)) have been incorporated into PVA to from crosslinked membranes by covalently linking the sulfonated groups of the phenolic resin and the hydroxyl groups of the PVA at $110^{\circ} \mathrm{C}$ (Table 4; 4). This approach sacrifices a certain amount of the sulfonated groups, leading to a slight reduction of proton conductivity. However, the residual conductivity is still significant $\left(10^{-2} \mathrm{~S} \cdot \mathrm{cm}^{-1}\right)$. The reduced methanol permeability $\left(10^{-7} \mathrm{~cm}^{2} \cdot \mathrm{s}^{-1}\right)$ was due to an increase in the s-Ph concentration with an increasing curing temperature, leading to a reduction of methanol uptake as well as to the membrane's higher selectivity towards water. The conductivity/permeability ratios (selectivity) of the crosslinked PVA/s- $\mathrm{Ph} \mathrm{40/60}$ composition (40:60 by weight) membranes showed the highest value $\left(0.97 \times 10^{-4} \mathrm{~S} \cdot \mathrm{cm}^{-3} \cdot \mathrm{s}^{-1}\right)$, which is higher than that determined for Nafion ${ }^{\circledR}$ 117. Sulfonated polyhedral oligosilsesquioxane (sPOSS) has also been incorporated into PVA and crosslinked by ethylene diaminetetraacetic dianhydride (EDTAD) to produce PVA-based crosslinked membranes [131] (Table 4; 5). The resulting crosslinked PVA/sPOSS membranes showed that proton conductivity increased and methanol permeability decreased with increasing sPOSS content. Incorporating $20 \mathrm{wt} \%$ sPOSS, led to a proton conductivity of about $2 \times 10^{-2} \mathrm{~S} \cdot \mathrm{cm}^{-1}$, which is comparable to Nafion ${ }^{\circledR} 117$ : increasing the sPOSS further to 50 wt\% led to a conductivity of $0.042 \mathrm{~S} \cdot \mathrm{cm}^{-1}$. Additionally, the methanol permeability of PVA/sPOSS membranes decreases significantly with increases in the sPOSS content rendering it lower than Nafion ${ }^{\circledR}$ 117. sPOSS cages, as crosslinkers and sources of proton, can provide ion conduction paths while the hydrophobic portions of the same sPOSS cages combine to form a barrier to methanol permeation while contributing to the improved thermal stability of the membrane. 
Table 4. Characteristics of various crosslinked membranes that incorporate water soluble polymers.

\begin{tabular}{|c|c|c|c|c|c|c|c|c|}
\hline \multirow{2}{*}{$\frac{\text { Line }}{1}$} & \multirow{2}{*}{$\begin{array}{c}\text { Polymer } \\
\text { PVA }\end{array}$} & \multirow{2}{*}{$\begin{array}{c}\begin{array}{c}\text { Acid Monomer } \\
\text { /Polymer }\end{array} \\
\text { SSA }\end{array}$} & \multirow{2}{*}{$\begin{array}{c}\text { Crosslinker } \\
\text { SSA }\end{array}$} & \multirow{2}{*}{$\begin{array}{c}\begin{array}{c}\text { Ionic Partner } \\
(\mathrm{wt} \%)\end{array} \\
5-30\end{array}$} & \multicolumn{2}{|c|}{$\begin{array}{l}\text { Proton Conductivity }\left(\mathrm{mS} \cdot \mathrm{cm}^{-1}\right) \\
\text { /Measurement Condition }\end{array}$} & \multirow{2}{*}{$\begin{array}{c}\begin{array}{c}\text { Methanol Permeability } \\
\times \mathbf{1 0}^{\mathbf{8}}\left(\mathbf{c m}^{\mathbf{2}} \cdot \mathbf{s}^{-\mathbf{1}}\right)\end{array} \\
10-100\end{array}$} & \multirow{2}{*}{$\begin{array}{c}\text { Reference } \\
{[71]}\end{array}$} \\
\hline & & & & & $\sim 1-10$ & $25-50{ }^{\circ} \mathrm{C}$ & & \\
\hline 2 & PVA & PSSA-PMA & PSSA-PMA & 5-11 & $\sim 1-10$ & $25-90{ }^{\circ} \mathrm{C}$ & $10-100$ & [72] \\
\hline 3 & PVA & PAA-PMA & PAA-PMA & 7 & $\sim 1-10$ & 30 and $50^{\circ} \mathrm{C}$ & - & {$[76]$} \\
\hline 4 & PVA & $\mathrm{sPh}$ & $\mathrm{sPh}$ & $20-80$ & $12-86$ & - & $20.9-181$ & {$[130]$} \\
\hline 5 & PVA & sPOSS & EDTAD & $20-50$ & $\sim 10-50$ & $25^{\circ} \mathrm{C}$ & $10-100$ & {$[131]$} \\
\hline 6 & PVA & SPPESK & PVA & $60-85$ & $\sim 5-23$ & $60^{\circ} \mathrm{C}$ & - & [132] \\
\hline 7 & PVA & SPAEK & PVA & $85-100$ & $100-220$ & $30-80{ }^{\circ} \mathrm{C}$ & $19.0-41.6$ & {$[74]$} \\
\hline 8 & sPVA & - & GA & 100 & $1-15$ & RT & $30-290$ & [69] \\
\hline 9 & PVA & DSDSBA & GA & $\sim 16-64$ & $3-41$ & $25^{\circ} \mathrm{C}$ & $41-105$ & [70] \\
\hline 10 & PVA & $\begin{array}{l}\text { PS- } b \text {-PHEA- } b- \\
\text { PSSA and SSA }\end{array}$ & SSA & $10-100$ & $18-44$ & $25^{\circ} \mathrm{C}$ & - & [73] \\
\hline 11 & PEG & SPI & PEG & $75-100$ & $10-120$ & $30-90{ }^{\circ} \mathrm{C}$ & - & [47] \\
\hline 12 & PEG & $\begin{array}{l}\text { (PMA-alt-PS)-co- } \\
\text { PAMPS }\end{array}$ & PEG & $60-80$ & $0.9-68$ & $30-90{ }^{\circ} \mathrm{C}$ & - & [48] \\
\hline 13 & PEG & SPAEK & PEG & $70-100$ & $\sim 60-180$ & $20-80{ }^{\circ} \mathrm{C}$ & - & [51] \\
\hline 14 & PEG & SPEEK & $\begin{array}{l}\text { PEG } \\
\text { CDM }\end{array}$ & $\begin{array}{l}60-75 \\
67-75\end{array}$ & $\begin{array}{l}\sim 0.4-100 \\
\sim 0.4-100\end{array}$ & $\begin{array}{l}100^{\circ} \mathrm{C}, 40-100 \% \mathrm{RH} \\
100{ }^{\circ} \mathrm{C}, 60-100 \% \mathrm{RH}\end{array}$ & - & {$[50]$} \\
\hline 15 & sSBS & - & - & - & 23 & $25^{\circ} \mathrm{C}$ & 8.1 & {$[133]$} \\
\hline 16 & NaSS-4VP & NaSS-4VP & DBD & $75-92$ & $\sim 61-223$ & $30-70{ }^{\circ} \mathrm{C}, 90 \% \mathrm{RH}$ & $21-646$ & {$[134]$} \\
\hline 17 & CS & SSA & SSA and GA & $0-16$ & $\sim 10-120$ & $25-90{ }^{\circ} \mathrm{C}$ & $\sim 60-120$ & {$[39]$} \\
\hline
\end{tabular}


Sulfonated aromatic polymers, such as sulfonated poly (phthalazinone ether sulfone ketone) (SPPESK) [132] and sulfonated poly (arylene ether ketone) bearing carboxylic acid groups (SPAEK-C) [74], have been used with PVA to modify the membrane's properties by covalent crosslinking. Gu et al. [132] investigated the effect of using PVA as the crosslinker in comparison with a small molecule crosslinker comprising glycol and glycerol: the results indicated that the crosslinking of SPPSK with PVA requires a relatively lower crosslinking temperature and has a much higher stability in water (Table 4; 6). The swelling ratio and proton conductivity of the SPPESK/PVA crosslinked membrane decreases rapidly with increasing PVA content, because of the decreasing IEC and the increasing crosslinker density. When SPPESK with a high degree of sulfonation (DS: $140 \%$ ) is incorporated with a lower content of PVA $(<30 \mathrm{wt} \%)$ the resulting membranes have a higher proton conductivity than stable pristine SPPESK (DS: $81 \%)$. The highest proton conductivity $\left(2.00 \times 10^{-2} \mathrm{~S} \cdot \mathrm{cm}^{-1}\right)$ was obtained with SPPESK/PVA $85 / 15(85: 15$ by weight $)$ which is almost twice as that $\left(1.03 \times 10^{-2} \mathrm{~S} \cdot \mathrm{cm}^{-1}\right)$ of a pristine SPPEKSK membrane (DS: 81\%). More recently, Zhao et al. [74] have also used PVA as a crosslinker incorporated into sulfonated poly (arylene ether ketone) bearing carboxylic acid groups (SPAEK-C) using thermal esterification to form a crosslinked membrane (Table 4; 7). Similar results were observed in SPAEK-C/PVA crosslinked membranes-that is the proton conductivities of these membranes decreased with increasing amounts of PVA due to the lower water uptake and lower IEC. From the relationship between the relative proton conductivity decrease (from 1 to $0.63 \%$ ) and the relative water uptake decrease (from 1 to $0.27 \%$ ), it is interesting to find that decreases in the ratios of both proton conductivity and IEC are small with respect to the decrease in the uptake of water. This result indicates that the crosslinked structure of SPAEK-C and PVA can significantly decrease water uptake while maintaining high proton conductivity. Additionally, the methanol permeabilities of SPAEK-C/PVA membranes gradually decreased (from $4.16 \times 10^{-7}$ to $1.9 \times 10^{-7} \mathrm{~cm}^{2} \cdot \mathrm{s}^{-1}$ ) when the PVA content increased (from 0 to $15 \mathrm{wt} \%$ ), and were all lower than that of Nafion ${ }^{\circledR} 115\left(10.05 \times 10^{-7} \mathrm{~cm}^{2} \cdot \mathrm{s}^{-1}\right)$ under the same measurement conditions. The SPPAEK-C/PVA crosslinked membranes with PVA (15 wt\%) possess better selectivity, lower water uptakes and adequate proton conductivity, i.e., nearly five times higher than Nafion ${ }^{\circledR} 115$. Both sulfonated aromatic polymers used PVA as a crosslinker, showing that these crosslinked membranes are promising proton conducting materials and have potential applications in DMFCs.

Another approach is to select PVA as the PEM polymer matrix and modify it with negatively charged ions to facilitate proton transfer. In order to improve the mechanical and thermal stabilities of PVA-based membranes, glutaraldehyde (GA) was used as the crosslinking agent to form PVA network membranes. Thus, Shen et al. [69] have used PVA as the polymer matrix for PEMs while the protogenic sulfonic acid groups have been introduced by chlorosulfonic acid through a condensation reaction to form sulfonated PVA (sPVA) (Table 4; 8). The crosslinked sPVA membranes were obtained by an aldol condensation between the $\mathrm{OH}$ groups of PVA and the aldehyde groups of GA. Crosslinked sPVA membranes with a high DS show higher conductivity $\left(1.4 \times 10^{-3} \mathrm{~S} \cdot \mathrm{cm}^{-1}\right)$ and lower methanol permeability $\left(0.3 \times 10^{-6} \mathrm{~cm}^{2} \cdot \mathrm{s}^{-1}\right)$ than membranes with a low DS (proton conductivity: $0.96 \times 10^{-3} \mathrm{~S} \cdot \mathrm{cm}^{-1}$; methanol permeability: $0.8 \times 10^{-6} \mathrm{~cm}^{2} \cdot \mathrm{s}^{-1}$ ); this is quite different to other sulfonated polymer or perfluorinated ionomer membranes where the methanol permeability increases with conductivity. The authors believe the effect is due to the quite different microstructures and morphologies in these membranes. The same group have also prepared crosslinked s-PVA based 
membranes by introducing the 4-formyl-1, 3-benzenedisulfonic acid disodium salt (DSDSBA) into the PVA chains act as an ion carrier while using GA as a crosslinker to form the sPVA network [70] (Table 4; 9). The combination of a flexible backbone, with short and rigid side chains and dense acid functionalities improved the proton conduction in these sPVA based crosslinked membranes. It was found that by increasing the DSDSBA content up to about $20 \mathrm{wt} \%$, proton the conductivities of these membranes $\left(>1.4 \times 10^{-2} \mathrm{~S} \cdot \mathrm{cm}^{-1}\right)$ were higher than that of $\mathrm{Nafion}^{\circledR} 117\left(1.3 \times 10^{-2} \mathrm{~S} \cdot \mathrm{cm}^{-1}\right)$; however, the methanol permeability of these membranes $\left(<0.78 \times 10^{-6} \mathrm{~cm}^{2} \cdot \mathrm{s}^{-1}\right)$ is significantly low when compared to Nafion ${ }^{\circledR} 117\left(2.43 \times 10^{-6} \mathrm{~cm}^{2} \cdot \mathrm{s}^{-1}\right)$. These results can be attributed to the well connected system of narrow water channels that facilitated both a lower methanol permeation and the high mobility of the protonic charge carriers.

Finally, proton conducting crosslinked membranes have also been prepared using polymer blends of poly (styrene-b-hydroxyethyl acrylate-b-styrene sulfonic acid) (PS- $b$-PHEA- $b$-PSSA) and PVA (Table $4 ; 10$ ). The middle PHEA triblock copolymer was crosslinked with PVA by an esterification reaction using sulfosuccinic acid (SSA) as a crosslinking agent. Similar results were also observed in the IEC values (from 1.56 to $0.61 \mathrm{meq} \cdot \mathrm{g}^{-1}$ ) and proton conductivity $\left(4.4 \times 10^{-2}\right.$ to $1.8 \times 10^{-2} \mathrm{~S} \cdot \mathrm{cm}^{-1}$ ), which continuously decreased with an increasing PVA content (from 33 to $66 \mathrm{wt} \%$ ). In contrast, the mechanical properties increased from 15.0 to $38.5 \mathrm{MPa}$ with increases in the PVA content, due to the decrease of water uptake (from 87.0 to $44.3 \%$ ). Operating in an $\mathrm{H}_{2} / \mathrm{O}_{2}$ polymer electrolyte membrane fuel cell (PEMFC), the crosslinked membrane containing PVA $50 \mathrm{wt} \%$ had a power density of $230 \mathrm{~mW} \cdot \mathrm{cm}^{-2}$ at $70{ }^{\circ} \mathrm{C}$ and $100 \mathrm{RH} \%$.

\subsection{Crosslinked Poly (ethylene glycol) Based Membranes}

Other WSP polymers, e.g., poly (ethylene glycol) (PEG), have also been employed in the preparation of crosslinked membranes for fuel cell applications. PEG is generally used as a crosslinker and has been introduced into several sulfonated polymer matrices, such as sulfonated polyimide (SPI) [47], poly [(maleic anhydride)-alt-styrene-co-(2-acrylamido-2-methyl-1-propanesulfonic acid)] (PMA-alt-PS)-co-PAMPS [48], sulfonated poly (arylene ether ketone) (SPAEK) [51] and sulfonated poly (ether ether ketone) (SPEEK) [50], to improve the membrane's mechanical and hydrolytic stabilities while reducing methanol crossover without compromising proton conductivity and brittleness. (Figure 8 and Table 4; 11-14) Thus, Yang et al. [47] prepared a series of crosslinked SPI/PEG membranes with various ratios of maleic anhydride SPI and PEG diacrylate as PEMs (Table 4; 11). Their results showed that the water uptake (from 23.8 to $24.3 \%$ ) and the proton conductivity increased with increasing contents of PEG (from 0 to $25 \mathrm{wt} \%$ ) despite a decrease in the ion exchange capacity (IEC) (from 1.27 to $1.23 \mathrm{meq} \cdot \mathrm{g}^{-1}$ ) and an increase in the crosslinking density. The effect of the flexible PEG crosslinker on the proton conductivities and hydrolytic stabilities in the crosslinked SPI membrane with $25 \mathrm{wt} \%$ content of PEG were more obvious, showing high proton conductivities $\left(>0.1 \mathrm{~S} \cdot \mathrm{cm}^{-1}\right)$ and good hydrolytic stabilities $(>200 \mathrm{~h}$ to the time when the film started to disintegrate) at high temperatures $\left(80 \sim 90{ }^{\circ} \mathrm{C}\right)$. 
Figure 8. Proposed structure of sulfonated polymer/ Poly (ethylene glycol) (PEG) crosslinked membranes.
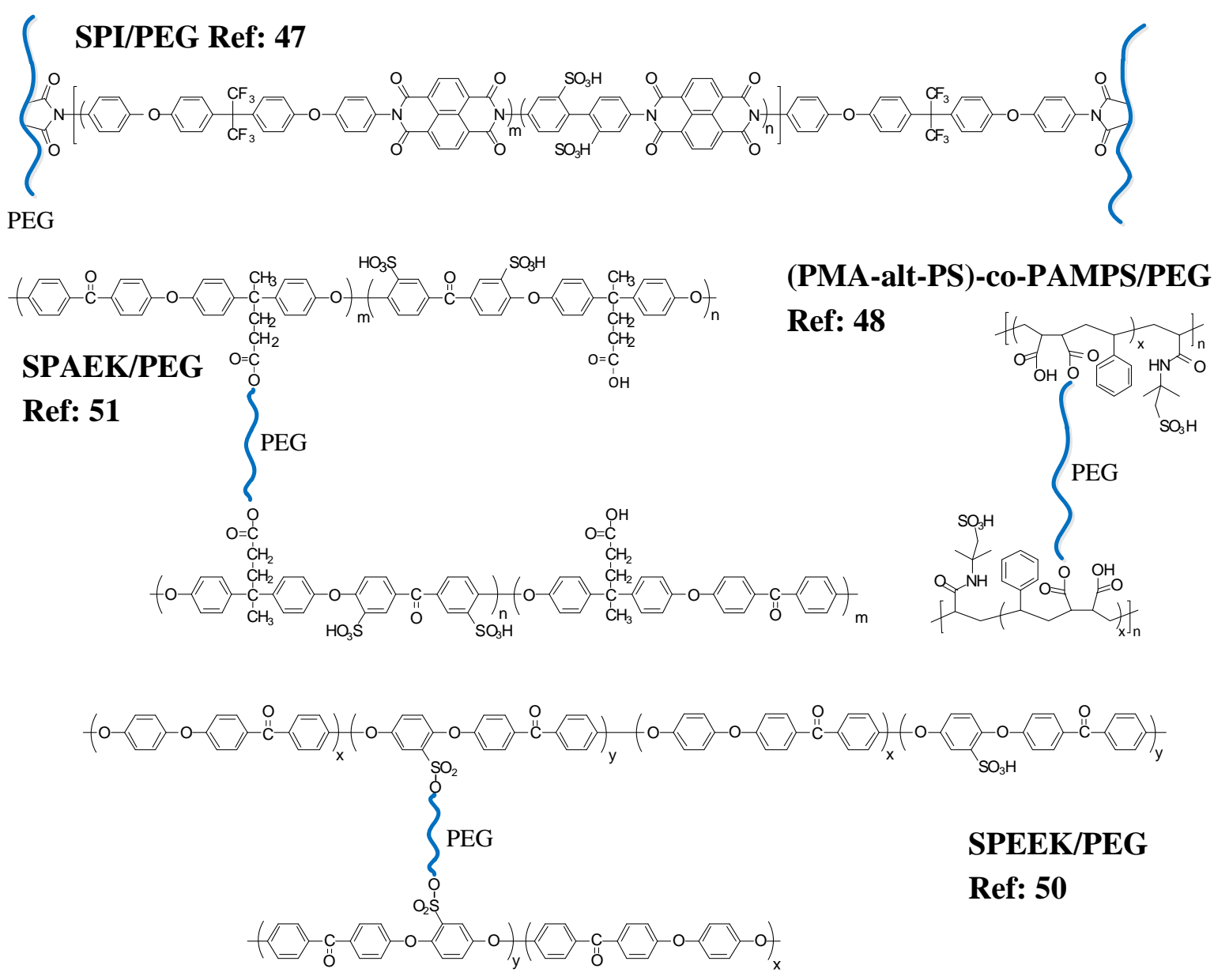

Effects due to the molecular weight and the amount of PEG incorporated on the membrane's properties include alterations to its mechanical properties, swelling behavior, and proton conductivity; these are discussed in (PMA-alt-PS)-co-PAMPS [48] and SPAEK systems [51]. A series of (PMA-altPS)-co-PAMPS crosslinked membranes using PEG with different molecular weights $\left(\mathrm{M}_{\mathrm{n}}=200,1450\right.$ and 4,000 $\mathrm{g} \cdot \mathrm{mol}^{-1}$ ) and amounts (20-40 wt\%) have been prepared [48] (Table 4; 12). The resulting membrane' tensile strength slightly increased with decreasing PEG chain lengths-this chain length decrease also has the effect of making the membranes more rigid. These results imply that short PEG crosslinking molecules in the polymer matrix could not provide sufficient flexibility to produce stable membranes when compared to longer PEG crosslinking molecules. With respect to swelling behavior, the water absorption was increased with an increase in the chain length of PEG and a decrease in its content. The highest proton conductivity was obtained when the membranes were prepared with a lower content (20 wt\%) of the PEG crosslinker but with a high molecular weight $\left(\mathrm{M}_{\mathrm{n}}=4,000 \mathrm{~g} \cdot \mathrm{mol}^{-1}\right)$. Similar results have also been observed for a SPAEK/PEG membrane, in which PEG was used as the crosslinker [51] (Table 4; 13). In all SPAEK/PEG crosslinked membranes the conductivity decreased with an increasing PEG content. The decrease in water uptake and IEC with increasing PEG content is thought to be the reason for the observed decrease in proton conductivity. Although the introduction of the crosslinker PEG in the membranes generally leads to a decrease in proton conductivity; at higher 
temperatures $\left(80^{\circ} \mathrm{C}\right)$ a significant increase in proton conductivity and chemical stability is apparent. More recently, Gupta et al. [50] have prepared crosslinked membranes based on SPEEK in the presence of varying amounts of PEG and cyclohexane dimethanol (CDM) (Table 4; 14). PEG is more flexible and hydrophilic than CDM, so this structural difference is reflected clearly in the finer morphology of the network produced, the enhanced storage modulus, the glass transition temperature and the proton conductivity. The highest proton conductivity $\left(5.7 \times 10^{-2} \mathrm{~S} \cdot \mathrm{cm}^{-1}\right)$ was achieved in SPEEK/PEG 67/33 (67: 33 by weight) which is comparable to neat SPEEK $\left(5.6 \times 10^{-2} \mathrm{~S} \cdot \mathrm{cm}^{-1}\right)$. Results from various sulfonated polymer matrices made using PEG as crosslinker showed that PEG is a very effective crosslinker in the sense that it maintains hydrolytic stability even at higher temperatures with no compromise in proton conductivity.

\subsection{Other Crosslinked Membranes Involve Water Soluble Polymer}

Other crosslinked membranes that incorporate WSP have been prepared for application in fuel cells. Won et al. [133] used a crosslinking approach to control and fix microphase separated sulfonated poly (styrene-b-butadiene-b-styrene) (sSBS) to reduce methanol permeability while maintaining high proton conductivity (Table $4 ; 15$ ). The crosslinked sulfonated SBS membranes (scSBS) were prepared by photo-crosslinking and additional sulfonating to obtain well-structured (i.e., semi-rigid) PEMs. The effect of fixed channels on methanol permeability and proton conductivity were confirmed by comparing the resulting properties of scSBS and non-crosslinkable sulfonated poly (styrene-b(ethylene-r-butylene)-b-styrene (sSEBS) membranes. The results show that the scSBS membrane (DS = 36.8) exhibits a methanol permeability of $8.1 \times 10^{-8} \mathrm{~cm}^{2} \cdot \mathrm{s}^{-1}$, i.e., more than 30 times smaller than that of Nafion ${ }^{\circledR} 117\left(2.9 \times 10^{-6} \mathrm{~cm}^{2} \cdot \mathrm{s}^{-1}\right)$, and a proton conductivity of $2.3 \times 10^{-2} \mathrm{~S} \cdot \mathrm{cm}^{-1}$, which is comparable to that of Nafion ${ }^{\circledR} 117\left(6.3 \times 10^{-2} \mathrm{~S} \cdot \mathrm{cm}^{-1}\right)$ and sSEBS $\left(3.8 \times 10^{-2} \mathrm{~S} \cdot \mathrm{cm}^{-1}\right)$. These results indicated that limiting the ionic channel size would severely limit the methanol permeability but would not affect the proton conductivity. Crosslinked membranes composed of zwitterionic molecules with various crosslinking densities have also been fabricated for the development of high durability PEMs (Table 4; 16). After crosslinking poly (styrene sulfonic acid-co-vinylpyridine) (NaSS-4VP) membranes with a crosslinking fraction of 90.3 showed excellent hydrolytic stability with only slightly changes in weight (decrease in weight: $1.9 \%$ ) and proton conductivity (from 7.1 to $5.5 \times 10^{-2} \mathrm{~S} \cdot \mathrm{cm}^{-1}$ ) after 28 days of testing in water at $100{ }^{\circ} \mathrm{C}$ : note that the initial NaSS-4VP is a WSP. Moreover, an optimum membrane maintained adequate proton conductivities $\left(>10^{-2} \mathrm{~S} \cdot \mathrm{cm}^{-1}\right)$ after $120 \mathrm{~h}$ in a high concentration of Fenton's reagent, and is thus much stronger than other sulfonated polymers that typically decompose after 24-60 h. The optimum membrane possessed a high selectivity for methanol fuel cells $\left(3.38 \times 10^{5} \mathrm{~S} \cdot \mathrm{cm}^{-3} \cdot \mathrm{s}^{-1}\right)$, i.e., approximately five times that of Nafion ${ }^{\circledR} 117\left(0.71 \times 10^{5} \mathrm{~S} \cdot \mathrm{cm}^{-3} \cdot \mathrm{s}^{-1}\right)$.

With its distinct advantages in forming an excellent alcohol barrier while maintaining acceptable ion conductivity properties, chitosan (CS) has been used for the polymer matrix of PEMs [39] (Table 4; 17). Various compositions of sulfosuccinic acid (SSA) and GA were introduced into CS as a binary crosslinking agent to form CS network membranes. It was found that both proton conductivity and methanol permeability were increased with increasing contents of proton sources of SSA. According to selectivity value calculations, the optimum composition of crosslinking agent was chosen as 12 and 2 weight $\%$ of SSA and GA. The optimum membrane (CS/SSA/GA 12) showed relatively high proton 
conductivity $\left(4.5 \times 10^{-2} \mathrm{~S} \cdot \mathrm{cm}^{-1}\right)$ and low methanol permeability $\left(9.6 \times 10^{-7} \mathrm{~cm}^{2} \cdot \mathrm{s}^{-1}\right)$. The selectivity of the optimum membrane was approximately $4.7 \times 10^{4} \mathrm{~S} \cdot \mathrm{cm}^{-3} \cdot \mathrm{s}^{-1}$ compared to $4.1 \times 10^{4} \mathrm{~S} \cdot \mathrm{cm}^{-3} \cdot \mathrm{s}^{-1}$ for Nafion ${ }^{\circledR}$. The single cell DMFC performance test showed that the CS/SSA/GA 12 membrane had a maximum power density (with $2 \mathrm{M}$ methanol feed at $30^{\circ} \mathrm{C}$ ) of $17 \mathrm{~mW} \cdot \mathrm{cm}^{-2}$, while a higher power density $41 \mathrm{~mW} \cdot \mathrm{cm}^{-2}$ was obtained at $60{ }^{\circ} \mathrm{C}$. From the results, it is apparent that these CS based crosslinked membranes have promising potential for use in DMFC applications.

\subsection{Summary for Crosslinked Membranes Involve Water Soluble Polymer as Fuel Cell Membrane}

In summary, several WSPs have been effectively optimized for fuel cell applications by crosslinking. Proton conductivities have been used to compare the properties of the PVA-based crosslinked membranes (Figure 9); interestingly, the addition of PVA to a sulfonated polymer leads to the formation of membranes with high flexibility, good water resistance and low methanol permeability without a significant decrease in conductivity. The methanol permeability of PVA-based crosslinked membranes is generally lower than that of Nafion ${ }^{\circledR}$ due to the PVA polymer reinforcing methanol barrier. In addition, sulfonated polymer matrices made using PEG as crosslinker allow good control of swelling simply by changing the content and length of the crosslinking PEG molecules. The reported results show that crosslinking with PEG leads to a significant increase in both proton conductivity and chemical stability at higher temperatures. Unfortunately, no report related to the methanol permeability of these membranes has yet appeared. The best reported stability is that of crosslinked membranes composed of zwitterionic molecules, which withstand exposure to boiling water for 28 days while maintaining adequate proton conductivity after $120 \mathrm{~h}$ in high concentrations of Fenton's reagent. It can be conclude that the properties of the crosslinked membrane are adjustable according to the selection of the WSP and can thus give desireable properties for fuel cell applications.

Figure 9. Conductivity versus the methanol permeability of PVA-based crosslinked membranes. Only values given in the text of articles (rather than values that can merely be read from a figure) are plotted. Various Nafion ${ }^{\circledR}$ values are plotted for comparison.

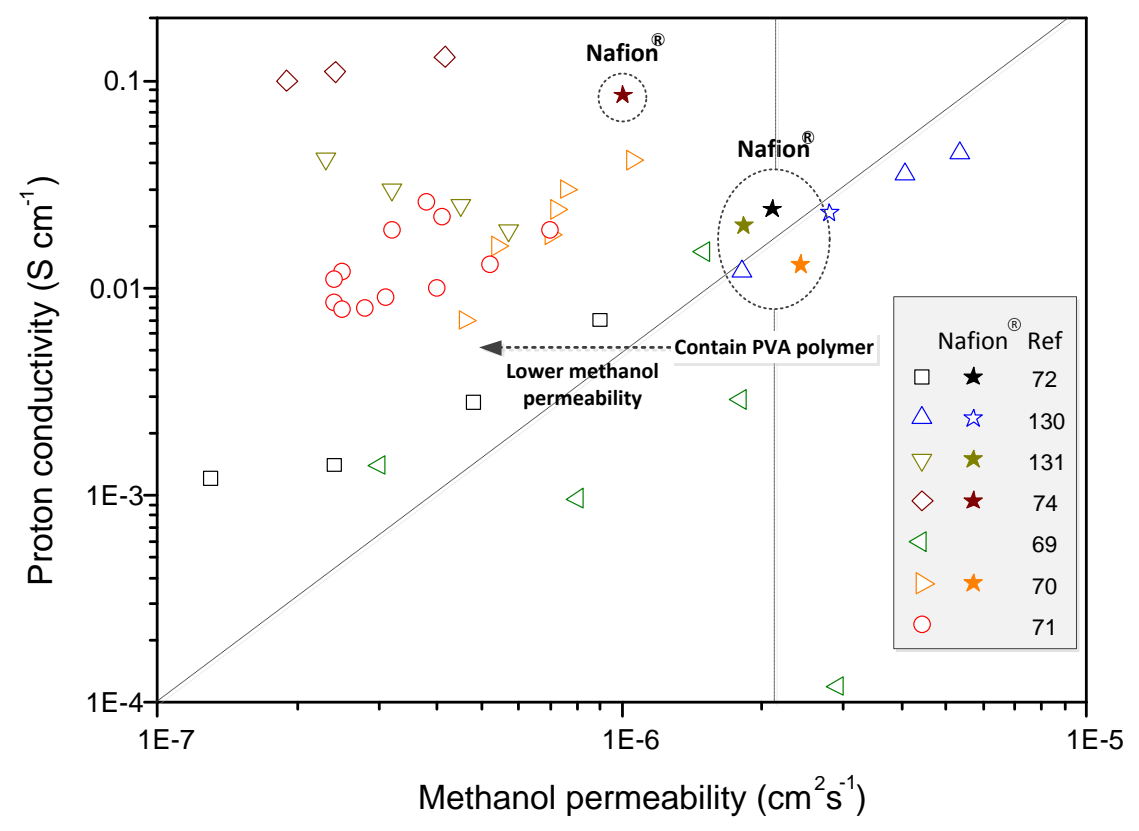




\section{Crosslinked Proton Exchange Membranes Based on Semi-Interpenetrating (Semi-IPN) and Interpenetrating (IPN) Architectures}

Both semi-interpenetrating networks (semi-IPN) and interpenetrating networks (IPN) have characteristics that make them very different from common networks. For a common polymer network system, there is usually only one network structure in the final form of the polymer, i.e., it is formed without an entrapped linear polymer. An illustration of polymer networks, including common networks, semi-IPNs and IPNs is presented in Figure 10 together with the IUPAC definitions [129]. Briefly, semi-IPN networks are composited of one linear polymer entrapped within the network of another polymer, while IPN networks comprise more than one polymer network structures interlaced on a molecular scale. Generally, the synthesis of semi-IPNs and IPNs can be classified into two main pathways, namely in situ and impregnation synthesis [135]. According to these two synthetic approaches, the water soluble polymers (WSPs) can be introduced into semi-IPN membranes as crosslinkers or liner polymers.

Figure 10. Schematic representation of semi- interpenetrating polymer networks (IPNs) and IPNs.
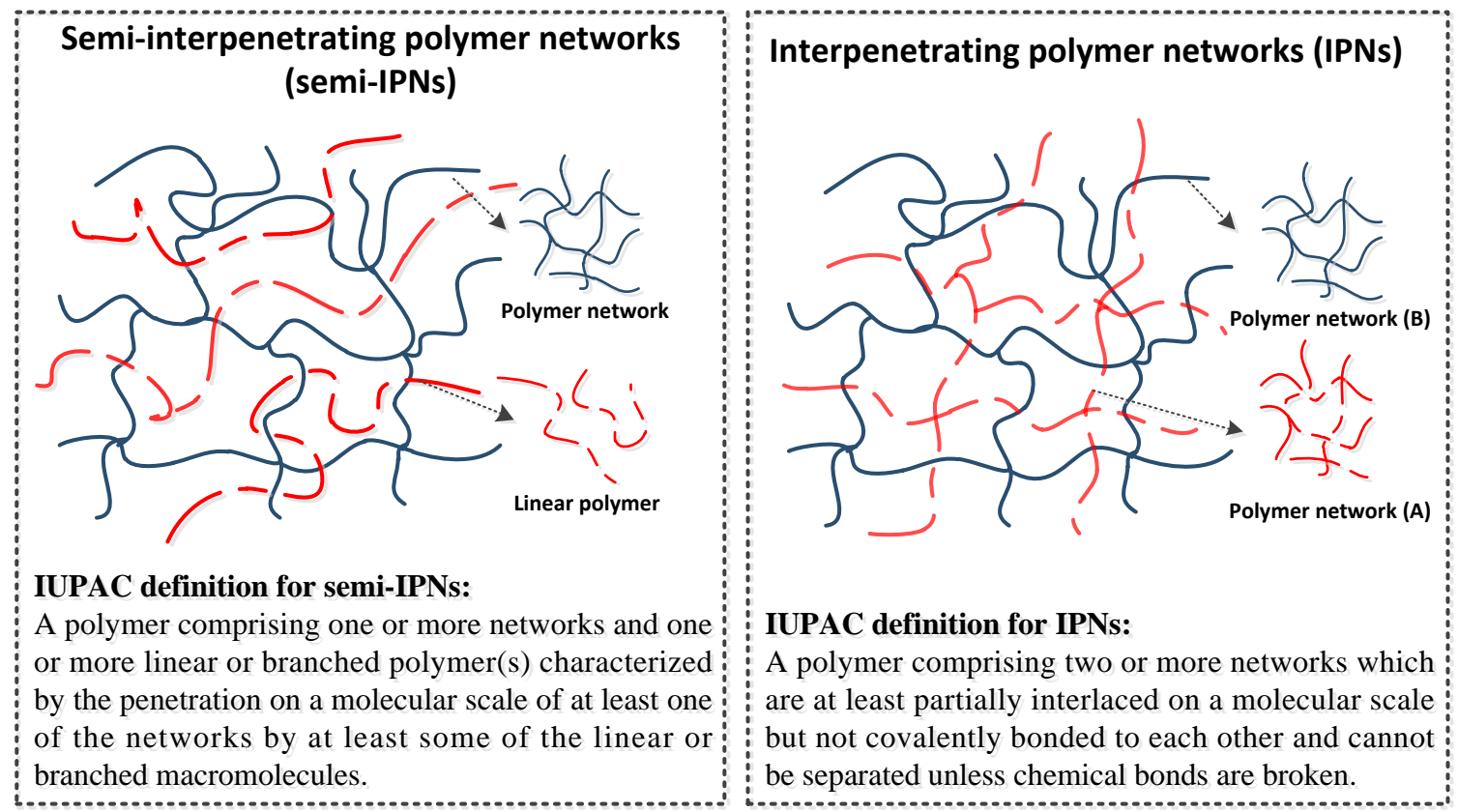

When using semi-IPNs in fuel cell applications, it is necessary to introduce the polymer with proton sources in the semi-IPN membranes, which can be either a linear polymer or a network polymer. WSPs containing sulfonic acid groups, such as poly (styrene sulfonic acid) (PSSA) and poly (2-acrylamido-2-methylpropanesulfonic acid) (PAMPS), have been used as linear polymers or network polymers in the semi-IPN membranes due to their high conductivities. However, linear PSSA and PAMPS are water soluble polymers, thus the formation of a copolymer or network can limit over swelling; however, the membranes still lack sufficient strength and toughness for fuel cell applications. As mentioned above, the combination of PVA and a sulfonated polymer to form a crosslinked membrane resulted in PVA-based crosslinked membranes with higher flexibility, good water resistance and low methanol permeability. Considering their respective advantages, linear PSSA or 
PAMPS have often been combined with a PVA network to form a semi-IPN architecture to achieve desirable properties for fuel cell applications. However, the PVA/PAMPS based semi-IPN system needs to introduce a third medium by grafting or blending into the PVA network to overcome the membrane's shortcomings of being stiff and brittle. When PSSA or PAMPS is formed as crosslinked structure, it requires to be associated with another polymer, such as poly (vinylidene fluoride) (PVDF) [88,136], poly (tetrafluoroethylene) (PTFE) [137,138], poly (vinyl chloride) (PVC) [139], Nafion ${ }^{\circledR}[140,141]$, and PVA [88], in order to obtain adequate mechanical and swelling properties. Other semi-IPNs in different combinations involve WSPs, such as poly (ethylene glycol) (PEG) [52], chitosan (CS) and poly (vinyl pyrolidone) (PNVP) [79], have also been prepared as semi-IPN membranes for fuel cell applications. Next, we describe the preparation and performance of semi-IPN membranes based on WSPs for fuel cell membrane applications, in terms of their conductivities, stabilities, and permeabilities.

\subsection{PVA Polymer Network Based Semi-IPN Membranes}

Based on the advantages of PVA-based crosslinked membranes, semi-IPNs combining PVA network and linear PSSA or poly (styrene sulfonic acid-co-maleic acid) (PSSA-PMA) copolymers have been produced according to an impregnation [62] or an in situ [60,66-68] process to form semi-IPN membranes (Table 5; 1-3). To form a PVA network, the PVA is most commonly combined with a dialdehyde, such as glutaraldehyde (GA), and a dicarboxylic acid, such as sulfosuccinic acid (SSA), using an aldol condensation followed by esterification to form the 3D network structure. Previously, various PVA/PSSA-PMA semi-IPN membranes have been prepared using GA as a crosslinking agent with various amounts of linear PSSA and PSSA-PMA to achieve desirable proton conductivities and methanol permeabilities for fuel cell applications [62]. The degree of membrane swelling was controlled by adding a GA as a crosslinker allowing the resulting PVA-GA polymer network to function as a hydrophobic methanol barrier. It was found that the proton conductivity of the PVA/PSSA or PVA/PSSA-PMA semi-IPN membranes was strongly dependent on the content of the linear acid polymer. Maximum proton conductivity $\left(\sim 10^{-1} \mathrm{~S} \cdot \mathrm{cm}^{-1}\right)$ was observed for PVA/PSSA semi-IPNs with $50 \mathrm{wt} \%$ PSSA which is comparable to that of Nafion ${ }^{\circledR} 117$. PVA/PSSA-PMA semi-IPN membranes are more suitable than PVA/PSSA membranes due to their stronger mechanical properties, and moderate hydrolytic stabilities. The methanol permeabilities of PVA/PSSA-PMA membranes are at least seven-fold lower than those of Nafion ${ }^{\circledR} 117$ in all methanol concentrations (5-40 wt\% MeOH). In addition to the high methanol resistance of PVA-based network structures, their low permeability can be attributed to a narrower ionic channel size in the crosslinked membrane than in Nafion ${ }^{\circledR} 117$ as can be inferred from SAXS studies [the size (d) of the separation of channels, $\mathrm{d}=5.09 \mathrm{~nm}$ for Nafion ${ }^{\circledR} 117$ and $\mathrm{d}=4.28$ for PVA/PSSA-PMA crosslinked membrane]. 
Table 5. Characteristic of various semi-IPN membranes involve water soluble polymers.

\begin{tabular}{|c|c|c|c|c|c|c|c|c|c|}
\hline \multirow{2}{*}{ Line } & \multirow{2}{*}{ Linear Polymer } & \multirow{2}{*}{ Polymer Network } & \multicolumn{2}{|c|}{ Third Components } & \multirow{2}{*}{$\begin{array}{c}\text { Ionic Partner } \\
(\mathbf{w t} \%)\end{array}$} & \multirow{2}{*}{\multicolumn{2}{|c|}{$\begin{array}{l}\text { Proton Conductivity }\left(\mathrm{mS} \cdot \mathrm{cm}^{-1}\right) \\
\text { / Measurement Condition }\end{array}$}} & \multirow{2}{*}{$\begin{array}{l}\text { Methanol Permeability } \\
\quad \times 10^{8}\left(\mathrm{~cm}^{2} \cdot \mathrm{s}^{-1}\right)\end{array}$} & \multirow{2}{*}{ References } \\
\hline & & & Name & wt\% & & & & & \\
\hline \multirow[b]{2}{*}{1} & PSSA & \multirow[b]{2}{*}{ PVA-GA } & \multirow{2}{*}{\multicolumn{2}{|c|}{-}} & 25 & 65 & \multirow[b]{2}{*}{$25^{\circ} \mathrm{C}$} & $19.5-168.5 \quad(5-40 \mathrm{wt} \%$ & \multirow[b]{2}{*}[62]{} \\
\hline & PSSA-PMA & & & & 50 & 95 & & $3.2-25.3 \quad \mathrm{MeOH})$ & \\
\hline 2 & PSSA & PVA-GA & - & & $0-35$ & $\sim 0.01-50$ & $30{ }^{\circ} \mathrm{C}, 0-100 \% \mathrm{RH}$ & - & {$[60]$} \\
\hline 3 & PSSA-PMA & PVA-SSA & - & & $\sim 16-50$ & $0.8-54.9$ & $20-50{ }^{\circ} \mathrm{C}$ & $9.6-41.0$ & {$[66,67]$} \\
\hline 4 & $\mathrm{sD}$ & PVA-GA & - & & $10-30$ & $\sim 2-14$ & $25^{\circ} \mathrm{C}, 100 \% \mathrm{RH}$ & $\sim 10-20,000$ & {$[65]$} \\
\hline 5 & PNVP & PVA-SSA & - & & $\sim 37-52$ & $1.4-10$ & RT & $2.4-10$ & [81] \\
\hline \multirow{4}{*}{6} & \multirow{4}{*}{ PAMPS } & \multirow{4}{*}{ PVA-TA } & - & & $\sim 33-71$ & $\sim 40-120$ & \multirow{4}{*}{$25^{\circ} \mathrm{C}$} & \multirow{4}{*}{-} & \multirow{4}{*}[61]{} \\
\hline & & & BA & \multirow{3}{*}{$2-20$} & & $57-120$ & & & \\
\hline & & & HA & & $50-60$ & $78-110$ & & & \\
\hline & & & $\mathrm{OA}$ & & & $83-120$ & & & \\
\hline 7 & PAMPS & PVA-GA & $\mathrm{OA}$ & $10-40$ & $\sim 67$ & $92-118$ & $25^{\circ} \mathrm{C}$ & $\sim 125-180$ & [86] \\
\hline 8 & PAMPS & PVA-GA & PEG & $11-50$ & $\sim 14-45$ & $10-85$ & $25^{\circ} \mathrm{C}$ & $41.8\left(\mathrm{~cm}^{2} \cdot \mathrm{min}^{-1} \cdot \mathrm{cm} \cdot \mathrm{Hg}^{-1}\right)$ & {$[64]$} \\
\hline \multirow{4}{*}{9} & \multirow{4}{*}{ PAMPS } & \multirow{4}{*}{ PVA-GA } & PEGDCE & 20 & 40 & 99 & \multirow{4}{*}{$25^{\circ} \mathrm{C}$} & 101 & \multirow{4}{*}[87]{} \\
\hline & & & PEG & 20 & 40 & 109 & & 117 & \\
\hline & & & PEGME & $\sim 17$ & $\sim 42$ & 113 & & 102 & \\
\hline & & & PEGDE & $\sim 13$ & $\sim 43$ & 99 & & 96 & \\
\hline 10 & PAMPS & PVA-GA & PEGBCME & $\sim 8-27$ & $\sim 25-45$ & 95 & $25^{\circ} \mathrm{C}$ & $40-150$ & [49] \\
\hline 11 & PAMPS & PVA-GA & PNVP & $\sim 6-43$ & $\sim 14-57$ & $10-130$ & $25^{\circ} \mathrm{C}$ & $15-120$ & [63] \\
\hline 12 & PTFE & PVSA-PAA & \multicolumn{2}{|l|}{-} & $\sim 23-56$ & $\sim 8-35$ & $25^{\circ} \mathrm{C}$ & $\sim 20-75\left(\mathrm{Kg} \cdot \mu \mathrm{m} \cdot \mathrm{m}^{-2} \cdot \mathrm{h}^{-1}\right)$ & {$[137]$} \\
\hline 13 & PTFE & PSSA-DVB & \multicolumn{2}{|l|}{-} & - & $80-110$ & $25^{\circ} \mathrm{C}$ & $13-67(5 \mathrm{M} \mathrm{MeOH})$ & [138] \\
\hline 14 & PVDF & PSSA-DVB & \multicolumn{2}{|l|}{-} & $10-35$ & $55-88$ & $23^{\circ} \mathrm{C}$ & - & {$[136]$} \\
\hline 15 & PVC & PSSA-DVB & \multicolumn{2}{|l|}{-} & $\sim 33-40$ & 45-107 & - & - & [139] \\
\hline 16 & $\begin{array}{l}\text { PVDF } \\
\text { PVA }\end{array}$ & PAMPS-BAA & - & & $\begin{array}{l}64-79 \\
83-85\end{array}$ & $\begin{array}{c}0.02-500 \\
20-1500\end{array}$ & $\begin{array}{l}20-90{ }^{\circ} \mathrm{C} \\
50-70{ }^{\circ} \mathrm{C}\end{array}$ & - & {$[88]$} \\
\hline 17 & TCPB & $\begin{array}{l}\text { PAMPS-PHEMA- } \\
\text { PEGDMA }\end{array}$ & - & & $13-26$ & $\sim 10^{-8}-30$ & $70^{\circ} \mathrm{C}$ & $1-10$ & [89] \\
\hline 18 & Nafion $^{\circledR}$ & PAMPS-EMA-HPDA & - & & $30-60$ & $\sim 7.5-18.5$ & RT & $6.6-112$ & {$[140]$} \\
\hline 19 & SPI & PEGDA & - & & $40-80$ & $21-154$ & $30-90{ }^{\circ} \mathrm{C}$ & - & {$[52]$} \\
\hline 20 & $\begin{array}{l}\text { SPI (contain } \\
\text { decyl chains) }\end{array}$ & PEGDA & - & & $50-90$ & 53-194 & $30-90{ }^{\circ} \mathrm{C}$ & - & {$[53]$} \\
\hline 21 & PNVP & CS-GA & - & & - & $\sim 20-110$ & $30-120^{\circ} \mathrm{C}$ & $7.3(50 \mathrm{wt} \% \mathrm{MeOH})$ & [79] \\
\hline 22 & Nafion ${ }^{\circledR}$ & PNVP & - & & - & $69-111$ & $25^{\circ} \mathrm{C}$ & $126-145$ & {$[145]$} \\
\hline
\end{tabular}


Semi-IPNs combining linear PSSA and PVA-GA polymer networks, showing high proton conductivities and high water retention capabilities for PEM applications in fuel cells, have also been prepared [60,68]. The maximum proton conductivity was observed for a PVA/PSSA semi-IPN membrane with about $35 \mathrm{wt} \%$ PSSA (PVA/PSSA $35 \mathrm{wt} \%$ ) at all humidity values $(0-100 \% \mathrm{RH})$. The PVA/PSSA $35 \mathrm{wt} \%$ membrane showed adequate proton conductivity-the value being about two orders of magnitude higher than the conductivity values of a pristine PVA membrane and similar to that of Nafion ${ }^{\circledR}$ 1135. These results confirmed that the addition of the PVA-GA polymer network in the semi-IPN membranes can effective improve the membrane's water retention capability and enhance its proton conductivity at low RH. Similar results were obtained by the same authors [68] and showed the PVA/PSSA semi-IPN membranes with $25 \mathrm{wt} \%$ of PSSA having a maximum proton conductivity of $3.3 \times 10^{-2} \mathrm{~S} \cdot \mathrm{cm}^{-1}$ at $100{ }^{\circ} \mathrm{C}$ and a low methanol crossover compared to Nafion ${ }^{\circledR} 117$. Considering the cost-effectiveness of the membranes-the cost of the PVA/PSSA semi-IPN membranes is about 50 times lower than that of Nafion ${ }^{\circledR}$ membranes; thus, they may be considered as potentially cost-effective substitutions for Nafion ${ }^{\circledR}$ membranes. Power density values $>200 \mathrm{~mW} \cdot \mathrm{cm}^{-2}$ and $90 \mathrm{~mW} \cdot \mathrm{cm}^{-2}$ were obtained for electrode assemblies consisting of the optimum membrane at $75{ }^{\circ} \mathrm{C}$ with $\mathrm{H}_{2}$ and $\mathrm{O}_{2}$ and $70{ }^{\circ} \mathrm{C}$ with aqueous $\mathrm{MeOH}$ and $\mathrm{O}_{2}$ (all at atmospheric pressure), respectively.

PVA/PSSA-PMA semi-IPN membranes incorporating PVA crosslinked synthesized by an esterification reaction with SSA have used as PEMs for DMFC [66,67]. Crosslinkers containing sulfonic acid groups (SSA) not only reinforce the network but also provide extra proton conditioning paths. The proton conductivities and methanol permeabilities of PVA/PSSA-PMA semi-IPN membranes have been found to be strongly dependent on the PSSA-PMA content. Increasing the PSSA-PMA content (20-80\% determined by the weight of PVA) in PVA/PSSA-PMA semi-IPN membranes significantly increased the proton conductivity of the resulting membranes (from $6.63 \times 10^{-3}$ to $4.10 \times 10^{-2} \mathrm{~S} \cdot \mathrm{cm}^{-1}$ ) due to the increase of sulfonic acid and carboxylic groups in the membrane. However, high amounts of PSSA-PMA also led to an increase in the water uptake (from 29.4 to $62.9 \%$ ) and resulted in an increase in the membrane's methanol permeability (from $9.56 \times 10^{-8}$ to $4.1 \times 10^{-7} \mathrm{~cm}^{2} \cdot \mathrm{s}^{-1}$ ). The PVA/PSSA-PMA semi-IPN membrane with $80 \%$ PSSA-PMA exhibited high selectivity (proton conductivity/methanol permeability) determined as $6.32 \times 10^{4} \mathrm{~S} \cdot \mathrm{cm}^{-3} \mathrm{~s}$ a value eight times higher than that of Nafion ${ }^{\circledR} 115\left(0.78 \times 10^{4} \mathrm{~S} \cdot \mathrm{cm}^{-3} \cdot \mathrm{s}\right)$. The effect of the molecular weight of PVA on the membrane's properties has also been investigated, it was shown that the water uptake (from 62.9 to $50.3 \%$ ) and methanol permeability (from $4.10 \times 10^{-7}$ to $3.19 \times 10^{-7} \mathrm{~cm}^{2} \cdot \mathrm{s}^{-1}$ ) both decreased an increase in the molecular weight (from 89,000 to $195,000 \mathrm{~g} \cdot \mathrm{mol}^{-1}$ ). However, there was no significant effect related to molecular weight on the membrane's proton conductivity. A power density value $>100 \mathrm{~mW} \cdot \mathrm{cm}^{-2}$ was obtained for a PVA/PSSA-PMA $80 \%$ membrane electrode assembly at $80{ }^{\circ} \mathrm{C}$ with aqueous $\mathrm{MeOH}$ and $\mathrm{O}_{2}$ feeding.

Other types of linear polymers, such as sulfonated dextran (sD) [65] and poly (vinyl pyrrolidone) (PNVP) [81], have also been successfully combined with PVA-based polymer networks to form semi-IPN membranes. Won et al. [65] have selected a stiff sD as linear acid polymer to combine with PVA-GA polymer network to form a semi-IPN membrane with the regular ionic sites along the stiff dextran chain providing continuous a route for ionic transport, an additional advantage being that the dextran polymer matrix has good computability with PVA. The proton conductivity of PVA/sD semi-IPN membranes increased for sD contents up to $30 \mathrm{wt} \%$, and then decreased with more $\mathrm{sD}$ 
loading (>30 wt\%) due to inhomogeneity of the membranes preventing proton transport through the membrane. However, increasing the content of $\mathrm{sD}$ also increased the methanol permeability. The PVA/sD semi-IPN membrane with $25 \mathrm{wt} \% \mathrm{sD}$ showed an maximum selectivity $\left(3 \times 10^{4} \mathrm{~S} \cdot \mathrm{cm}^{-3} \cdot \mathrm{s}\right)$, which is in the same order of magnitude as Nafion ${ }^{\circledR} 117\left(5 \times 10^{4} \mathrm{~S} \cdot \mathrm{cm}^{-3} \cdot \mathrm{s}\right)$. Huang et al. [81] performed a similar study (Table 5; 3) by replacing the PSSA-PMA by poly (vinyl pyrrolidone) (PNVP). Both PSSA-PMA and PNVP are water soluble polymers that absorb water into the membrane; however, PNVP is nonionic - this may be the reason why the water uptake of the PVA/PNVP semi-IN membrane shows non-linear increases with an increase in the ionic exchange capacity (IEC). The proton conductivity of these membranes increases with the PNVP content and reaches a maximum value of $1 \times 10^{-2} \mathrm{~S} \cdot \mathrm{cm}^{-1}$ when the PNVP content reaches $20 \%$ (determined by the weight of PVP) and then decreases with more PNVP loading $(>20 \%)$. The methanol permeability of PVA/PNVP semi-IPN membranes increases (from $2.35 \times 10^{-8}$ to $1.00 \times 10^{-7} \mathrm{~cm}^{2} \cdot \mathrm{s}^{-1}$ ) as the PNVP content increases (from 10 to $60 \%$ ) which correlates well with an increase in the water uptake (from 53.3 to $127.9 \%$ ). The optimum ratio of PNVP content (20\%) in the PVA/PNVP semi-IPN membrane shows very low methanol permeability-i.e., about one and a half orders of magnitude lower than that of Nafion ${ }^{\circledR} 115$.

\subsection{Modified Semi-IPN Membranes with Third Components}

As mentioned above, in order to overcome the drawback of stiff and brittle PVA/PAMPS semi-IPN membranes, the introduction of a third 'partner' is a very effective method of modifying the membrane's mechanical properties, stability, swelling level, proton conductivity and permeability. Third components have been introduced into PVA/PAMPS based semi-IPN membranes by grafting or blending as described below (Figure 11). Qiao et al. have introduced various alkyl aldehydes into PVA/PAMPS semi-IPN membranes as third partners on the conceptual basis of binary chemical crosslinking. Terephthalaldehyde (TA) was used as a crosslinker to form a PVA-TA network, while alkyl aldehydes with different spacer lengths, e.g., n-butylaldehyde (BA), n-hexylaldehyde (HA) and n-octylaldehyde (OA), were used as auxiliary agents to form side chains on the PVA-TA polymer network. The water uptake of the resulting membranes significantly increased with an increase in the content of PAMPS and auxiliary crosslinkers, but slightly decreased with increasing crosslinker spacer lengths. Although the water uptake of the PVA/PAMPS semi-IPN membranes significantly increased with an increase in the PAMPS content there was no formal linear increase in proton conductivity due to an excess of water induced swelling caused a dilution of charge carriers. The resulting membranes with longer hydrophobic side chains (OA) displayed higher proton conductivities compared to shorter systems (BA and HA) due to the formation of better microphase separation of structures in the membrane. The highest proton conductivity $\left(1.2 \times 10^{-1} \mathrm{~S} \cdot \mathrm{cm}^{-1}\right)$ was obtained for PVA/PAMPS 1/1.5 (1:1.5 by mass) with $5 \mathrm{wt} \%$ of $\mathrm{OA}$ as an auxiliary crosslinker which is slightly higher than that of Nafion ${ }^{\circledR} 117\left(9.1 \times 10^{-2} \mathrm{~S} \cdot \mathrm{cm}^{-1}\right)$. In addition, the membranes with 5 and $10 \mathrm{wt} \% \mathrm{OA}$ as auxiliary crosslinker showed a much better hydrolytic stability without any change in appearance, flexibility, or toughness even after being boiled in $100{ }^{\circ} \mathrm{C}$ water for $24 \mathrm{~h}$. The mechanical properties (tensile strength, young's modulus and elongation) and methanol permabilities of these membranes have been further examined by the same authors' (86). It was shown that a higher mechanical strength (tensile strength: from 1.3 to $2.2 \mathrm{~kg} \cdot \mathrm{mm}^{-2}$ ) has been achieved with an increase in the OA content (from 10 to $40 \%$ ). 
However, the OA content hardly affects the methanol permeability of the semi-IPN (Table 5; 7), thus it still remains lower than that of Nafion ${ }^{\circledR} 117\left(2.11 \times 10^{-6} \mathrm{~cm}^{2} \cdot \mathrm{s}^{-1}\right)$.

Figure 11. Scheme for illustrating the preparation of PVA/PAMPS based semi-IPN membranes.

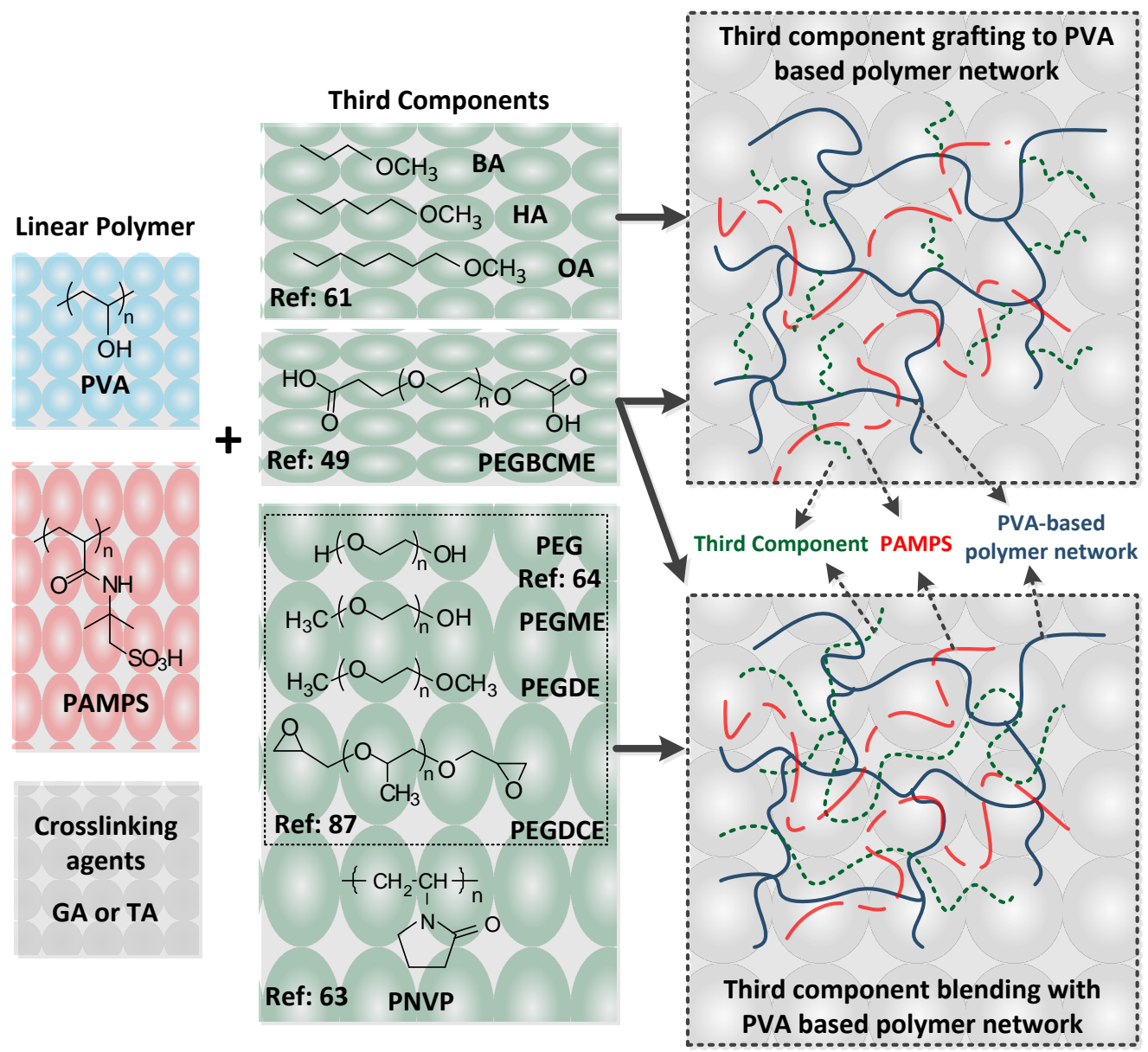

Linear polyethylene glycol (PEG) has also been incorporated into PVA/PAMPS semi-IPN membranes as a plasticizing agent (not grafted to the PVA polymer network) in order to improve the robustness and flexibility of the membranes (Table 5; 8). There is an optimal ratio of PMAPS and PEG in the semi-IPN, with more than $40 \mathrm{wt} \%$ PAMPS the membranes become fragile although high proton conductivity can still be achieved $\left(8.3 \times 10^{-2} \mathrm{~S} \cdot \mathrm{cm}^{-1}\right)$, which is comparable to that of Nafion ${ }^{\circledR} 117$ $\left(9.1 \times 10^{-2} \mathrm{~S} \cdot \mathrm{cm}^{-1}\right)$. For optimal mechanical characteristics, the semi-IPN composition should comprise 5-25 wt $\%$ PEG and less than $40 \mathrm{wt} \%$ PAMPS. The optimum membrane exhibits low methanol permeability (one-fifth) compared to that of Nafion ${ }^{\circledR} 117$. Other PEG derivatives, poly (ethylene glycol) methyl ether (PEGME), poly (ethylene glycol) dimethyl ether (PEGDE), and poly (ethylene glycol) diglycidyl ether (PEGDCE), have also been successfully incorporated into PVA/PAMPS based semi-IPN membranes as third components (Table 5; 9) [87]. These PVA/PAMPS based membranes all showed high proton conductivity $\left(9.9-11.3 \times 10^{-2} \mathrm{~S} \cdot \mathrm{cm}^{-1}\right)$ comparable to Nafion ${ }^{\circledR} 117\left(0.1 \times 10^{-1} \mathrm{~S} \cdot \mathrm{cm}^{-1}\right)$ and a low methanol permeability $\left(0.96-1.17 \times 10^{-6} \mathrm{~cm}^{2} \cdot \mathrm{s}^{-1}\right)$, i.e., only half that of Nafion ${ }^{\circledR} 117\left(2.13 \times 10^{-6} \mathrm{~cm}^{2} \cdot \mathrm{s}^{-1}\right)$. In addition, these membranes exhibited excellent hydrolytic and oxidative stabilities. In the hydrolytic test, PVA/PAMPS/PEGME 1/1/0.4 (1:1:0.4 by mass) semi-IPN membranes retained high proton conductivities $\left(\sim 0.1 \times 10^{-1} \mathrm{~S} \cdot \mathrm{cm}^{-1}\right)$ after soaking in 
$0.1 \mathrm{M} \mathrm{H}_{2} \mathrm{SO}_{4}$ at $60{ }^{\circ} \mathrm{C}$ for more than 2,000 h. In the oxidative stability test of PVA/PAMPS/PEGDEC $1 / 1 / 0.5$ (1:1:0.5 by mass) semi-IPN membrane it was observed that about $70-80 \mathrm{wt} \%$ of the original mass was retained after $30 \mathrm{~h}$ of Fenton reagent treatment $\left(\mathrm{H}_{2} \mathrm{O}_{2} 3 \%\right.$ and $\left.\mathrm{FeSO}_{4} 2 \mathrm{ppm}\right)$ at $60{ }^{\circ} \mathrm{C}$. The same authors further have fabricated PVA/PAMPS semi-IPN membranes by incorporating poly (ethylene glycol) bis (carboxymethyl) ether (PEGBCME) as a third component [49] (Table 5; 10). When using this third component, which is different to other PEG derivatives (not grafted to the PVA polymer network); this third component may be grafted onto the PVA network or crosslinked PVA chains via esterification between the $\mathrm{OH}$ groups of PVA and the carboxylic acid groups of PEGBCME. The results showed a higher proton conductivity than was the cases for other PEG derivatives due to additional proton contributions from double carboxylic acid end groups in PEGBCME the value being around $9.5 \times 10^{-1} \mathrm{~S} \cdot \mathrm{cm}^{-1}$ for an optimum sample (composition PVA/PAMPS/PEGBCME = 1:0.75:0.4 in mass). Moreover, this sample showed a low methanol permeability that was nearly one-third that of Nafion ${ }^{\circledR} 117$ with an even higher water uptake than Nafion ${ }^{\circledR} 117$ (three-fold that of Nafion ${ }^{\circledR} 117$ ). Although high proton conductivity and low permeability were obtained in the PVA/PAMPS/PEGBCME membranes they showed a relatively lower cell performance in real DMFCs as compare with Nafion ${ }^{\circledR}$ 117. Poor adhesion between the catalyst layer and the semi-IPN membrane is reason for the low power density values.

Linear PNVP has also been selected as a third component for improving of the mechanical properties and the oxidative stability of PVA/PAMPS semi-IPN membranes [63]. The proton conductivity of these membranes (from about $1 \times 10^{-2}$ to $1.2 \times 10^{-1} \mathrm{~S} \cdot \mathrm{cm}^{-1}$ ) increased with the content of PAMPS (from 14.3 to $57.1 \mathrm{wt} \%$ ) due to the higher concentration of sulfonic acid. The proton conductivity increased with the content of PNVP and reached a maximum of $8.8 \times 10^{-2} \mathrm{~S} \cdot \mathrm{cm}^{-1}$ as the PNVP content increased from 5.9 to $20 \mathrm{wt} \%$, then decreased with the further introduction of PNVP. The proton conductivity in the membrane did not increase linearly with the water uptake due to dilution of charge carries from the increasing hydrophilic effect of PNVP like the cases of PVA-SSA/PNVP system [63]. The methanol permeability of these membranes (from 1.5 to $12 \times 10^{-7} \mathrm{~cm}^{2} \cdot \mathrm{s}^{-1}$ ) strongly depends on the water uptake (from 0.4 to $1.3 \mathrm{~g} \cdot \mathrm{g}^{-1}$ dry polymer) and shows almost linear increases with increasing contents of PAMPS (from about 14 to $50 \mathrm{wt} \%$ ) and PNVP (from about 6 to 33 wt $\%$ ) in the membrane. Although the PVA/PAMPS membranes showed a much higher water uptake than Nafion ${ }^{\circledR} 117$, the methanol permeability was much lower than Nafion ${ }^{\circledR} 117$ which indicates that PNVP effectively inhibits methanol permeation through the membranes. In addition, PNVP was found to play a crucial role in improving oxidative durability and water stability. It was show that the membranes displayed a relatively high oxidative durability without weight loss (e.g., $100 \mathrm{~h}$ in $3 \% \mathrm{H}_{2} \mathrm{O}_{2}$ solution and $20 \mathrm{~h}$ in $10 \% \mathrm{H}_{2} \mathrm{O}_{2}$ solution at $60{ }^{\circ} \mathrm{C}$ ) and excellent stability towards water for a long time without any decrease in proton conductivity (e.g., for $240 \mathrm{~h}, 25^{\circ} \mathrm{C}$ ).

\subsection{Sulfonated Polymer Network Based Semi-IPN Membranes}

In order to obtain adequate mechanical and swelling properties, sulfonated polymer based networks, such as PSSA, PAMPS and poly (acrylic acid) (PAA), are usually combined with linear polymers using monomer-impregnated polymerization or by in situ polymerization approaches to form semi-IPN membranes. The impregnation polymerization approach most commonly was used to prepare 
crosslinked PSSA- or PAA-based semi-IPN membranes. In the impregnation method, both hydrophobic porous and dense polymer films have been used as the substrate matrix to prevent excess swelling of the filling polymer and improve the dimensional stability of membrane, in the transition from the dry to the swollen state. Figure 12 represents the concept of porous and dense polymer films containing filling polyelectrolyte materials. For porous composite membranes, porous PTFE, poly (ethylene) (PE) or polycarbonates (PC) have been widely used as substrates for pore filling of the electrolyte membrane and have successfully increased its mechanical strength and chemical stability while at the same time reducing the preparation cost of original polymer electrolyte membranes [142-144].

Figure 12. The concept of a pore-filling electrolyte membrane.
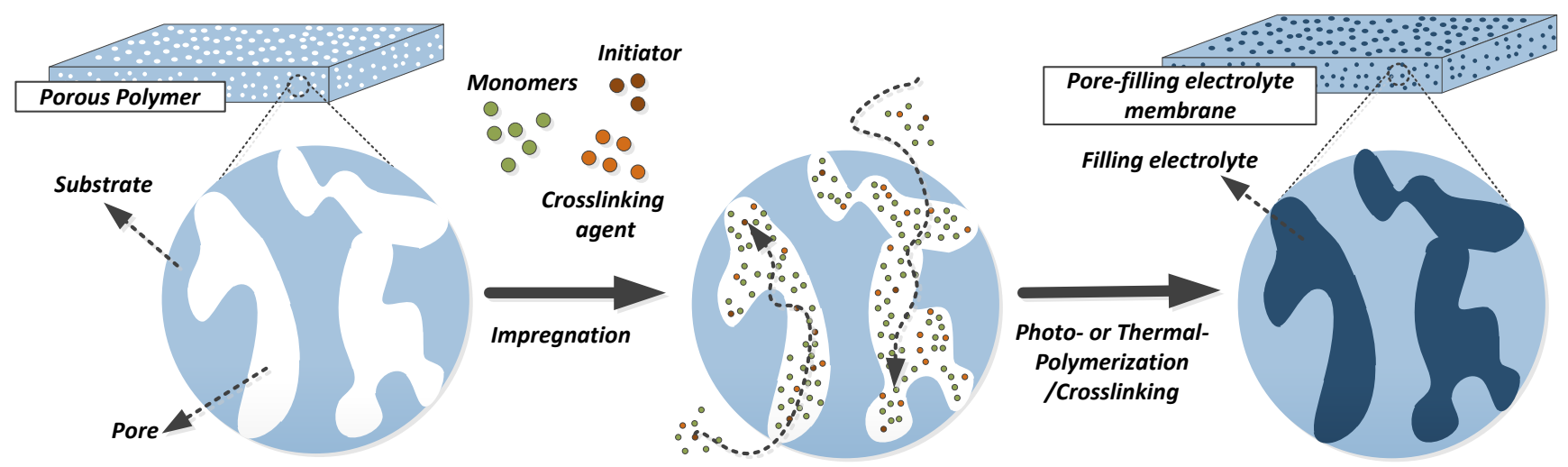

Yamaguchi et al. [137] have prepared poly (vinylsulfonic acid-co-acrylic acid) (PVSA-PAA) pore filling composite membranes using the thermal polymerization of acrylic acid-sodium vinylsulfonatedivinyl benzene crosslinker (DVB) (AA-VSA-DVB) catalyzed by initiator mixtures in porous PTFE membranes for used as PEMs in DMFCs (Table 5; 12). The results show that the pore filling structure is effective in suppressing membrane water swelling and results in low methanol permeability. In addition, the PVSA-PAA/PTFE pore-filling membranes are stable at high temperatures $\left(130{ }^{\circ} \mathrm{C}\right)$ due to high durability of the PTFE substrate. Although the water swelling level and methanol permeability can be controlled by changing the ratio of the pore filling, the proton conductivity of these membranes $\left(>3.5 \times 10^{-2} \mathrm{~S} \cdot \mathrm{cm}^{-1}\right)$ is general lower than that of Nafion ${ }^{\circledR} 117\left(8 \times 10^{-2} \mathrm{~S} \cdot \mathrm{cm}^{-1}\right)$. Other pore filling composite membranes (PSSA/PTFE) have also been prepared using similar procedures by replacing AA-VSA-DVB with styrene-divinyl benzene (ST-DVB) mixtures in porous PTFE membranes, with further sulfonation by chlorosulfonic acid [138] (Table 5; 13). The degree of sulfonation and the water content of these composite membranes were successfully controlled by changing the ST/DVB ratio in the PTFE substrate. Moreover, on decreasing the ST/DVB ratio, the methanol permeability decreased from $6.6 \times 10^{-7}$ to $1.3 \times 10^{-7} \mathrm{~cm}^{2} \cdot \mathrm{s}^{-1}$, and the proton conductivity decreased from $11.0 \times 10^{-2}$ to $8.2 \times 10^{-2} \mathrm{~S} \cdot \mathrm{cm}^{-1}$ due to the water content and the sulfonic acid content of the sulfonated composite membranes decreasing with increasing degrees of crosslinking. These proton conductivity and methanol permeability values are comparable, or better than, the values achieved with Nafion ${ }^{\circledR} 117$ (proton conductivity $=8.0 \times 10^{-2} \mathrm{~S} \cdot \mathrm{cm}^{-1}$, and methanol permeability $=1.0 \times 10^{-7} \mathrm{~cm}^{2} \cdot \mathrm{s}^{-1}$ ). Moreover, the optimum composite membrane with a ST/DVB ratio of $85 / 15$ ( $85: 15$ by mass) showed the highest 
selectivity (proton conductivity/methanol permeability $=5.89 \times 10^{5} \mathrm{~S} \cdot \mathrm{cm}^{-3} \cdot \mathrm{s}^{-1}$ ) which is about seven times higher than that of Nafion ${ }^{\circledR} 117\left(0.81 \times 10^{5} \mathrm{~S} \cdot \mathrm{cm}^{-3} \cdot \mathrm{s}^{-1}\right)$.

The impregnation-type approach has also been used for the crosslinking of PSSA in the presence of dense hydrophobic PVDF films (Table 5; 14) [136]. In a similar procedure to the preparation of pore filling composite membranes, impregnated PVDF films containing a mixture of ST-DVB introduced through thermal polymerization and subsequent sulfonation procedure were used to form PSSA/PVDF semi-IPN membranes. The resulting membranes were flexible and showed lower crossover rates in operating fuel cells compared to $\mathrm{Nafion}^{\circledR} 117$ systems. Moreover, high proton conductivity was observed with a number of PSSA/PVDF membranes, ranging from $5.5 \times 10^{-1}$ to $8.8 \times 10^{-1} \mathrm{~S} \cdot \mathrm{cm}^{-1}$, this being comparable to values reported for Nafion ${ }^{\circledR} 117$ under similar conditions $\left(0.7-0.8 \times 10^{-1} \mathrm{~S} \cdot \mathrm{cm}^{-1}\right)$. Similar results have been obtained for PSSA/poly (vinyl chloride) (PVC) semi-IPN membranes made by replacing the PVDF with a PVC dense polymer substrate via thermal polymerization and subsequent sulfonation [139] (Table 5; 15). The degree of sulfonation, water uptake, oxidative stability and proton conductivity of the resulting membranes was strongly dependent on the DVB content in the membranes. With the DVB content increasing from 1 to $20 \%$, the water uptake decreased from 85 to $36 \%$ and the degree of sulfonation decreased from 99 to $87 \%$. The proton conductivity with 1 and $5 \%$ DVB reached the maximum conductivity $\left(>0.1 \mathrm{~S} \cdot \mathrm{cm}^{-1}\right)$; however, the conductivity decreased as the DVB content increased to $20 \%$ (from $1.04 \times 10^{-1}$ to $0.45 \times 10^{-1} \mathrm{~S} \cdot \mathrm{cm}^{-1}$ ). Moreover, it was found that DVB also improved the oxidative stability of the more compact structure by restricting the diffusion of $\mathrm{OH}$. radical into the membrane, thereby the reducing the possibility of radical attack on the polymer chain. The best oxidative stability was observed with membranes formed with $20 \%$ DVB which were able to withstand exposure to Fenton's solution ( $3 \mathrm{wt} \% \mathrm{H}_{2} \mathrm{O}_{2}$ and $4 \mathrm{ppm} \mathrm{Fe}^{2+}$ ) for 6.5 days. The effect of sulfonation has also been studied: the higher the chlorosulfonic acid concentration, the more side reactions are favored (sulfonyl chloride formation and sulfone bind cross-linking), thereby inducing decreases in the IEC and proton conductivity. However, the formation of sulfone bridges causes the membranes to become more resistant to the hydrogen peroxide solution and thus results in an enhancement in oxidative stability. These results show that a nonionic linear polymer substrate (PVDF or PVC) when combined with a PSSA network results in improved fuel performance and fuel cell efficiencies for DMFCs. The PVC/PSSA semi-IPN membrane showed a high power density (maximum power density $=740 \mathrm{~mW} \cdot \mathrm{cm}^{2}$ ) which is twice than that of Nafion ${ }^{\circledR} 117\left(380 \mathrm{~mW} \cdot \mathrm{cm}^{2}\right)$. In addition, a PSSA-DVB polymer network has also been combined with a Nafion ${ }^{\circledR} 117$ linear polymer using a similar approach and showed a dramatic improvement in power density performance [141]. These results indicate that the formation of semi-IPN membranes offers promise for PEMFC applications.

PAMPS has also commonly been incorporated into semi-IPN membranes as a crosslinked polymer network due to its superior ability to support ion conduction under low water conditions compared with Nafion ${ }^{\circledR}$. Monikowska et al. [88] have been prepared PAMPS/PVDF semi-IPN membranes by photochemical crosslinking of AMPS (2-acrylamido-2-methylpropane sulfonic acid) with $\mathrm{N}, \mathrm{N}^{\prime}$-methylene-bis-acrylamide (BAA) in a colloidal dispersion of PVDF in dimethylformamide (DMF) or dimethylacetamide (DMAc) (Table 5; 16). The resulting membrane containing $20 \mathrm{wt} \%$ of PVDF reached higher conductivity values $\left(\sim 0.5 \mathrm{~S} \cdot \mathrm{cm}^{-1}\right)$ at ambient temperature in comparison with membranes having the least amount of PVDF (15 wt\%; proton conductivity: $\sim 6 \times 10^{-3} \mathrm{~S} \cdot \mathrm{cm}^{-1}$ ) c.f. Nafion ${ }^{\circledR} 117\left(8 \times 10^{-2}-1 \times 10^{-1} \mathrm{~S} \cdot \mathrm{cm}^{-1}\right)$. The conductivity is lower $\left(10^{-2}\right.$ to $\left.10^{-1} \mathrm{~S} \cdot \mathrm{cm}^{-1}\right)$ and the 
mechanical strength is not satisfactory when PVDF is replaced by hydrophilic PVA in the semi-IPN. However, the PAMPS/PVA semi-IPN membrane with $10 \mathrm{wt} \%$ PVA content shows maximum proton conductivity value reaching $1.5 \mathrm{~S} \cdot \mathrm{cm}^{-1}$, and high adhesion to materials. Other crosslinked PAMPS based semi-IPN membranes have been fabricated that consist of a methanol-blocking three component polymer blend (TCPB), i.e., poly (4-vinylphenol-co-methyl methacrylate) (P4-VP-PMMA), poly (butyl methacrylate) (PBMA), and Paraloid ${ }^{\circledR}$ acrylic copolymer resin, together with an embedded proton source comprising a copolymer of AMPS and 2-hydroxyethyl methacrylate (HEMA) crosslinked by poly (ethylene glycol) dimethylacrylate (PEGDMA) [89] (Table 5; 17). After embedded polymerization, an asymmetric structure was obtained in which the conducting network was sandwiched by two outer layers of predominantly hydrophobic TCPB. The proton conductivity of the resulting membrane was strongly dependent on the sulfonic acid content reaching its highest proton conductivity $\left(3 \times 10^{-2} \mathrm{~S} \cdot \mathrm{cm}^{-1}\right)$ with the highest AMPS content $(25.6 \mathrm{wt} \%)$ in the membrane, which is about one-third that of Nafion ${ }^{\circledR} 117$ at $70{ }^{\circ} \mathrm{C}$. Although the proton conductivities are lower than Nafion ${ }^{\circledR} 117$, the methanol permeabilities of the PAMPS/TCPB semi-IPN membranes are in the range $10^{-8}$ to $10^{-7} \mathrm{~cm}^{2} \cdot \mathrm{s}^{-1}$, which is much lower than that of Nafion ${ }^{\circledR} 117\left(\sim 2 \times 10^{-6} \mathrm{~cm}^{2} \cdot \mathrm{s}^{-1}\right)$. Moreover, the mechanical properties of these membranes are superior to those of Nafion ${ }^{\circledR} 117$. The monomer impregnation approach has also been used for the crosslinking of PMAPS in the presence of commercial Nafion ${ }^{\circledR}$ films [140] (Table 5; 18). Impregnating Nafion ${ }^{\circledR}$ films with a mixture of AMPS, ethyl methacrylate (EMA) with 1,6-hexanediol propoxylate diacrylate (HPDA) crosslinker through photo-polymerization/crosslinking. The proton conductivity of the resulting membranes increased with increasing AMPS contents (30 to $60 \mathrm{wt} \%$ ) in the membranes and reached $1.85 \times 10^{-2} \mathrm{~S} \cdot \mathrm{cm}^{-1}$ in the membrane with $60 \mathrm{wt} \%$ AMPS which is comparable to Nafion ${ }^{\circledR} 117$. The methanol permeability of these membranes also showed a linear increase with an increase in the AMPS content from $6.55 \times 10^{-7}$ to $1.12 \times 10^{-6} \mathrm{~cm}^{2} \cdot \mathrm{s}^{-1}$ which are all lower than that of Nafion ${ }^{\circledR} 117\left(2.32 \times 10^{-6} \mathrm{~cm}^{2} \cdot \mathrm{s}^{-1}\right)$. The optimum membrane (with $60 \mathrm{wt} \%$ AMPS) showed that the membrane had lower methanol permeability ( 50\%), maintained a high proton conductivity and increased the maximum power density by $22.2 \%$ in fuel cell test as compared with Nafion ${ }^{\circledR} 117$.

\subsection{Other Semi-IPN Membranes Involve Water Soluble Polymers}

As mention above, linear PEG has been incorporated into crosslinked membranes as a plasticizing agent or crosslinking agent to improve robustness, flexibility and methanol permeation. PEG has also been incorporated into linear sulfonated polyimide (SPI) as a crosslinker in order to improve the hydrolytic stability of SPI. Lee et al. [52] have prepared PEG/SPI semi-IPN membranes according to an in situ synthesis, whereby the free radical crosslinking of poly (ethylene glycol) diacrylate (PEGDA) was thermally initiated (Table 5; 19). As expected, the IEC value linearly decreased (from 1.17 to $0.59 \mathrm{meq}^{-\mathrm{g}^{-1}}$ ) with increased PEG content (20-60 wt\%) in the PEG/SPI semi-IPN membranes due to reduction in the proportion of sulfonic acid group in resulting membranes. The decrease in IEC with increasing PEGDA content resulted in a decrease in water uptake and proton conductivity at temperatures below $70{ }^{\circ} \mathrm{C}$. When the temperature reached $90{ }^{\circ} \mathrm{C}$, the membrane with $40 \mathrm{wt} \%$ PEGDA content showed the highest proton conductivity $\left(1.54 \times 10^{-1} \mathrm{~S} \cdot \mathrm{cm}^{-1}\right)$ which is comparable to Nafion ${ }^{\circledR}$ $117\left(1.87 \times 10^{-1} \mathrm{~S} \cdot \mathrm{cm}^{-1}\right)$. Moreover, water stability improved as the PEGDA content increased owing 
to its flexibility and semi-IPN structures, which enhances the mechanical stability of the SPI in water condition. The same authors have prepared similar PEG/SPI semi-IPN membranes in which the SPI contained flexible decyl chains [53] (Table 5; 20). However, opposite results were observed in which the water uptake increased (from 10.9 to $13.6 \%$ at $30{ }^{\circ} \mathrm{C}$; from 27.3 to $32.9 \%$ at $80{ }^{\circ} \mathrm{C}$ ) with increases of PEGDA content (from 10 to $50 \mathrm{wt} \%$ ) despite decreases in the content of sulfonic acid groups (IEC: from 1.79 to $0.98 \mathrm{meg} \cdot \mathrm{g}^{-1}$ ). The proton conductivity of these membranes also increased (from $1.66 \times 10^{-1}$ to $1.94 \times 10^{-1} \mathrm{~S} \cdot \mathrm{cm}^{-1}$ at $90{ }^{\circ} \mathrm{C}$ ) with an increase in the PEGDA content in all temperature ranges examined $\left(30-90{ }^{\circ} \mathrm{C}\right)$. These results can be attributed to the increase of water uptake that is associated with proton conductivity, thus explaining the high proton conductivity seen with higher contents of PEGDA. These results indicate that the combination of both hydrophilic PEG and sulfonic acid groups confers high proton conductivity upon the semi-IPN membranes compared to Nafion ${ }^{\circledR} 117$.

A semi-IPN membrane combining a CS network and linear PNVP has been synthesized by impregnation followed by crosslinking with GA and further crosslinking with sulfuric acid [79] (Table 5; 21). The CS/PNVP semi-IPN membrane exhibited a high water uptake (52.1\%) in comparison with Nafion ${ }^{\circledR} 117(33.3 \%)$, but a lower methanol uptake was observed $(0.11 \%)$ which is much lower than that of Nafion ${ }^{\circledR} 117(9.32 \%)$. The lower methanol uptake of the semi-IPN membrane resulted in a lower methanol permeability for semi-IPN membrane $\left(7.3 \times 10^{-8} \mathrm{~cm}^{2} \cdot \mathrm{s}^{-1}\right)$ which is three times lower than that of Nafion ${ }^{\circledR} 117\left(2.16 \times 10^{-7} \mathrm{~cm}^{2} \cdot \mathrm{s}^{-1}\right)$. Moreover, the methanol permeability of the semi-IPN membrane decreased (from $1.01 \times 10^{-7}$ to $0.45 \times 10^{-8} \mathrm{~cm}^{2} \cdot \mathrm{s}^{-1}$ ) with an increase in the methanol concentration (from 0.02 to $97.72 \mathrm{wt} \%$ ). Finally, the proton conductivity of the semi-IPN membrane was slightly enhanced from $1.9 \times 10^{-2}$ to $2.4 \times 10^{-2} \mathrm{~S} \cdot \mathrm{cm}^{-1}$; however, this is still much lower than Nafion ${ }^{\circledR} 117\left(8.6 \times 10^{-2} \mathrm{~S} \cdot \mathrm{cm}^{-1}\right)$. Low methanol permeability and cost effectiveness may be compensating factors for the low conductivity of the CS/PNVP semi-IPN membrane. More recently, PNVP has been transformed into network polymer when combined with Nafion ${ }^{\circledR} 117$ film by a monomer impregnation synthesis to form a semi-IPN membrane [145] (Table 5; 22). The water uptake of the PNVP/Nafion ${ }^{\circledR} 117$ membrane slightly decreased (from 36 to $32 \%$ ) with an increase in the PNVP content (1.5 to $2.3 \mathrm{wt} \%$ ) due to the restriction effect of the PNVP network on mobility of the Nafion polymer chains. The restriction effect also contributed to the suppression of methanol permeability and reducing it from $3.08 \times 10^{-6}$ to $1.26 \times 10^{-6} \mathrm{~cm}^{2} \mathrm{~s}^{-1}$. However, the proton conductivity increased and reached a maximum $\left(1.11 \times 10^{-1}\right)$ with a small amount of PNVP $(1.5 \mathrm{wt} \%)$ in the membrane and then decreased with further loading. The optimum sample (PNVP content $=1.5 \mathrm{wt} \%$ ) exhibits $53 \%$ lower methanol permeability but a $38 \%$ higher proton conductivity as compared to Nafion $^{\circledR} 117$.

\subsection{Other IPN Membranes Involve Water Soluble Polymers}

Only a few examples of IPN membranes involving WSP used for fuel cell membrane applications have been reported in the literature. One of the most comprehensive available studies was carried out on IPN membranes synthesized by the combination of in situ polymerization/crosslinking and impregnation reactions [146]. A two polymer network composite formed an IPN composed of a proton conducting PAMPS-PHEMA network [crosslinking by ethylene glycol dimethacrylate (EGDMA)] and a second polymer network, PVA-GA, serving as a methanol barrier. First, the PAMPS-PHEMA gel 
solution was synthesized by in situ polymerization/crosslinking of mixing of AMPS, PHEMA, EGDMA crosslinker and initiator azobisisobutyronitrile (AIBN) and further blending with PVA via cast-evaporation process to form a PVA/PAMPS-PHEMA film. The resulting film was further impregnated into GA solution using an aldol condensation to form the second polymer network in IPN membranes. However, the aldol condensation of GA can simultaneously occur with both the $\mathrm{OH}$ of PVA and the $\mathrm{OH}$ of PAMPS-PHEMA, thus the two networks were covalently bonded to each other. Herein, we ignore the possibility of this situation and summarize this system within the scope of IPN membranes. All of these PVA/PAMPS-PHEMA IPN membranes showed lower selectivity for methanol, the lowest value was obtained in PVA/PAMPS-PHEMA 75-4-21 (75:4:21 by weight) which had a methanol selectivity $\left(\mathrm{MeOH} / \mathrm{H}_{2} \mathrm{O}=0.16\right)$ that was 15 times less than Nafion ${ }^{\circledR} 117$ (2.4). In addition, the methanol permeability, water adsorption and swelling behavior can be controlled by the purity and the extent of the crosslinking of the PVA. Limited PVA-GA crosslinking reduces methanol selectivity, but has no significant effect on conductivity. However, the conductivity of these IPN membranes $\left(\sim 0.5 \times 10^{-3} \mathrm{~S} \cdot \mathrm{cm}^{-1}\right)$ was general lower than Nafion ${ }^{\circledR} 117\left(\sim 2 \times 10^{-2} \mathrm{~S} \cdot \mathrm{cm}^{-1}\right)$, which is more than one order of magnitude less conductivity than Nafion has at room temperature. From this reason, these IPN membranes have been shown to be unstable under fuel cell operating conditions and thus require further improvement.

Recently, a PVA/PAMPS-PHEMA IPN system has also been used as a PEM in combination with silica particles. This was formed using an in situ polymerization approach by sol-gel hydrolysis of tetraethoxysilane (TEOS) in the polymer network [125]. The proton conductivities, swelling and fuel permeability were found to be strongly dependent on the membranes' TEOS and PAMPS-PHEMA contents. The swelling ability was decreased with increased TEOS (from 0 to $43 \mathrm{wt} \%$ ) and resulted in decreased proton conductivity (from $\sim 9 \times 10^{-2}$ to $2 \times 10^{-2}$ ) and fuel permeability (from $\sim 0.5 \times 10^{-6}$ to $\sim 0.1 \times 10^{-6} \mathrm{~cm}^{2} \cdot \mathrm{s}^{-1}$ for methanol or ethanol). Opposite results, to those previously obtained, were observed i.e., proton conductivity $\left(\sim 2.5 \times 10^{-2}\right.$ to $\left.11 \times 10^{-2}\right)$ and fuel permeability (from $\sim 0.15 \times 10^{-6}$ to $\sim 0.6 \times 10^{-6} \mathrm{~cm}^{2} \cdot \mathrm{s}^{-1}$ for methanol or ethanol) increased with an increasing PAMPS-PHEMA weight proportion (from 25 to $57 \mathrm{wt} \%$ ) in the membranes. These IPN hybrid membranes have high proton conductivities at room temperature (from $2 \times 10^{-2}$ to $1.1 \times 10^{-1} \mathrm{~S} \cdot \mathrm{cm}^{-1}$ ), which are the same order of magnitude as that of the Nafion ${ }^{\circledR} 117\left(9 \times 10^{-2} \mathrm{~S} \cdot \mathrm{cm}^{-1}\right)$. In addition, these membranes also exhibited less swelling and low fuel permeability in methanol and ethanol $\left(>0.6 \times 10^{-6} \mathrm{~cm}^{2} \cdot \mathrm{s}^{-1}\right)$, which is lower than that of Nafion ${ }^{\circledR} 117\left(2.12 \times 10^{-6} \mathrm{~cm}^{2} \cdot \mathrm{s}^{-1}\right.$ for ethanol and $1.80 \times 10^{-6} \mathrm{~cm}^{2} \cdot \mathrm{s}^{-1}$ for methanol). The highest proton conductivity/fuel permeability ratio occurred in an optimal IPN membrane PVA/PAMPS-PHEMA/TEOS 1/1/1 (1:1:1 by weight), these were ten- and six times of those of Nafion in ethanol and methanol, respectively. In addition, the optimal membrane also exhibited a high chemical stability, with less than a $5 \mathrm{wt} \%$ loss in $1 \mathrm{M} \mathrm{H}_{2} \mathrm{SO}_{4}$ solution after 1 week and about $10 \mathrm{wt} \%$ in a $3 \mathrm{wt} \% \mathrm{H}_{2} \mathrm{O}_{2}$ solution after 1 day at room temperature.

According to a previous report, semi-IPN membranes have been prepared by a combination of linear polymer substrate and filling polymer electrolyte network to form a pore filling composite membrane. When the linear polymer substrate was replaced by a network polymer substrate, the resulting pore filling membrane was classified as an IPN membrane. Yamaguchi et al. [147] have prepared IPN type pore-filling electrolyte membranes by the thermal polymerization of an acrylamide-tert-butyl sulfonated sodium salt (ATBS-Na), bis-acylamide crosslinker and an initiator 
mixture in a porous crosslinked high density polyethylene substrate (CLPE). The proton conductivity and methanol permeability of CLPE/poly (acrylamide-tert-butylsulfonic acid) PATBS membranes were strongly dependent on the pore-filling ratio. The proton conductivity of the membranes with a high pore-filling ratio was $1.5 \times 10^{-1} \mathrm{~S} \cdot \mathrm{cm}^{-1}$ at $25^{\circ} \mathrm{C}$, which is higher than that of Nafion ${ }^{\circledR} 117$ $\left(8 \times 10^{-2} \mathrm{~S} \cdot \mathrm{cm}^{-1}\right)$ due to high sulfonic acid content of the PATBS filling polymer. However, the high pore-filling ratio also led to an increase in the methanol permeability; however, the value is still less than that of Nafion ${ }^{\circledR} 117$ or Nafion ${ }^{\circledR} 112$ membrane. When operating in an $\mathrm{H}_{2} / \mathrm{O}_{2}$ polymer electrolyte membrane fuel cell (PEMFC), a CLPE/PATBS membrane electrode assembly (MEA) showed a cell voltage of $0.5 \mathrm{~V}$ and a power density of $1.0 \mathrm{~W} \cdot \mathrm{cm}^{-2}$ at a current density of $2 \mathrm{~A} \cdot \mathrm{cm}^{-2}$ [148]. The MEA also showed a relatively high OCV of $\sim 1.0 \mathrm{~V}$, despite its thinness $(\sim 20 \mu \mathrm{m})$, indicating that the CLPE/PATBS membrane suppresses $\mathrm{H}_{2}$ fuel crossover. Moreover, the MEA with this pore-filing membrane also showed high PEMFC performances $\left(\sim 50 \mathrm{~mW} \cdot \mathrm{cm}^{-2}\right.$ at $\left.50{ }^{\circ} \mathrm{C}\right)$ using DMFC even when a high methanol concentration (10 M) was employed [149].

\subsection{Summary of Semi-IPN Membranes Comprising Water Soluble Polymers as Fuel Cell Membranes}

Several WSP have been described in the literature that introduce linear polymer matrices (PSSA, PNVP, PAMPS and PVA) or network polymers (PVA, PSSA, PEG and PNVP) into semi-IPN membranes to optimize the membrane performance. Several semi-IPN membranes based on crosslinked PVA networks combined with linear polyelectrolytes including PSSA-PMA, PAMPS, PNVP and sD have been prepared and used as PEMs in fuel cells. The conductivity versus the methanol permeability of PVA-based semi-IPN membranes is shown in Figure 13. It is apparent that the nature of PVA and the crosslinking density of network strongly affect the methanol permeability and absorption. Thus, the methanol permeabilities of PVA-based semi-IPN membranes are usually lower than that of Nafion ${ }^{\circledR}$, even for membranes with high water uptake. However, the incorporation of PAMPS as a linear polyelectrolyte in PVA-based semi-IPN membranes leads to a lower reduction in methanol permeability in comparison with other introduced linear polyelectrolytes. But the proton conductivities of PVA/PAMPS semi-IPN membranes are better than other PVA-based semi-IPN membranes with some samples even showing more conductivity than Nafion ${ }^{\circledR}$. In addition, the incorporation of PEG as third partner into the membranes effective improves its swelling characteristics, mechanical properties and stability. When a crosslinked PVA network combines with linear PNVP it shows the most significant reduction in methanol permeability of all PAV-based semi-IPN membranes while also exhibiting adequate proton conductivity together with excellent oxidative durability and water stability.

Sulfonated polymer based networks exhibit significant improvements in membrane stability while effectively reducing methanol permeability. These membranes maintain a high proton conductivity and have a low methanol permeability which effective improve their performance. The best reported stability was found in a PSSA/poly (vinyl chloride) (PVC) semi-IPN membrane, which was able to withstand exposure to Fenton's solution for 6.5 days. Other semi-IPN membranes, involving PEG or PNVP, have also been used in WSP and polymer electrolyte combinations and found to impart high proton conductivities and lower methanol permeabilities to the semi-IPN membranes. Although at the time of writing the data collected with respect to IPN and semi-IPN systems appears to hold promise it 
should be treated as preliminary as the body of literature dedicated to this group of polymers is extremely limited.

Figure 13. Conductivity versus the methanol permeability of PVA-based semi-IPN membranes. Only values given in the text of articles (rather than values that can merely be read from a figure) are plotted. Various Nafion ${ }^{\circledR}$ values are plotted for comparison.

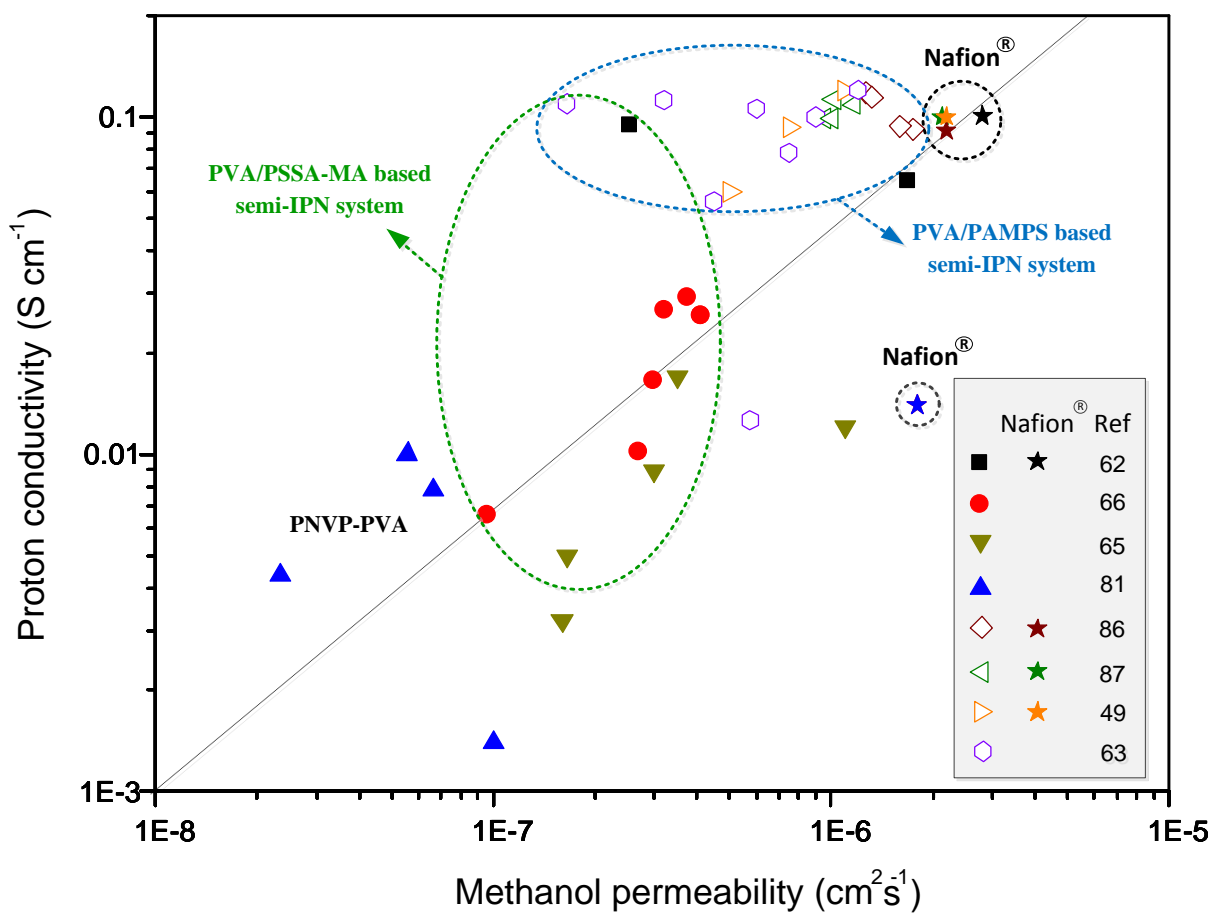

\section{Conclusions}

The benefits of the water soluble polymers (WSPs) for fuel cell membranes have been highlighted. The aim of this review was to introduce progress in polymer synthesis, architecture, characterization, strategy, and performance as PEMs, mostly focusing on proton conductivity and methanol permeability. Promising WSPs for application in PEMs have been categorized into the following three groups: (1) blend polymers which contain WSPs; (2) network polymers which are composed of WSPs as a linear polymer matrix or that function as a crosslinker; (3) semi-IPNs or IPNs based on WSPs. All methods aim at the fabrication of flexible and tough membranes with high chemical and hydrolytic stabilities while maintaining high proton conduction even at low $\mathrm{RH}$ and high operating temperatures. The most important is effective control of swelling and limiting fuel permeation. By optimally combining WSPs in the membranes based on these strategies, extraordinarily useful WSP based membranes possessing well-balanced properties for fuel cell applications have been realized. To build on gains already made a more thorough understanding of polymer structure design and control should be pursued in the future. 


\section{References}

1. Winter, M.; Brodd, R.J. What are batteries, fuel cells, and supercapacitors? Chem. Rev. 2004, 104, 4245-4270.

2. Dai, H.; Guan, R.; Li, C.; Liu, J. Development and characterization of sulfonated poly(ether sulfone) for proton exchange membrane materials. Solid State Ionics 2007, 178, 339-345.

3. Matsumoto, K.; Higashihara, T.; Ueda, M. Locally sulfonated poly(ether sulfone)s with highly sulfonated units as proton exchange membrane. J. Polym. Sci. Part A Polym. Chem. 2009, 47, 3444-3453.

4. Miyatake, K.; Chikashige, Y.; Higuchi, E.; Watanabe, M. Tuned polymer electrolyte membranes based on aromatic polyethers for fuel cell applications. J. Am. Chem. Soc. 2007, 129, 3879-3887.

5. Zhang, Y.; Wan, Y.; Zhao, C.; Shao, K.; Zhang, G.; Li, H.; Lin, H.; Na, H. Novel side-chain-type sulfonated poly(arylene ether ketone) with pendant sulfoalkyl groups for direct methanol fuel cells. Polymer 2009, 50, 4471-4478.

6. Bae, B.; Hoshi, T.; Miyatake, K.; Watanabe, M. Sulfonated block poly(arylene ether sulfone) membranes for fuel cell applications via oligomeric sulfonation. Macromolecules 2011, 44, 3884-3892.

7. Ghassemi, H.; McGrath, J.E. Synthesis and properties of new sulfonated poly(p-phenylene) derivatives for proton exchange membranes. I. Polymer 2004, 45, 5847-5854.

8. Hickner, M.A.; Fujimoto, C.H.; Cornelius, C.J. Transport in sulfonated poly(phenylene)s: Proton conductivity, permeability, and the state of water. Polymer 2006, 47, 4238-4244.

9. Zhong, S.; Cui, X.; Cai, H.; Fu, T.; Zhao, C.; Na, H. Crosslinked sulfonated poly(ether ether ketone) proton exchange membranes for direct methanol fuel cell applications. J. Power Sources 2007, 164, 65-72.

10. Liu, B.; Robertson, G.P.; Kim, D.-S.; Guiver, M.D.; Hu, W.; Jiang, Z. Aromatic poly(ether ketone)s with pendant sulfonic acid phenyl groups prepared by a mild sulfonation method for proton exchange membranes. Macromolecules 2007, 40, 1934-1944.

11. Choi, J.; Patel, R.; Han, J.; Min, B. Proton conducting composite membranes comprising sulfonated Poly(1,4-phenylene sulfide) and zeolite for fuel cell. Ionics 2010, 16, 403-408.

12. Asano, N.; Aoki, M.; Suzuki, S.; Miyatake, K.; Uchida, H.; Watanabe, M. Aliphatic/aromatic polyimide ionomers as a proton conductive membrane for fuel cell applications. J. Am. Chem. Soc. 2006, 128, 1762-1769.

13. Sun, F.; Wang, T.; Yang, S.; Fan, L. Synthesis and characterization of sulfonated polyimides bearing sulfonated aromatic pendant group for DMFC applications. Polymer 2010, 51, 3887-3898.

14. Li, Q.F.; Rudbeck, H.C.; Chromik, A.; Jensen, J.O.; Pan, C.; Steenberg, T.; Calverley, M.; Bjerrum, N.J.; Kerres, J. Properties, degradation and high temperature fuel cell test of different types of PBI and PBI blend membranes. J. Membr. Sci. 2010, 347, 260-270.

15. Jouanneau, J.; Mercier, R.; Gonon, L.; Gebel, G. Synthesis of sulfonated polybenzimidazoles from functionalized monomers: Preparation of Ionic conducting membranes. Macromolecules 2007, 40, 983-990. 
16. Mader, J.A.; Benicewicz, B.C. Sulfonated polybenzimidazoles for high temperature PEM fuel cells. Macromolecules 2010, 43, 6706-6715.

17. Li, J.; Lee, C.H.; Park, H.B.; Lee, Y.M. Novel sulfonated poly(arylene ether ketone) containing benzoxazole membranes for proton exchange membrane fuel cell. Macromol. Res. 2006, 14, $438-442$.

18. Tan, N.; Xiao, G.Y.; Yan, D.Y. Synthesis and hydrolytic stability of soluble sulfonated polybenzoxazoles derived from bis(3-sulfonate-4-carboxyphenyl) sulfone. Polym. Bull. 2009, 62, 593-604.

19. Tan, N.; Chen, Y.; Xiao, G.Y.; Yan, D.Y. Synthesis and properties of sulfonated polybenzothiazoles with benzimidazole moieties as proton exchange membranes. J. Membr. Sci. 2010, 356, 70-77.

20. Tan, N.; Xiao, G.Y.; Yan, D.Y. Sulfonated polybenzothiazoles: A novel candidate for proton exchange membranes. Chem. Mater. 2010, 22, 1022-1031.

21. Herranen, J.; Kinnunen, J.; Mattsson, B.; Rinne, H.; Sundholm, F.; Torell, L. Characterisation of poly(ethylene oxide) sulfonic acids. Solid State Ionics 1995, 80, 201-212.

22. Park, J.K.; Kang, Y.S.; Won, J. Characterization of deoxyribonucleic acid/poly(ethylene oxide) proton-conducting membranes. J. Membr. Sci. 2008, 313, 217-223.

23. Qingfeng, L.; Hjuler, H.A.; Bjerrum, N.J. Phosphoric acid doped polybenzimidazole membranes: Physiochemical characterization and fuel cell applications. J. Appl. Electrochem. 2001, 31, 773-779.

24. Li, Q.; He, R.; Jensen, J.O.; Bjerrum, N.J. PBI-based polymer membranes for high temperature fuel cells - preparation, characterization and fuel cell demonstration. Fuel Cells 2004, 4, 147-159.

25. Kumar, N.; Varaprasad, K.; Reddy, G.; Sivabharathi, Y.; Naidu, S. Biodegradable water soluble copolymer for antimicrobial applications. J. Polym. Environ. 2011, 19, 225-229.

26. Jain, A.; Jain, S.K. PEGylation: An approach for drug delivery. A review. Crit. Rev. Ther. Drug Carr. Syst. 2008, 25, 403-447.

27. Flatt, R.J. Dispersants in concrete. Surfactant Sci. Ser. 2001, 104, 247-294.

28. Bolto, B.; Gregory, J. Organic polyelectrolytes in water treatment. Water Res. 2007, 41, 2301-2324.

29. Bai, H.; Ho, W.S.W. New poly(ethylene oxide) soft segment-containing sulfonated polyimide copolymers for high temperature proton-exchange membrane fuel cells. J. Membr. Sci. 2008, 313, 75-85.

30. Shalaby, S.W.; McCormick, C.L.; Buttler, G.B. Water-Soluble Polymers. Synthesis, Solution Properties and Applications. In ACS Symposium Series; American Chemical Society: Washington, DC, USA, 1991; Volume 467.

31. Varshney, P.; Gupta, S. Natural polymer-based electrolytes for electrochemical devices: A review. Ionics 2011, 17, 479-483.

32. Dash, M.; Chiellini, F.; Ottenbrite, R.M.; Chiellini, E. Chitosan-A versatile semi-synthetic polymer in biomedical applications. Prog. Polym. Sci. 2011, 36, 981-1014.

33. Mukoma, P.; Jooste, B.R.; Vosloo, H.C.M. A comparison of methanol permeability in Chitosan and Nafion 117 membranes at high to medium methanol concentrations. J. Membr. Sci. 2004, 243, 293-299. 
34. Mukoma, P.; Jooste, B.R.; Vosloo, H.C.M. Synthesis and characterization of cross-linked chitosan membranes for application as alternative proton exchange membrane materials in fuel cells. J. Power Sources 2004, 136, 16-23.

35. Wu, H.; Zheng, B.; Zheng, X.; Wang, J.; Yuan, W.; Jiang, Z. Surface-modified Y zeolite-filled chitosan membrane for direct methanol fuel cell. J. Power Sources 2007, 173, 842-852.

36. Yuan, W.; Wu, H.; Zheng, B.; Zheng, X.; Jiang, Z.; Hao, X.; Wang, B. Sorbitol-plasticized chitosan/zeolite hybrid membrane for direct methanol fuel cell. J. Power Sources 2007, 172, 604-612.

37. Cui, Z.; Liu, C.; Lu, T.; Xing, W. Polyelectrolyte complexes of chitosan and phosphotungstic acid as proton-conducting membranes for direct methanol fuel cells. J. Power Sources 2007, 167, 94-99.

38. Wang, J.; Zheng, X.; Wu, H.; Zheng, B.; Jiang, Z.; Hao, X.; Wang, B. Effect of zeolites on chitosan/zeolite hybrid membranes for direct methanol fuel cell. J. Power Sources 2008, 178, 9-19.

39. Dashtimoghadam, E.; Hasani-Sadrabadi, M.M.; Moaddel, H. Structural modification of chitosan biopolymer as a novel polyelectrolyte membrane for green power generation. Polym. Adv. Technol. 2010, 21, 726-734.

40. Smitha, B.; Sridhar, S.; Khan, A.A. Polyelectrolyte complexes of chitosan and poly(acrylic acid) as proton exchange membranes for fuel cells. Macromolecules 2004, 37, 2233-2239.

41. Smitha, B.; Sridhar, S.; Khan, A.A. Synthesis and characterization of poly(vinyl alcohol)-based membranes for direct methanol fuel cell. J. Appl. Polym. Sci. 2005, 95, 1154-1163.

42. Smitha, B.; Sridhar, S.; Khan, A.A. Chitosan-sodium alginate polyion complexes as fuel cell membranes. Eur. Polym. J. 2005, 41, 1859-1866.

43. Veronese, F.M.; Pasut, G. PEGylation, successful approach to drug delivery. Drug Discov. Today 2005, 10, 1451-1458.

44. Fergus, J.W. Ceramic and polymeric solid electrolytes for lithium-ion batteries. J. Power Sources 2010, 195, 4554-4569.

45. Han, H.W.; Liu, W.; Zhang, J.; Zhao, X.Z. A hybrid poly(ethylene oxide)/ poly(vinylidene fluoride)/TiO2 nanoparticle solid-state redox electrolyte for dye-sensitized nanocrystalline solar cells. Adv. Funct. Mater. 2005, 15, 1940-1944.

46. Wei, D. Dye sensitized solar cells. Int. J. Mol. Sci. 2010, 11, 1103-1113.

47. Yang, S.-J.; Jang, W.; Lee, C.; Shul, Y.G.; Han, H. The effect of crosslinked networks with poly(ethylene glycol) on sulfonated polyimide for polymer electrolyte membrane fuel cell. $J$. Polym. Sci. Part B: Polym. Phys. 2005, 43, 1455-1464.

48. Devrim, Y.G.; Rzaev, Z.; Pişkin, E. Physically and chemically cross-linked poly\{[(maleic anhydride)-alt-styrene]-co-(2-acrylamido-2-methyl-1-propanesulfonic acid) \}/poly(ethylene glycol) proton-exchange membranes. Macromol. Chem. Phys. 2007, 208, 175-187.

49. Qiao, J.; Ikesaka, S.; Saito, M.; Kuwano, J.; Okada, T. Life test of DMFC using poly(ethylene glycol)bis(carboxymethyl)ether plasticized PVA/PAMPS proton-conducting semi-IPNs. Electrochem. Commun. 2007, 9, 1945-1950.

50. Gupta, D.; Choudhary, V. Studies on novel heat treated sulfonated poly(ether ether ketone) [SPEEK]/diol membranes for fuel cell applications. Int. J. Hydrog. Energy 2011, 36, 8525-8535. 
51. Li, Z.; Liu, X.; Chao, D.; Lu, X.; He, L.; Yang, Y.; Zhang, W. Crosslinked sulfonated poly(arylene ether ketone) with pendant carboxylic acid group via poly(ethylene glycol) for proton exchange membrane. J. Appl. Polym. Sci. 2010, 118, 3318-3323.

52. Lee, S.; Jang, W.; Choi, S.; Tharanikkarasu, K.; Shul, Y.; Han, H. Sulfonated polyimide and poly (ethylene glycol) diacrylate based semi-interpenetrating polymer network membranes for fuel cells. J. Appl. Polym. Sci. 2007, 104, 2965-2972.

53. Seo, J.; Jang, W.; Lee, S.; Han, H. The stability of semi-interpenetrating polymer networks based on sulfonated polyimide and poly(ethylene glycol) diacrylate for fuel cell applications. Polym. Degrad. Stabil. 2008, 93, 298-304.

54. Marten, M.L. Encyclopedia of Polymer Science and Technology, 3rd ed.; Kroschwitz, J.I., Ed.; Wiley: New York, NY, USA, 2004; Volume 8, pp. 399-436.

55. Silva, R.; Muniz, E.C.; Rubira, A.F. Multiple hydrophilic polymer ultra-thin layers covalently anchored to polyethylene films. Polymer 2008, 49, 4066-4075.

56. Hansen, E.W.; Holm, K.H.; Jahr, D.M.; Olafsen, K.; Stori, A. Reaction of poly(vinyl alcohol) and dialdehydes during gel formation probed by $1 \mathrm{H}$ n.m.r.-A kinetic study. Polymer 1997, 38, 4863-4871.

57. Chiang, W.-Y.; Chen, C.-L. Separation of water-alcohol mixture by using polymer membranes- 6 . Water-alcohol pervaporation through terpolymer of PVA grafted with hydrazine reacted SMA. Polymer 1998, 39, 2227-2233.

58. Pivovar, B.S.; Wang, Y.; Cussler, E.L. Pervaporation membranes in direct methanol fuel cells. J. Membr. Sci. 1999, 154, 155-162.

59. Li, L.; Xu, L.; Wang, Y. Novel proton conducting composite membranes for direct methanol fuel cell. Mater. Lett. 2003, 57, 1406-1410.

60. Sahu, A.K.; Selvarani, G.; Bhat, S.D.; Pitchumani, S.; Sridhar, P.; Shukla, A.K.; Narayanan, N.; Banerjee, A.; Chandrakumar, N. Effect of varying poly(styrene sulfonic acid) content in poly(vinyl alcohol)-poly(styrene sulfonic acid) blend membrane and its ramification in hydrogen-oxygen polymer electrolyte fuel cells. J. Membr. Sci. 2008, 319, 298-305.

61. Qiao, J.; Hamaya, T.; Okada, T. Chemically modified poly(vinyl alcohol)-poly(2-acrylamido-2methyl-1-propanesulfonic acid) as a novel proton-conducting fuel cell membrane. Chem. Mater. 2005, 17, 2413-2421.

62. Kang, M.-S.; Kim, J.H.; Won, J.; Moon, S.-H.; Kang, Y.S. Highly charged proton exchange membranes prepared by using water soluble polymer blends for fuel cells. J. Membr. Sci. 2005, 247, 127-135.

63. Qiao, J.; Hamaya, T.; Okada, T. New highly proton-conducting membrane poly(vinylpyrrolidone)(PVP) modified poly(vinyl alcohol)/2-acrylamido-2-methyl-1-propanesulfonic acid (PVA-PAMPS) for low temperature direct methanol fuel cells (DMFCs). Polymer 2005, 46, 10809-10816.

64. Hamaya, T.; Inoue, S.; Qiao, J.; Okada, T. Novel proton-conducting polymer electrolyte membranes based on PVA/PAMPS/PEG400 blend. J. Power Sources 2006, 156, 311-314.

65. Won, J.; Ahn, S.M.; Cho, H.D.; Ryu, J.Y.; Ha, H.Y.; Kang, Y.S. Sulfonated dextran/poly(vinyl alcohol) polymer electrolyte membranes for direct methanol fuel cells. Macromol. Res. 2007, 15, 459-464. 
66. Lin, C.W.; Huang, Y.F.; Kannan, A.M. Semi-interpenetrating network based on cross-linked poly(vinyl alcohol) and poly(styrene sulfonic acid-co-maleic anhydride) as proton exchange fuel cell membranes. J. Power Sources 2007, 164, 449-456.

67. Lin, C.W.; Huang, Y.F.; Kannan, A.M. Cross-linked poly(vinyl alcohol) and poly(styrene sulfonic acid-co-maleic anhydride)-based semi-interpenetrating network as proton-conducting membranes for direct methanol fuel cells. J. Power Sources 2007, 171, 340-347.

68. Sahu, A.K.; Selvarani, G.; Pitchumani, S.; Sridhar, P.; Shukla, A.K.; Narayanan, N.; Banerjee, A.; Chandrakumar, N. PVA-PSSA membrane with interpenetrating networks and its methanol crossover mitigating effect in DMFCs. J. Electrochem. Soc. 2008, 155, B686-B695.

69. Shen, C.-C.; Joseph, J.; Lin, Y.-C.; Lin, S.-H.; Lin, C.-W.; Hwang, B.J. Modifying microphase separation of PVA based membranes for improving proton/methanol selectivity. Desalination 2008, 233, 82-87.

70. Hwang, B.-J.; Joseph, J.; Zeng, Y.-Z.; Lin, C.-W.; Cheng, M.-Y. Analysis of states of water in poly (vinyl alcohol) based DMFC membranes using FTIR and DSC. J. Membr. Sci. 2011, 369, 88-95.

71. Rhim, J.-W.; Park, H.B.; Lee, C.-S.; Jun, J.-H.; Kim, D.S.; Lee, Y.M. Crosslinked poly(vinyl alcohol) membranes containing sulfonic acid group: proton and methanol transport through membranes. J. Membr. Sci. 2004, 238, 143-151.

72. Kim, D.S.; Guiver, M.D.; Nam, S.Y.; Yun, T.I.; Seo, M.Y.; Kim, S.J.; Hwang, H.S.; Rhim, J.W. Preparation of ion exchange membranes for fuel cell based on crosslinked poly(vinyl alcohol) with poly(styrene sulfonic acid-co-maleic acid). J. Membr. Sci. 2006, 281, 156-162.

73. Lee, D.; Park, J.; Choi, J.; Roh, D.; Lee, J.; Shul, Y.; Kim, J. Proton conducting crosslinked membranes by polymer blending of triblock copolymer and poly(vinyl alcohol). Macromol. Res. 2008, 16, 549-554.

74. Zhao, C.; Lin, H.; Na, H. Novel cross-linked sulfonated poly (arylene ether ketone) membranes for direct methanol fuel cell. Int. J. Hydrog. Energy 2010, 35, 2176-2182.

75. Witt, M.A.; Barra, G.M.O.; Bertolino, J.R.; Pires, A.T.N. Crosslinked chitosan/poly (vinyl alcohol) blends with proton conductivity characteristic. J. Braz. Chem. Soc. 2010, 21, 1692-1698.

76. Rhim, J.; Hwang, H.; Kim, D.; Park, H.; Lee, C.; Lee, Y.; Moon, G.; Nam, S. Aging effect of poly(vinyl alcohol) membranes crosslinked with poly(acrylic acid-co-maleic acid). Macromol. Res. 2005, 13, 135-140.

77. Kerres, J.A. Development of ionomer membranes for fuel cells. J. Membr. Sci. 2001, 185, 3-27.

78. Chen, N.; Hong, L. Proton-conducting membrane composed of sulfonated polystyrene microspheres, poly(vinylpyrrolidone) and poly(vinylidene fluoride). Solid State Ionics 2002, 146, 377-385.

79. Smitha, B.; Sridhar, S.; Khan, A.A. Chitosan-poly(vinyl pyrrolidone) blends as membranes for direct methanol fuel cell applications. J. Power Sources 2006, 159, 846-854.

80. Lu, J.; Nguyen, Q.; Zhou, J.; Ping, Z.-H. Poly(vinyl alcohol)/poly(vinyl pyrrolidone) interpenetrating polymer network: Synthesis and pervaporation properties. J. Appl. Polym. Sci. 2003, 89, 2808-2814. 
81. Huang, Y.F.; Chuang, L.C.; Kannan, A.M.; Lin, C.W. Proton-conducting membranes with high selectivity from cross-linked poly(vinyl alcohol) and poly(vinyl pyrrolidone) for direct methanol fuel cell applications. J. Power Sources 2009, 186, 22-28.

82. Karlsson, L.E.; Wesslén, B.; Jannasch, P. Water absorption and proton conductivity of sulfonated acrylamide copolymers. Electrochim. Acta 2002, 47, 3269-3275.

83. Randin, J.-P. Ion-containing polymers as semisolid electrolytes in WO3-based electrochromic devices. J. Electrochem. Soc. 1982, 129, 1215-1220.

84. Karlsson, L.E.; Jannasch, P.; Wesslén, B. Preparation and solution properties of amphiphilic sulfonated acrylamide copolymers. Macromol. Chem. Phys. 2002, 203, 686-694.

85. Shen, Y.; Xi, J.; Qiu, X.; Zhu, W. A new proton conducting membrane based on copolymer of methyl methacrylate and 2-acrylamido-2-methyl-1-propanesulfonic acid for direct methanol fuel cells. Electrochim. Acta 2007, 52, 6956-6961.

86. Qiao, J.; Hamaya, T.; Okada, T. New highly proton conductive polymer membranes poly(vinyl alcohol)-2-acrylamido-2-methyl-1-propanesulfonic acid (PVA-PAMPS). J. Mater. Chem. 2005, $15,4414-4423$.

87. Qiao, J.; Okada, T. Highly durable, proton-conducting semi-interpenetrating polymer networks from PVA/PAMPS composites by incorporating plasticizer variants. Electrochem. Solid-State Lett. 2006, 9, A379-A381.

88. Zygadlo-Monikowska, E.; Florjanczyk, Z.; Wielgus-Barry, E.; Hildebrand, E. Proton conducting gel polyelectrolytes based on 2-acrylamido-2-methyl-1-propanesulfonic acid (AMPSA) copolymers: Part II. Hydrogels. J. Power Sources 2006, 159, 392-398.

89. Pei, H.; Hong, L.; Lee, J.Y. Polymer electrolyte membrane based on 2-acrylamido-2-methyl propanesulfonic acid fabricated by embedded polymerization. J. Power Sources 2006, 160, 949-956.

90. Pei, H.; Hong, L.; Lee, J.Y. Effects of polyaniline chain structures on proton conduction in a PEM host matrix. J. Membr. Sci. 2008, 307, 126-135.

91. Okada, O.; Yokoyama, K. Development of polymer electrolyte fuel cell cogeneration systems for residential applications. Fuel Cells 2001, 1, 72-77.

92. Ding, J.; Chuy, C.; Holdcroft, S. A Self-organized network of nanochannels enhances ion conductivity through polymer films. Chem. Mater. 2001, 13, 2231-2233.

93. Ding, J.; Chuy, C.; Holdcroft, S. Enhanced conductivity in morphologically controlled proton exchange membranes: Synthesis of macromonomers by SFRP and their incorporation into graft polymers. Macromolecules 2002, 35, 1348-1355.

94. Ehrenberg, S.G.; Serpico, J.M.; Wnek, G.E.; Rider, J.N. Fuel Cell Incorporating Novel IonConducting Membrane. U.S. Patent 5,468,574, 21 November 1995.

95. Gupta, B.; Büchi, F.N.; Scherer, G.G.; Chapiró, A. Materials research aspects of organic solid proton conductors. Solid State Ionics 1993, 61, 213-218.

96. Gupta, B.; Büchi, F.N.; Scherer, G.G.; Chapiro, A. Development of radiation-grafted FEP-gpolystyrene membranes: Some property-structure correlations. Polym. Adv. Technol. 1994, 5, 493-498. 
97. Chuy, C.; Basura, V.I.; Simon, E.; Holdcroft, S.; Horsfall, J.; Lovell, K.V. Electrochemical characterization of ethylenetetrafluoroethylene-g-polystyrenesulfonic acid solid polymer electrolytes. J. Electrochem. Soc. 2000, 147, 4453-4458.

98. Chuy, C.; Ding, J.; Swanson, E.; Holdcroft, S.; Horsfall, J.; Lovell, K.V. Conductivity and electrochemical ORR mass transport properties of solid polymer electrolytes containing poly(styrene sulfonic acid) graft chains. J. Electrochem.Soc. 2003, 150, E271-E279.

99. Flint, S.D.; Slade, R.C.T. Investigation of radiation-grafted PVDF-g-polystyrene-sulfonic-acid ion exchange membranes for use in hydrogen oxygen fuel cells. Solid State Ionics 1997, 97, 299-307.

100. Wei, J.; Stone, C.; Steck, A.E. Trifluorostyrene and Substituted Trifluorostyrene Copolymeric Compositions and Ion-Exchange Membranes Formed Therefrom. U.S. Patent 5,422,411, 6 June 1995.

101. Seeponkai, N.; Wootthikanokkhan, J. Proton exchange membranes for a direct methanol fuel cell based on sulfonated styrene-(ethylene-butylene)-styrene/polyvinylidene fluoride blends. J. Appl. Polym. Sci. 2010, 117, 393-399.

102. Mokrini, A.; Huneault, M.A. Proton exchange membranes based on PVDF/SEBS blends. J. Power Sources 2006, 154, 51-58.

103. Mokrini, A.; Huneault, M.A.; Gerard, P. Partially fluorinated proton exchange membranes based on PVDF-SEBS blends compatibilized with methylmethacrylate block copolymers. J. Membr. Sci. 2006, 283, 74-83.

104. Piboonsatsanasakul, P.; Wootthikanokkhan, J.; Thanawan, S. Preparation and characterizations of direct methanol fuel cell membrane from sulfonated polystyrene/poly(vinylidene fluoride) blend compatibilized with poly(styrene)-b-poly(methyl methacrytlate) block copolymer. J. Appl. Polym. Sci. 2008, 107, 1325-1336.

105. Paul, D.R.; Newman, S. Polymer Blends; Academic Press: New York, NY, USA, 1978.

106. Hasegawa, M.; Mita, I.; Kochi, M.; Yokota, R. Miscibility of polyimide/polyimide blends and charge-transfer fluorescence spectra. Polymer 1991, 32, 3225-3232.

107. Simmons, A.; Natansohn, A. Solid-state NMR study of charge-transfer interactions in polymer blends. Macromolecules 1991, 24, 3651-3661.

108. He, Y.; Zhu, B.; Inoue, Y. Hydrogen bonds in polymer blends. Prog. Polym. Sci. 2004, 29, 1021-1051.

109. Mignon, P.; Loverix, S.; Geerlings, P. Interplay between [pi]-[pi] interactions and the H-bonding ability of aromatic nitrogen bases. Chem. Phys. Lett. 2005, 401, 40-46.

110. Tseng, F.-P.; Tseng, C.-R.; Chang, F.-C.; Lin, J.-J.; Cheng, I.J. Compatibilization of PS and PA6 blends by means of poly(oxyalkylene)amine modified styrene-maleic anhydride copolymer. J. Polym. Res. 2005, 12, 439-447.

111. Moussaif, N.; Jérôme, R. Compatibilization of immiscible polymer blends (PC/PVDF) by the addition of a third polymer (PMMA): Analysis of phase morphology and mechanical properties. Polymer 1999, 40, 3919-3932.

112. Pimbert, S.; Avignon-Poquillon, L.; Levesque, G. Calorimetric study of fluorinated methacrylic and vinyl polymer blends: part 2: correlation between miscibility, chemical structure and [chi]12 interaction parameter in binary systems. Polymer 2002, 43, 3295-3302. 
113. Deimede, V.; Voyiatzis, G.A.; Kallitsis, J.K.; Qingfeng, L.; Bjerrum, N.J. Miscibility behavior of polybenzimidazole/sulfonated polysulfone blends for use in fuel cell applications. Macromolecules 2000, 33, 7609-7617.

114. Swier, S.; Ramani, V.; Fenton, J.M.; Kunz, H.R.; Shaw, M.T.; Weiss, R.A. Polymer blends based on sulfonated poly(ether ketone ketone) and poly(ether sulfone) as proton exchange membranes for fuel cells. J. Membr. Sci. 2005, 256, 122-133.

115. Wu, H.-L.; Ma, C.-C.M.; Li, C.-H.; Lee, T.-M.; Chen, C.-Y.; Chiang, C.-L.; Wu, C. Sulfonated poly(ether ether ketone)/poly(amide imide) polymer blends for proton conducting membrane. $J$. Membr. Sci. 2006, 280, 501-508.

116. Wang, L.; Yi, B.L.; Zhang, H.M.; Xing, D.M. Characteristics of polyethersulfone/sulfonated polyimide blend membrane for proton exchange membrane fuel cell. J. Phys. Chem. B 2008, $112,4270-4275$.

117. Fu, R.-Q.; Julius, D.; Hong, L.; Lee, J.-Y. PPO-based acid-base polymer blend membranes for direct methanol fuel cells. J. Membr. Sci. 2008, 322, 331-338.

118. Chen, N.; Hong, L. Embedding poly(styrene sulfonic acid) into PVDF matrix--a new type of proton electrolyte membrane. Polymer 2004, 45, 2403-2411.

119. Yang, T. Preliminary study of SPEEK/PVA blend membranes for DMFC applications. Int. J. Hydrog. Energy 2008, 33, 6772-6779.

120. Wu, H.-L.; Ma, C.-C.M.; Kuan, H.-C.; Wang, C.-H.; Chen, C.-Y.; Chiang, C.-L. Sulfonated poly(ether ether ketone)/poly(vinylpyrrolidone) acid-base polymer blends for direct methanol fuel cell application. J. Polym. Sci.Part B: Polym. Phys. 2006, 44, 565-572.

121. Yang, S.J.; Jang, W.B.; Lee, C.; Shul, Y.G.; Han, H. The effect of crosslinked networks with poly(ethylene glycol) on sulfonated polyimide for polymer electrolyte membrane fuel cell. J. Polym. Sci. Pol. Phys. 2005, 43, 1455-1464.

122. Oh, Y.-S.; Lee, H.-J.; Yoo, M.; Kim, H.-J.; Han, J.; Kim, K.; Hong, J.-D.; Kim, T.-H. Azideassisted cross-linked sulfonated poly(ether sulfone)s as stable and highly conductive membranes with low methanol diffusion coefficients. Chem. Commun. 2008, 2028-2030.

123. Ye, Y.-S.; Yen, Y.-C.; Cheng, C.-C.; Chen, W.-Y.; Tsai, L.-T.; Chang, F.-C. Sulfonated poly(ether ether ketone) membranes crosslinked with sulfonic acid containing benzoxazine monomer as proton exchange membranes. Polymer 2009, 50, 3196-3203.

124. Ye, Y.-S.; Huang, Y.-J.; Cheng, C.-C.; Chang, F.-C. A new supramolecular sulfonated polyimide for use in proton exchange membranes for fuel cells. Chem. Commun. 2010, 46, 7554-7556.

125. Fu, R.Q.; Hong, L.; Lee, J.Y. Membrane design for direct ethanol fuel cells: A hybrid protonconducting interpenetrating polymer network. Fuel Cells 2008, 8, 52-61.

126. Kwon, Y.H.; Kim, S.C.; Lee, S.Y. Nanoscale phase separation of sulfonated poly(arylene ether sulfone)/poly(ether sulfone) semi-IPNs for DMFC membrane applications. Macromolecules 2009, 42, 5244-5250.

127. Guan, Y.S.; Pu, H.T.; Pan, H.Y.; Chang, Z.H.; Jin, M. Proton conducting membranes based on semi-interpenetrating polymer network of Nafion (R) and polybenzimidazole. Polymer 2010, 51, $5473-5481$. 
128. Pan, H.; Pu, H.; Wan, D.; Jin, M.; Chang, Z. Proton exchange membranes based on semi-interpenetrating polymer networks of fluorine-containing polyimide and Nafion ${ }^{\circledR}$. J. Power Sources 2010, 195, 3077-3083.

129. Jenkins, A.D.; Kratochvil, R.F.; Stepto, R.F.T.; Suter, U.W. Glossary of basic terms in polymer science. Pure Appl. Chem. 1996, 68, 2287-2311.

130. Wu, C.-S.; Lin, F.-Y.; Chen, C.-Y.; Chu, P.P. A polyvinyl alcohol/p-sulfonate phenolic resin composite proton conducting membrane. J. Power Sources 2006, 160, 1204-1210.

131. Chang, Y.-W.; Wang, E.; Shin, G.; Han, J.-E.; Mather, P.T. Poly(vinyl alcohol) (PVA)/sulfonated polyhedral oligosilsesquioxane (sPOSS) hybrid membranes for direct methanol fuel cell applications. Polym. Adv. Technol. 2007, 18, 535-543.

132. Gu, S.; He, G.; Wu, X.; Guo, Y.; Liu, H.; Peng, L.; Xiao, G. Preparation and characteristics of crosslinked sulfonated poly(phthalazinone ether sulfone ketone) with poly(vinyl alcohol) for proton exchange membrane. J. Membr. Sci. 2008, 312, 48-58.

133. Won, J.; Park, H.H.; Kim, Y.J.; Choi, S.W.; Ha, H.Y.; Oh, I.-H.; Kim, H.S.; Kang, Y.S.; Ihn, K.J. Fixation of nanosized proton transport channels in membranes. Macromolecules 2003, 36, 3228-3234.

134. Ye, Y.-S.; Chen, W.-Y.; Huang, Y.-J.; Cheng, M.-Y.; Yen, Y.-C.; Cheng, C.-C.; Chang, F.-C. Preparation and characterization of high-durability zwitterionic crosslinked proton exchange membranes. J. Membr. Sci. 2010, 362, 29-37.

135. Chikh, L.; Delhorbe, V.; Fichet, O. (Semi-)Interpenetrating polymer networks as fuel cell membranes. J. Membr. Sci. 2011, 368, 1-17.

136. Prakash, G.K.S.; Smart, M.C.; Wang, Q.-J.; Atti, A.; Pleynet, V.; Yang, B.; McGrath, K.; Olah, G.A.; Narayanan, S.R.; Chun, W.; et al. High efficiency direct methanol fuel cell based on poly(styrenesulfonic) acid (PSSA)-poly(vinylidene fluoride) (PVDF) composite membranes. J. Fluor. Chem. 2004, 125, 1217-1230.

137. Yamaguchi, T.; Miyata, F.; Nakao, S.-I. Pore-filling type polymer electrolyte membranes for a direct methanol fuel cell. J. Membr. Sci. 2003, 214, 283-292.

138. Shin, J.-P.; Chang, B.-J.; Kim, J.-H.; Lee, S.-B.; Suh, D.H. Sulfonated polystyrene/PTFE composite membranes. J. Membr. Sci. 2005, 251, 247-254.

139. Fu, R.-Q.; Woo, J.-J.; Seo, S.-J.; Lee, J.-S.; Moon, S.-H. Sulfonated polystyrene/polyvinyl chloride composite membranes for PEMFC applications. J. Membr. Sci. 2008, 309, 156-164.

140. Cho, K.-Y.; Jung, H.-Y.; Shin, S.-S.; Choi, N.-S.; Sung, S.-J.; Park, J.-K.; Choi, J.-H.; Park, K.-W.; Sung, Y.-E. Proton conducting semi-IPN based on Nafion and crosslinked poly(AMPS) for direct methanol fuel cell. Electroch. Acta 2004, 50, 588-593.

141. Kundu, P.P.; Kim, B.T.; Ahn, J.E.; Han, H.S.; Shul, Y.G. Formation and evaluation of semi-IPN of nafion 117 membrane for direct methanol fuel cell: 1. Crosslinked sulfonated polystyrene in the pores of nafion 117. J. Power Sources 2007, 171, 86-91.

142. Haufe, S.; Stimming, U. Proton conducting membranes based on electrolyte filled microporous matrices. J. Membr. Sci. 2001, 185, 95-103.

143. Liu, F.; Yi, B.; Xing, D.; Yu, J.; Zhang, H. Nafion/PTFE composite membranes for fuel cell applications. J. Membr. Sci. 2003, 212, 213-223. 
144. Kim, K.-H.; Ahn, S.-Y.; Oh, I.-H.; Ha, H.Y.; Hong, S.-A.; Kim, M.-S.; Lee, Y.; Lee, Y.-C. Characteristics of the Nafion ${ }^{\circledR}$-impregnated polycarbonate composite membranes for PEMFCs. Electrochim. Acta 2004, 50, 577-581.

145. Li, T.; Zhong, G.; Fu, R.; Yang, Y. Synthesis and characterization of Nafion/cross-linked PVP semi-interpenetrating polymer network membrane for direct methanol fuel cell. J. Membr. Sci. 2010, 354, 189-197.

146. Charles, W.; Walker, J. Proton-conducting interpenetrating polymer network with reduced methanol permeability. J. Electrochem. Soc. 2004, 151, A1797-A1803.

147. Yamaguchi, T.; Miyata, F.; Nakao, S. Polymer electrolyte membranes with a pore-filling structure for a direct methanol fuel cell. Adv. Mater. 2003, 15, 1198-1201.

148. Nishimura, H.; Yamaguchi, T. Performance of a pore-filling electrolyte membrane in hydrogen-oxygen PEFC. Electrochem. Solid-State Lett. 2004, 7, A385-A388.

149. Yamaguchi, T.; Kuroki, H.; Miyata, F. DMFC performances using a pore-filling polymer electrolyte membrane for portable usages. Electrochem. Commun. 2005, 7, 730-734.

\section{Appendix A.}

\begin{tabular}{|c|c|c|c|c|c|}
\hline \multicolumn{6}{|c|}{ Monomers } \\
\hline Acronym & Chemical Name & Chemical Structure & Acronym & Chemical Name & Chemical Structure \\
\hline AIBN & azobisisobutyronitrile & $\mathrm{H}_{3} \mathrm{C} \underset{\mathrm{CN}}{\stackrel{\mathrm{CN}}{\mathrm{H}_{3}}=\mathrm{N}} \underset{\mathrm{CN}}{\mathrm{C}_{1}} \mathrm{CH}_{3}$ & GA & glutaraldehyde & \\
\hline BA & n-butylaldehyde & & HPDA & $\begin{array}{c}\text { 1,6-hexanediol propoxylate } \\
\text { diacrylate }\end{array}$ & \\
\hline BAA & $\begin{array}{c}\mathrm{N}, \mathrm{N} \text {-methylene-bis- } \\
\text { acrylamide }\end{array}$ & & HA & n-hexylaldehyde & \\
\hline CDM & cyclohexane dimethanol & & HEMA & 2-hydroxyethylmethacrylate & \\
\hline DSDBA & $\begin{array}{c}\text { benzenedisulfonic acid } \\
\text { disodium salt }\end{array}$ & & $\mathrm{OA}$ & n-octylaldehyde & \\
\hline DVB & divinyl benzene & & SSA & sulfosuccinic acid & \\
\hline EDTAD & $\begin{array}{c}\text { ethylenediaminetetraacetic } \\
\text { dianhydride }\end{array}$ & & ST & styrene & \\
\hline EGDMA & ethylene glycol dimethacrylate & 0 & TA & terephthalaldehyde & o \\
\hline EMA & ethyl methacrylate & & TEOS & tetraethoxysilane & \\
\hline
\end{tabular}


Appendix B.

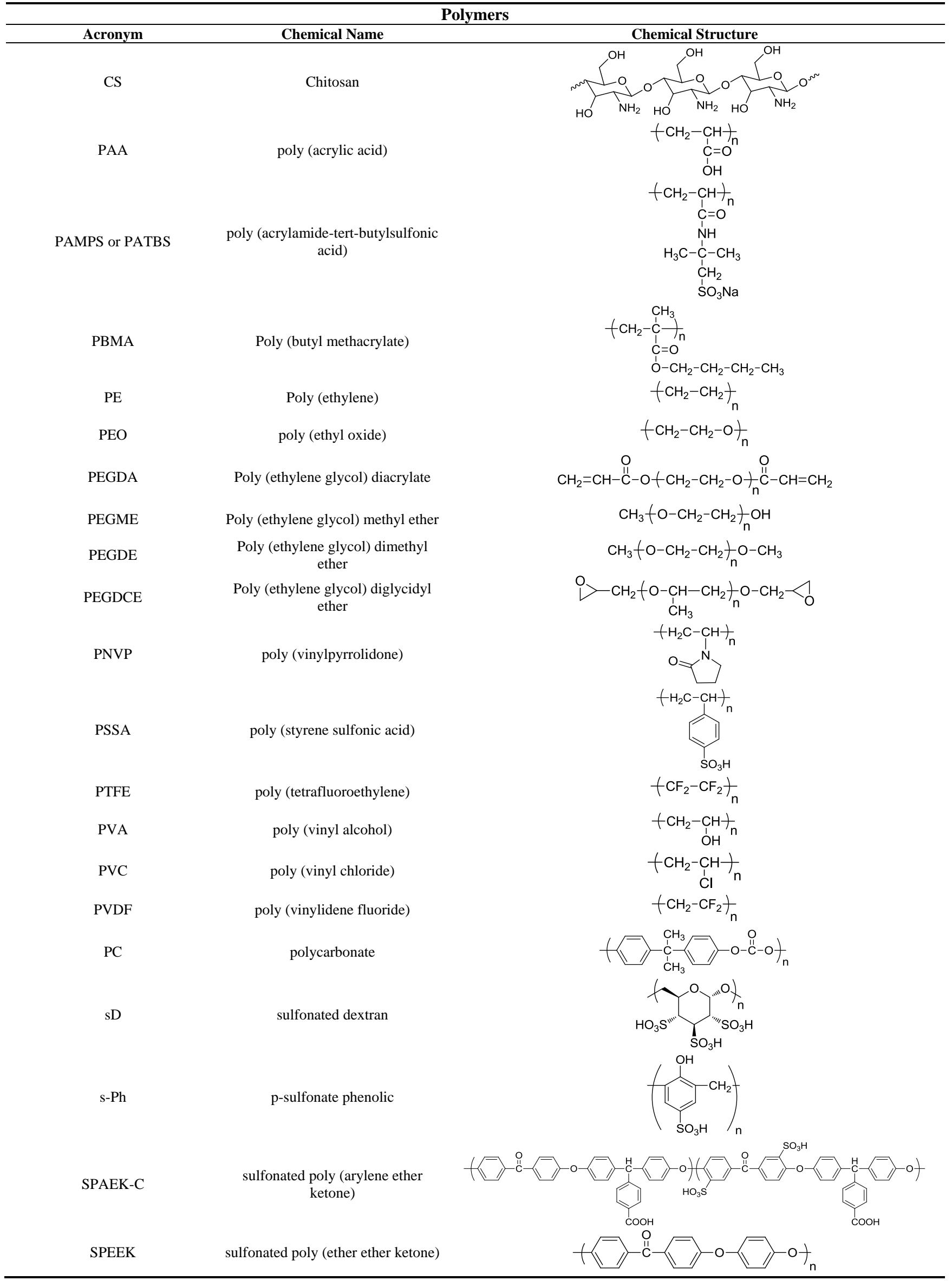


Appendix B. Cont.

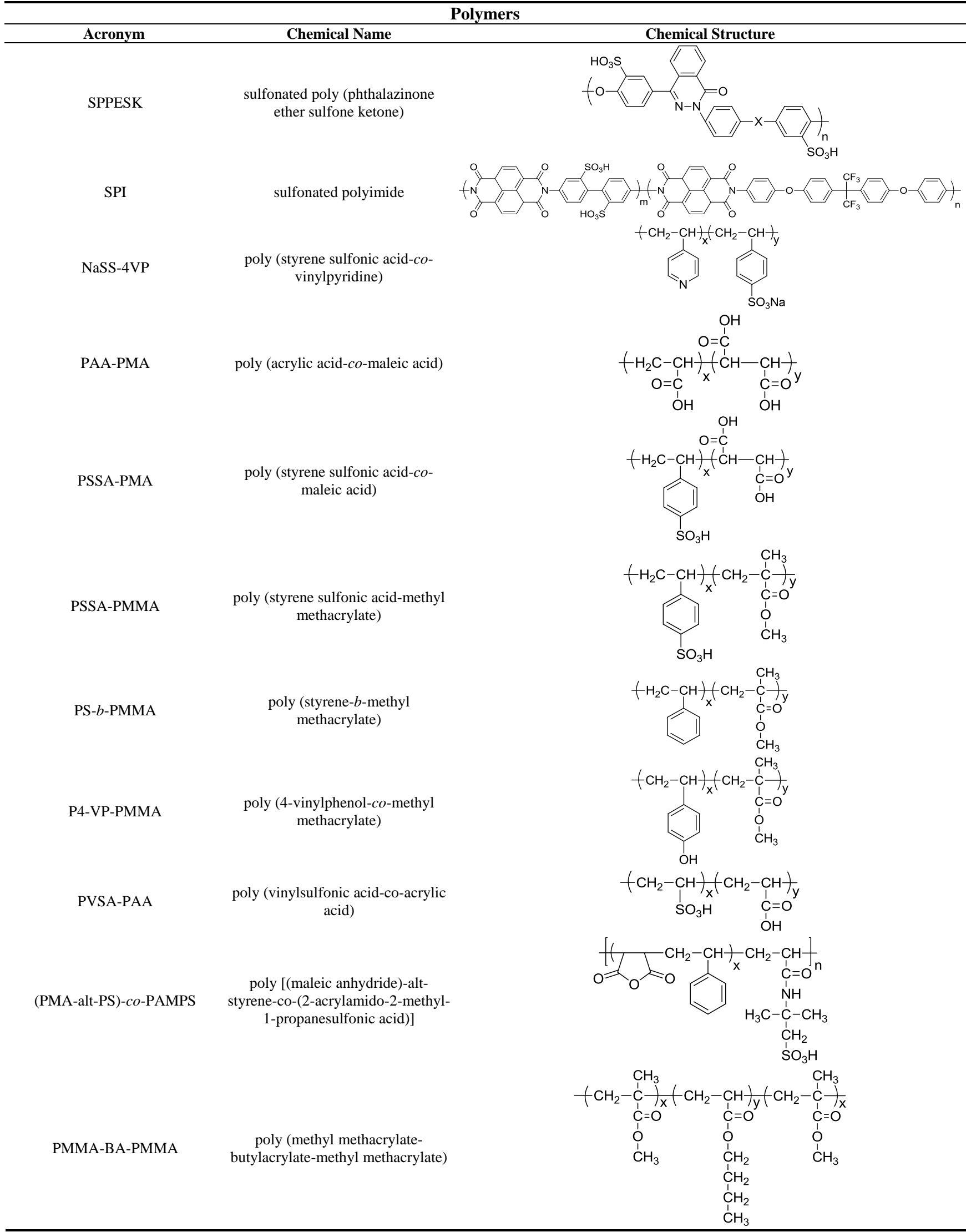


Appendix B. Cont.

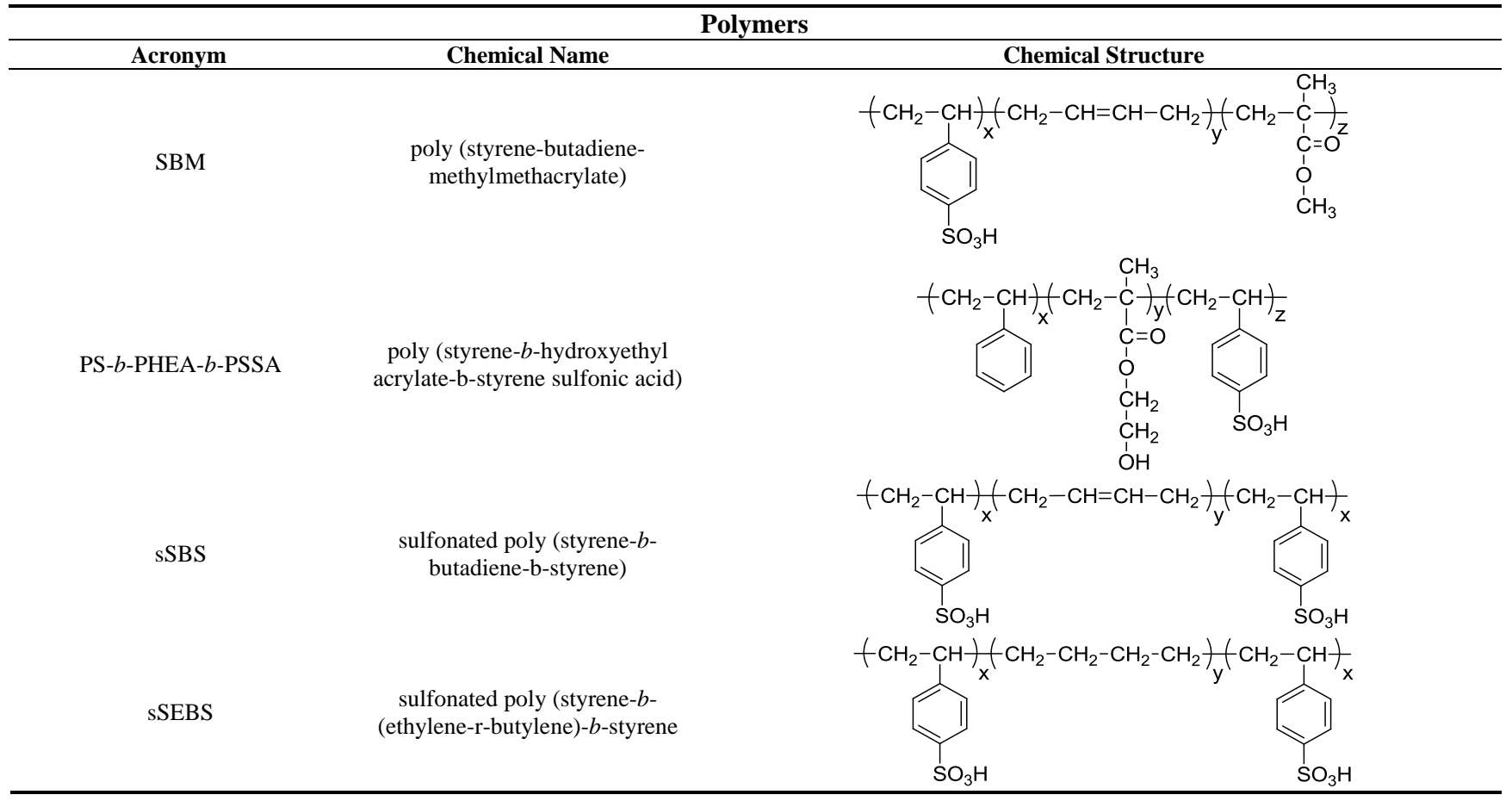

(C) 2012 by the authors; licensee MDPI, Basel, Switzerland. This article is an open access article distributed under the terms and conditions of the Creative Commons Attribution license (http://creativecommons.org/licenses/by/3.0/). 